Article

\title{
Sustainable Development of Smart Manufacturing Driven by the Digital Twin Framework: A Statistical Analysis
}

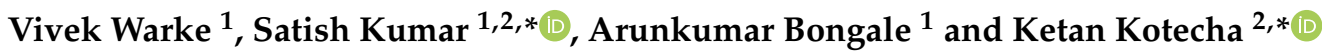 \\ 1 Symbiosis Institute of Technology, Symbiosis International (Deemed University), Lavale, Pune 412115, \\ Maharashtra, India; vivek.warke.phd2020@sitpune.edu.in (V.W.); arun.bongale@sitpune.edu.in (A.B.) \\ 2 Symbiosis Centre for Applied Artificial Intelligence, Symbiosis International (Deemed University), Lavale, \\ Pune 412115, Maharashtra, India \\ * Correspondence: satishkumar.vc@gmail.com (S.K.); head@scaai.siu.edu.in (K.K.)
}

Citation: Warke, V.; Kumar, S.; Bongale, A.; Kotecha, K. Sustainable Development of Smart

Manufacturing Driven by the Digital Twin Framework: A Statistical

Analysis. Sustainability 2021, 13, 10139. https://doi.org/10.3390/ su131810139

Received: 24 July 2021

Accepted: 30 August 2021

Published: 10 September 2021

Publisher's Note: MDPI stays neutral with regard to jurisdictional claims in published maps and institutional affiliations.

Copyright: (c) 2021 by the authors. Licensee MDPI, Basel, Switzerland. This article is an open access article distributed under the terms and conditions of the Creative Commons Attribution (CC BY) license (https:/ / creativecommons.org/licenses/by/ $4.0 /)$.
Abstract: The Fourth Industrial Revolution drives industries from traditional manufacturing to the smart manufacturing approach. In this transformation, existing equipment, processes, or devices are retrofitted with some sensors and other cyber-physical systems (CPS), and adapted towards digital production, which is a blend of critical enabling technologies. In the current scenario of Industry 4.0, industries are shaping themselves towards the development of customized and costeffective processes to satisfy customer needs with the aid of a digital twin framework, which enables the user to monitor, simulate, control, optimize, and identify defects and trends within, ongoing process, and reduces the chances of human prone errors. This paper intends to make an appraisal of the literature on the digital twin (DT) framework in the domain of smart manufacturing with the aid of critical enabling technologies such as data-driven systems, machine learning and artificial intelligence, and deep learning. This paper also focuses on the concept, evolution, and background of digital twin and the benefits and challenges involved in its implementation. The Scopus and Web of Science databases from 2016 to 2021 were considered for the bibliometric analysis and used to study and analyze the articles that fall within the research theme. For the systematic bibliometric analysis, a novel approach known as Proknow-C was employed, including a series of procedures for article selection and filtration from the existing databases to get the most appropriate articles aligned with the research theme. Additionally, the authors performed statistical and network analyses on the articles within the research theme to identify the most prominent research areas, journal/conference, and authors in the field of a digital twin. This study identifies the current scenarios, possible research gaps, challenges in implementing DT, case studies and future research goals within the research theme.

Keywords: digital twin; Industry 4.0; Proknow-C; artificial intelligence; machine learning; deep learning

\section{Introduction}

The technological advances, increases in global competitiveness, diversification of customer requirements, dynamic market trends, digitalization, and constantly increasing process complexities of the 21st century have significantly influenced traditional manufacturing industries [1]. This divergence drives the traditional manufacturing industries towards smart manufacturing, which integrates the elements (robots, Big Data, cloud computing, Internet-of-Things (IoT), Industrial Internet-of-Things (IIoT), simulations etc.) of the Industry 4.0 framework [2]. This helps in developing processes or products with built-in capabilities, such as decision-making, performance optimization, reconfiguration, and adaptation within the stated framework [3]. It is estimated that the smart manufacturing market will grow from USD 214.7 billion to USD 384.8 billion with a CAGR of $12.4 \%$ for the period of 2020-2025 [4]. Along with all the benefits of integrated elements and digitalization, maintenance is still a challenging issue in smart manufacturing. 
Maintenance is one of the key factors that affects the industry economically and has gained special attention in the era of digitalization. With the use of advanced technologies, such as sensors, actuators, automation, and mechanization, maintenance has become the key issue in today's industry [5]. The overall cost of maintenance is estimated at approximately $15-40 \%$ of the total production cost [6]. A lack of maintenance activities leads to sudden equipment failure, unplanned downtime, loss of productivity, and increases in production cost and time [7]. Hence, a proper maintenance strategy needs to be deployed to address the issue. In general, there are three maintenance strategies, viz. preventive maintenance, reactive maintenance, and predictive maintenance [8]. Preventive maintenance is analogous to scheduled maintenance or planned maintenance, in which the maintenance activities are scheduled or timed based on a process or product cycle [9]. Too high a frequency of preventive maintenance leads to higher production costs, excessive equipment planned downtime, and loss of resources [10]. However, reactive maintenance is a kind of failure-based maintenance, in which maintenance is performed after the failure of equipment or a component. It is also called "corrective maintenance" or "breakdown maintenance" [11,12]. Reactive maintenance leads to sudden equipment failure, unplanned downtime, losses of productivity, and increases in costs of production [13].

Among all the maintenance strategies, predictive maintenance is the most costeffective maintenance strategy, which allows one to schedule maintenance when the equipment or machinery needs maintenance. It is condition-based, and its performance is based on the predictions made from the signals acquired from the machine $[14,15]$. Predictive maintenance offers various benefits over traditional maintenance strategies such as earlier fault detection, reduced downtime, improved reliability, reduced cost, and improved performance [16]. According to U.S. department of energy, predictive maintenance saves approximately $8-12 \%$ over preventive maintenance, and up to $40 \%$ over reactive maintenance [17]. The use of predictive maintenance increased from $47 \%$ to $51 \%$, which reduced equipment failure from $61 \%$ to $57 \%$, between 2017 and 2018 [18]. Therefore, maintenance has a direct influence on the industry's economics. Additionally, in the present era of Industry 4.0, intelligent maintenance strategies with the help of digital twin (DT) can offer huge benefits over present maintenance approaches [19].

Within the Industry 4.0 paradigm, the technological advancements in cyber-physical systems (CPS) and the steady improvements in the smart manufacturing frameworks spawn the concept of "digital twin" [20]. DT is the systematic integration between a physical entity and virtual entity through different connections, and the real-time data of the process [21]. The advancement in enabling technologies, such as data analytics, IoT, IIoT, big data, cloud computing, sensors, augmented and virtual reality, simulation, artificial intelligence, etc., facilitates the seamless integration of DT into prominent fields [22]. The DT environment allows real-time decision making, rapid reconfiguration, and optimization; it also facilitates improved reliability, better productivity, reduced risk, early fault detection and lowered downtime [23]. Due to the enormous advantages, DT can be used in different fields, such as aerospace, automotive, biomedical, healthcare, manufacturing, etc. [24]. Therefore, the DT market is estimated to grow from USD 3.1 billion to USD 48.2 billion with CAGR of 58\% between 2020 and 2026 [25]. Hence, to study the different aspects of DT in the context of smart manufacturing, this paper provides a comprehensive bibliometric analysis of DT in the domain of smart manufacturing, and studies the benefits, applications, and challenges in implementing a DT in real-time.

\section{Significance of the Study}

The present industrial scenario in the context of Industry 4.0 drives the industries towards smart and intelligence. Additionally, with technological advancements in the Fourth Industrial Revolution and market competitiveness, industries face challenges to improve their position in an exponentially growing market [26]. As such, the industries thrive on making their product, process, or shop floor intelligent and smart, which involves self-decision-making and parameter optimization $[27,28]$. 
In the above context, the concept of digital twin proves to be a game-changer. DT has a wide variety of applications in manufacturing industries. Additionally, the growing demand for customized products and processes forces the implementation of DT in the existing processes. In smart manufacturing, to create intelligent products and virtual prototypes, manage industrial assets and systems, optimize processes, improve self-decision-making, reduce equipment downtime, and improve production efficiency, the development of intelligent shop floors with customer-driven product designs requires digital twin [29-31]. The DT model is built by retrofitting various sensors and actuators and applying different machine learning and artificial intelligence techniques, cloud technologies and IoT technologies to satisfy the above needs. In manufacturing industries, the processes can be monitored, controlled, and optimized through a DT model also known as "digital shadows". Digital shadows receives all the relevant data from the process, which aids in understanding the mechanism of process and its control [32]. In past studies, the characteristics, concept and definitions of digital twin and related processes have been discussed, along with a complete framework for identifying the future research trend of DT only in product-life cycle management [33]. As such, the present study focuses on the possible research gaps and future research potential in implementing digital twin for building a customized DT model in the context of smart manufacturing using bibliometric analysis.

Bibliometric analysis is used to study and analyze scientific activity. It can quantitatively measure and analyze the influence of research on a topic of interest by recognizing past characteristics, present critical points, and future research trends [34]. In this context, bibliometric analysis helps to identify the most prominent research community, research location, and application area in the domain of smart manufacturing using DT. The proposed bibliometric analysis uses two databases, viz., Scopus and Web of Science (WoS), to obtain the most relevant article regarding digital twin in the domain of smart manufacturing. The bibliometric analysis method uses a novel approach known as Proknow-C, which includes a series of procedures for article selection, filtration, and the formation of a bibliographic portfolio. Additionally, it consists of the statistical and network analysis of the articles obtained from two databases to get the most relevant articles, prominent authors, institutions, and countries aligned with the research theme. The paper covers the various aspects of digital twin, viz., evolution, background, architecture, framework, applications, challenges, benefits, methods of data collection, communication protocols, and decision-making algorithms used for implementing a DT in the domain of smart manufacturing.

Given the above discussion and to identify the potential research gaps and future research objectives, the rest of the paper is organized as follows. Section 2 presents a literature review of digital twin, which covers various aspects. Section 3 elaborates in detail the methodology and tools required for the bibliometric analysis. Section 4 critically analyzes the articles from the different aspects and case studies. Finally, Section 5 draws conclusion and outlines for the future work. Figure 1 shows the in-detail organization of the present article. 


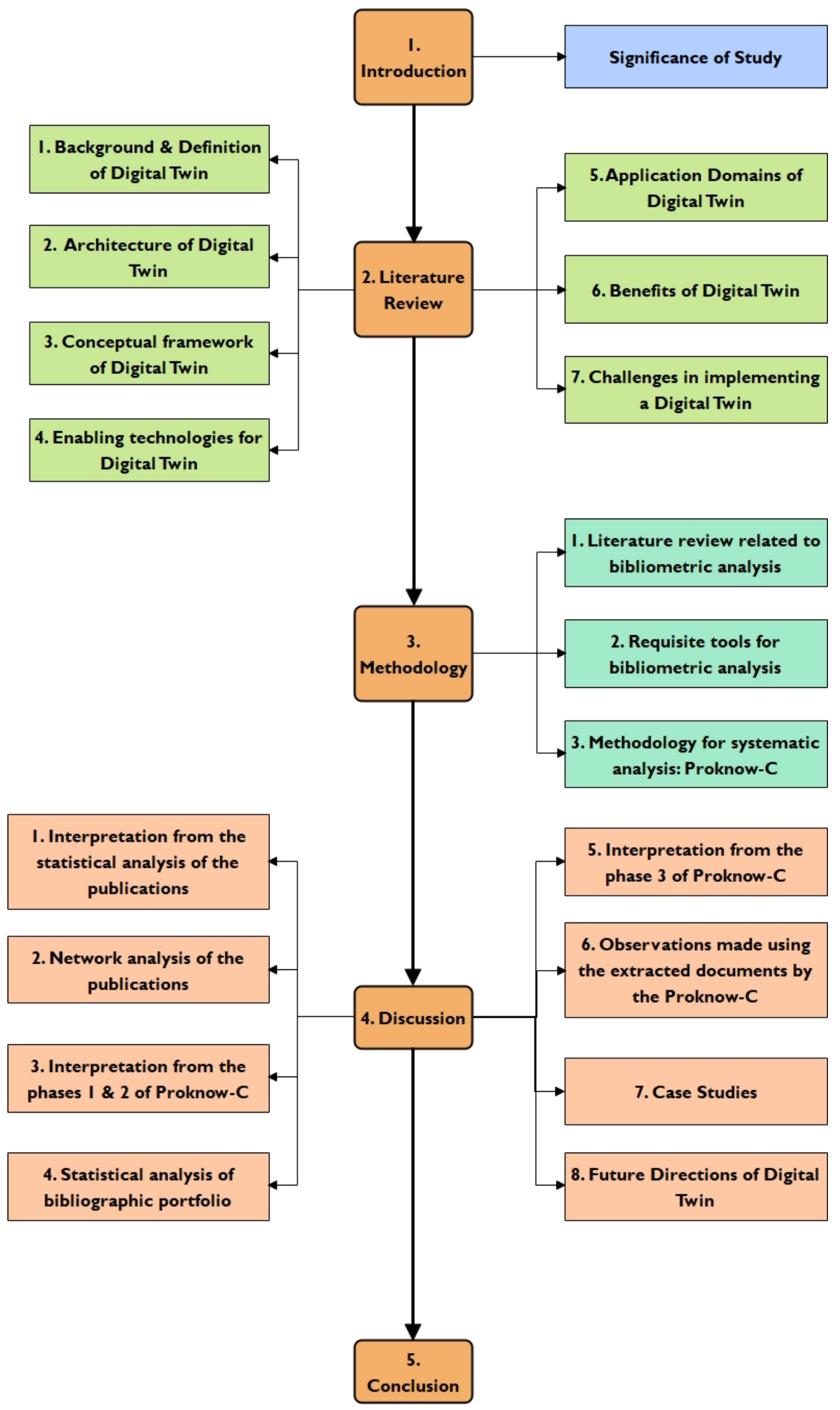

Figure 1. Organization of the bibliometric paper. 


\section{Literature Review}

DT is a blend of Big Data, cloud computing, IoT, IIoT, sensors, artificial intelligence, machine learning and many other technologies. These technologies are on a path of constant evolution. Hence, DT is assumed to evolve continuously with these technologies. Digital twin for manufacturing processes has undergone significant technological evolution over the past four decades, as shown in Figure 2. The recent technological advancements in sensing, monitoring, and decision-making tools during Industry 4.0 have enabled the precise implementation of digital twin for the real-time monitoring and optimization of the process [35]. The term "twins" in manufacturing was coined during NASA's Apollo 13 program [36]. NASA created two similar space vehicles during this program, of which one was used by astronauts to travel into space while the other remained on the ground, and was called its twin. The twin was used by NASA's engineers to simulate, monitor, and predict the condition of its counterpart, which helped the astronauts to make the decisions in any emergencies. In this stage, the twin is a physical twin. Later stage involve advancements in key computing and information technologies, such as CAD, CAM, CAE, CAPP, PDM, MRP, MES, and PLM. Within this context, Grieves proposed the concept of the virtual digital representation of equivalent physical products using three components, viz., virtual entity, physical entity, and networks of information and data [37]. After 2010, DT entered into a new development phase when the U.S. Air Force Research Laboratory (AFRL) proposed the concept of DT for the life prediction of aircraft structures, allowing better maintenance decisions [38]. Moreover, NASA and ARFL suggested a DT architecture in order for future vehicles to meet the demand of lighter weight while handling higher loads and more severe working conditions [39]. Subsequently, DT can be used in the transition from mass production to individualized production. DT in individualized production offers geometrical assurance, and considers design, pre-design, and production phases [40]. For the seamless integration of DT, one needs to understand all the aspects of DT; hence, the following subsection offers a brief overview of the different aspects of DT.
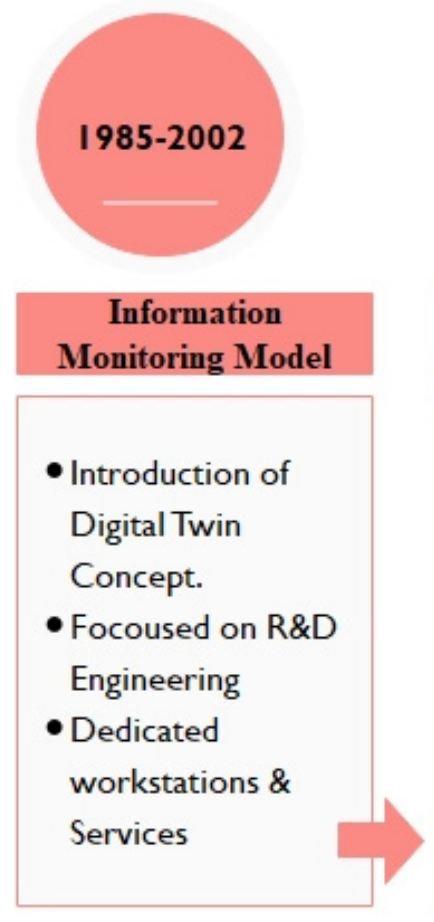
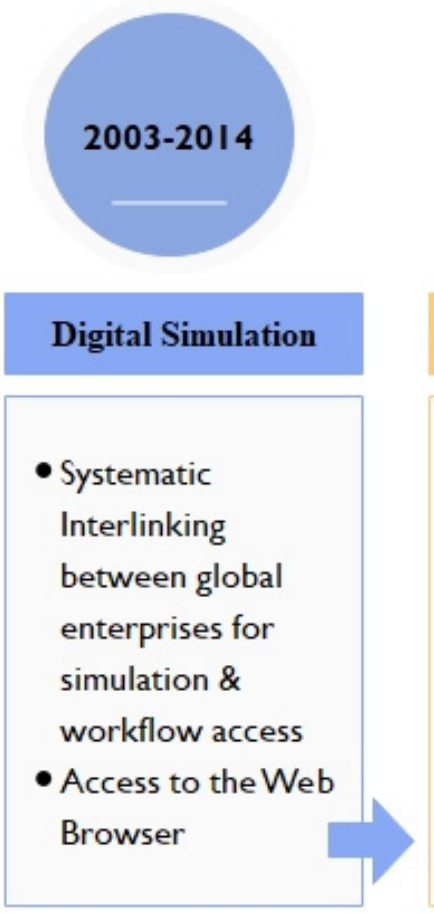
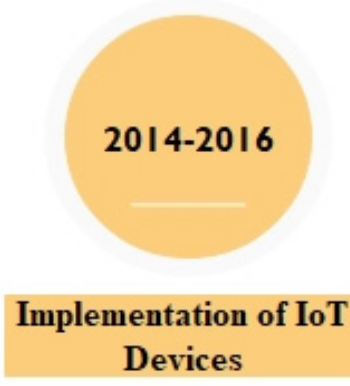

\section{- Device Connectivity}

- Effective data transmission between physical \& virtual spaces.

- Wide application of big data, loT, and cloud
2017-Present

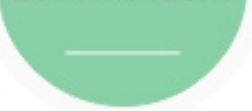

Use of Decision Making Tools

- Implementation of AR/VR for the real time simulations and control.

- Use of Artificial Intelligence and Machine Learning techniques for real time decision making, optimization, and fault detection.

Figure 2. Evolution of digital twin. 


\subsection{Background and Definition of Digital Twin}

Various organizations and researchers have defined DT. Among all the definitions, two are broadly accepted: those characterized by NASA and Grieves. NASA described the digital twin as follows: "A Digital Twin is an integrated multi-physics, multiscale, probabilistic simulation of an as-built vehicle or system that uses the best available physical models, sensor updates, fleet history, etc., to mirror the life of its corresponding flying twin" [41]. Grieves proposed that the basic digital twin model has three components, viz., physical entity in real space, virtual entity in virtual space, and the networks of information data that tie the physical and virtual entities or space together [37]. DT constructs a virtual replica of a physical scenario to monitor the behavior of the ongoing process, with condition monitoring, detection of anomalies, and prediction of future trends within the process. Based on the above literature research, the following are the definitions of the digital twin:

- DT is the digital representation of a physical entity with possible data and models. The term "data" refers to the data from all the processes obtained during the run time and the system's development phase [42];

- DT should always be synchronized with its related physical entities [43];

- It is a simulation model for the working of the related physical entity or process [29].

\subsection{Architecture of Digital Twin}

For the proper integration of devices with their virtual replicas in the cyber-physical domain, and the effective exchange of information and data among digital twins, physical twins, and the outside world, Ref. [44] proposed a six-layer DT architecture, as shown in Figure 3. The six-layer DT architecture is an extension of the 5C architecture [45]. The 5C architecture was developed before the term DT was coined. Hence, it involves the CPS, which replicates the physical system in the cyber domain. The $5 \mathrm{C}$ framework comprises five different stages of implementation, viz., intelligent connection, conversion of data to information, cyber integration, cognitive ability, and configuration of the architecture.

The architecture includes various physical devices, sensors, and data acquisition systems in the physical domain during the data transfer, processing, collection, computation, and communication in the virtual environment. In the architecture, Layers 1 and 2 constitute the physical entity or device. Layer 1 comprises actuators, sensors, and other physical devices, while the data source of the physical entity is specified by Layer 2. Layer 3 contains a local data vault, which acquires the controller values from Layer 2 . The interface for communication between different layers of architecture and the physical entity is in Layer 3. Open Platform Communication-Unified Architecture (OPC-UA) is the most vital element for effective data exchange between the layers. Layer 4 is a data-to-information converter, aided by IoT technologies. This layer enhances the value of the information obtained from Layer 3 and processes the acquired data to make it more valuable for the upper levels of the architecture. Layer 4 links Layer 3 with Layer 5 by converting data from Layer 2 into the information sent to Layer 5 . Here also, OPC-UA plays a vital role in communication. Layers 5 and 6 involve repositories of cloud and emulation and simulation tools, respectively. Layer 5 stores the historical information obtained from the previous layer. Layer 5 enhances the availability, ease of access, and precision of the digital twin. Layer 6 is the cognition layer of the architecture, which enables real-time monitoring of the machine health, and contains historical information of the physical twin. This layer facilitates user integration with a virtual replica of the physical twin, which helps in decision-making, optimization, and predictions of the various tasks and processes. Tools such as Siemens Tecnomatix Plant Simulation, OPC-UA and artificial intelligence prove advantageous in this layer for decision making, analysis, prediction, and optimization. Additionally, the digital twin's actual implementation is made possible because of some recent advancements in enabling technologies for DT, and the benchmark five-dimensional model of DT developed by $[21,43]$. 


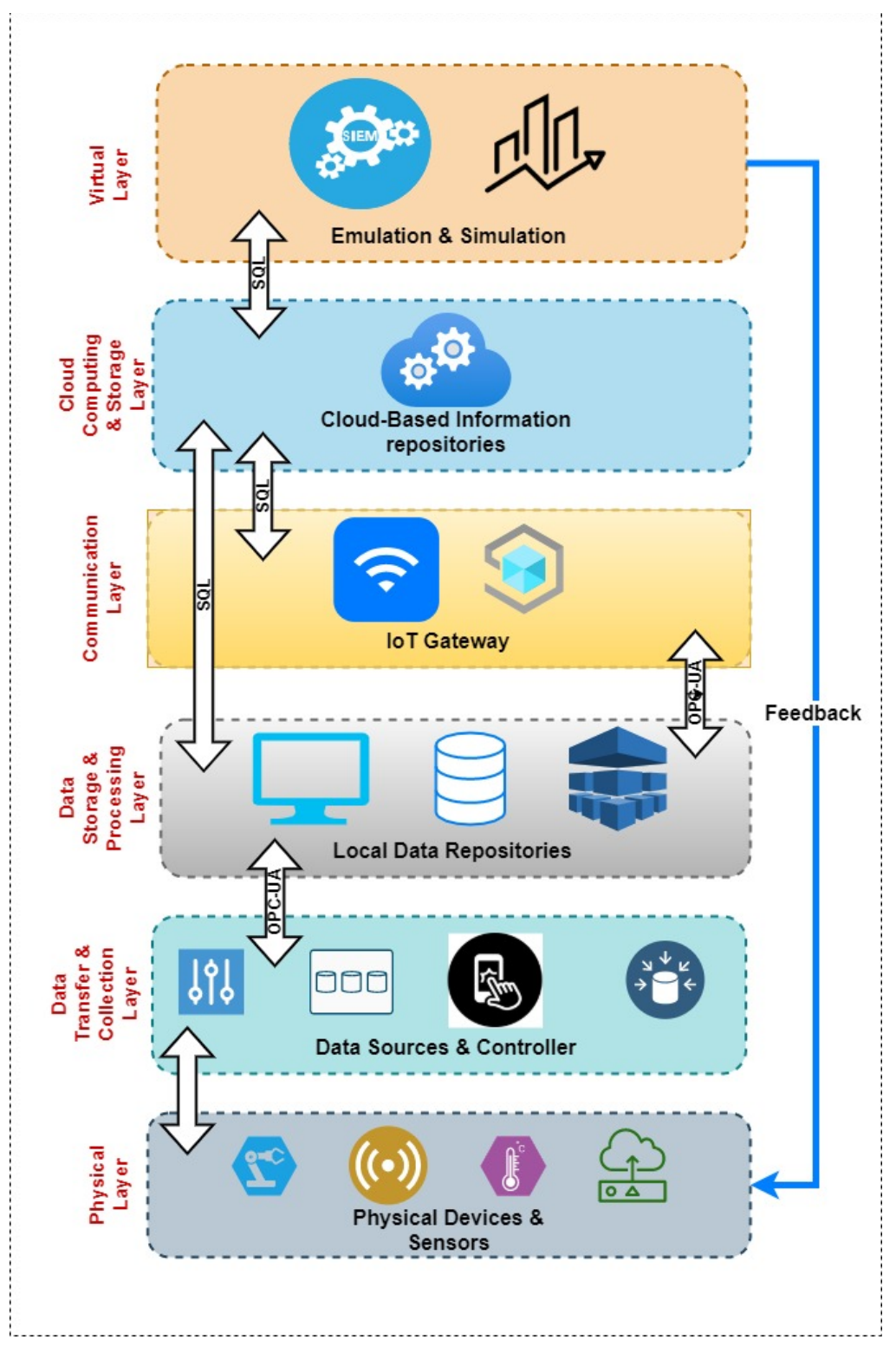

Figure 3. Six-layer architecture of digital twin.

\subsection{Conceptual Framework of Digital Twin}

The DT is a virtual replica of a physical entity or process running in physical space. It contains a physical layer and a virtual (cyber) layer. The physical layer consists of the actual physical system or process, while the virtual layer consists of the data and model of the physical systems or processes. It has three characteristics: synchronization with physical system/process; real-time data acquisition and simulation; behavior prediction. Artificial intelligence turns these DT models into intelligent digital twin models, which can make run-time decisions and optimize the process. To build a precise DT model of any physical entity or process requires different technologies, such as sensing, communication, and cloud and computation technologies. The systematic integration of these is also one of the challenging tasks.

The technological advancements that enable the tools and technologies of DT facilitate the effective integration of DT into existing systems. For the development and implementation of an efficient DT model, Ref. [21] proposed a five-dimensional model for DT, which removes the barriers in implementing DT in various fields. The model can be formulated 
as $M=(P E, V M, S s, D D, C N)$. These terms represent physical entity, virtual model, services, DT data and connections, respectively.

In the proposed models, the physical entity is the basis of the digital twin. "Physical entity" many refer to the device, process, product, physical system, or organization. The virtual replica can be built by considering physical and mathematical laws. Reconstructions of the geometries, behaviors, properties, and behavioral rules of physical entities are referred to as virtual models.

Data are a crucial part of a DT. During the development, implementation, and operational phases, the DT runs through multi-dimensional and heterogeneous data. The data may come from multi-sensor fusion, or may be simulation data, service data, or expert knowledge data. Service is a significant aspect of DT, since it involves the actual use of DT in real-time. DT provides various application services, including monitoring, optimization, simulation, diagnosis, validation, prognosis, etc. [46]. Additionally, it offers data, algorithms, and knowledge services. The connection enables effective data and information exchanges between the physical entities, virtual model, data, and services. In total, there are six connections, which are those between a physical entity and its services, a physical entity and the virtual model, a physical entity and data, a virtual model and its services, a virtual model and data, and the services and the data.

The conceptual framework of DT in manufacturing using a five-dimensional model is portrayed in Figure 4. The physical layer involves various physical scenarios playing out on the shop floor, involving machining, machines, assembly, logistics, packing, products, and workers, as shown in Figure 4. These physical objects and scenarios are the basis of the DT model. The data transfer and collection layer, and the data storage and processing layer, comprise the data center. The different sensors, actuators, and models are used to gather and store the data from the actual physical process and process the data acquired from the entity to remove the noise and filtration. Layer 4 constructs a communication gateway to facilitate the effective data and information exchange between various framework layers. Layer 5 gives real-time insights into the ongoing process by providing multiple services through the cloud, such as condition monitoring, function simulation, evolution simulation, predictive maintenance, dynamic scheduling, and quality control. This layer helps modify the system design or operational parameters through a feedback loop using decisionmaking and machining learning evolutionary algorithms. The final layer comprises the actual virtual replica of the physical entity or process, which outlines the run-time evolution of the physical entity or process and provides the services with artificial intelligence, machine learning, and simulation models. Layer 5 and layer 6 are used to modify the design, operational parameters, process plans and schedules through a feedback loop. The developed DT model reduces downtime, cost and wastage, and increases production efficiency, worker satisfaction, etc.

\subsection{Enabling Technologies of Digital Twin}

According to the five-dimensional model, achieving the successful implementation of DT in a real-world environment requires various technologies for practical data capturing, simulation, analysis and evaluation [46]. Recent technological advancements remove the technical barriers in the implementation of DT. Various techniques are incorporated into the DT framework, such as augmented reality/virtual reality, IoT, cloud computing, machine learning, and an application programming interface [47], to achieve DT implementation. These are discussed below.

- Machine learning-This is an exponentially evolving area of scientific computation. It considers the data and information from both physical and virtual models. It is a subset of artificial intelligence but has broader applicability. The advancements in statistical analysis techniques and hybrid algorithms include the synchronization of machine learning with the digital twin, which improves the DT model's efficiency. The DT model uses machine learning to predict, control, optimize, and generate feedback [48]. 
- Internet of Things (IoT) - This refers to the state wherein all the objects and attributes comprising a DT model are connected to a network. The rapid growth in communicating devices and embedded sensors enables effective communication between the devices, the human operator, and the shop floor [49]. This empowers the DT to monitor and control the ongoing process remotely without any human intervention [50].

- Cloud computing-Cloud computing is the evaluation service provided by the public network. The development of cloud computing technologies facilitates data storage, database access, communication, and computational ability. It reduces the cost of purchasing costly software and hardware for data storage and data processing. Users need to pay only for cloud services. Hence, cloud computing enables the production of low-cost digital twin models, even for small components [51].

- Augmented reality/virtual reality-Virtual reality creates a replica of the physical world in a virtual world and enhances user experience. It can also provide simulation results. In contrast, augmented reality adds a new information layer to the existing real world. In the digital twin, combining both techniques helps to realize the process in the virtual and physical world [52,53].

- Application programming interface (API) - API facilitates the interaction between sensors, databases, and networks, and allows information and data exchange. It reduces the effort of reprogramming following changes in the scenario [54].

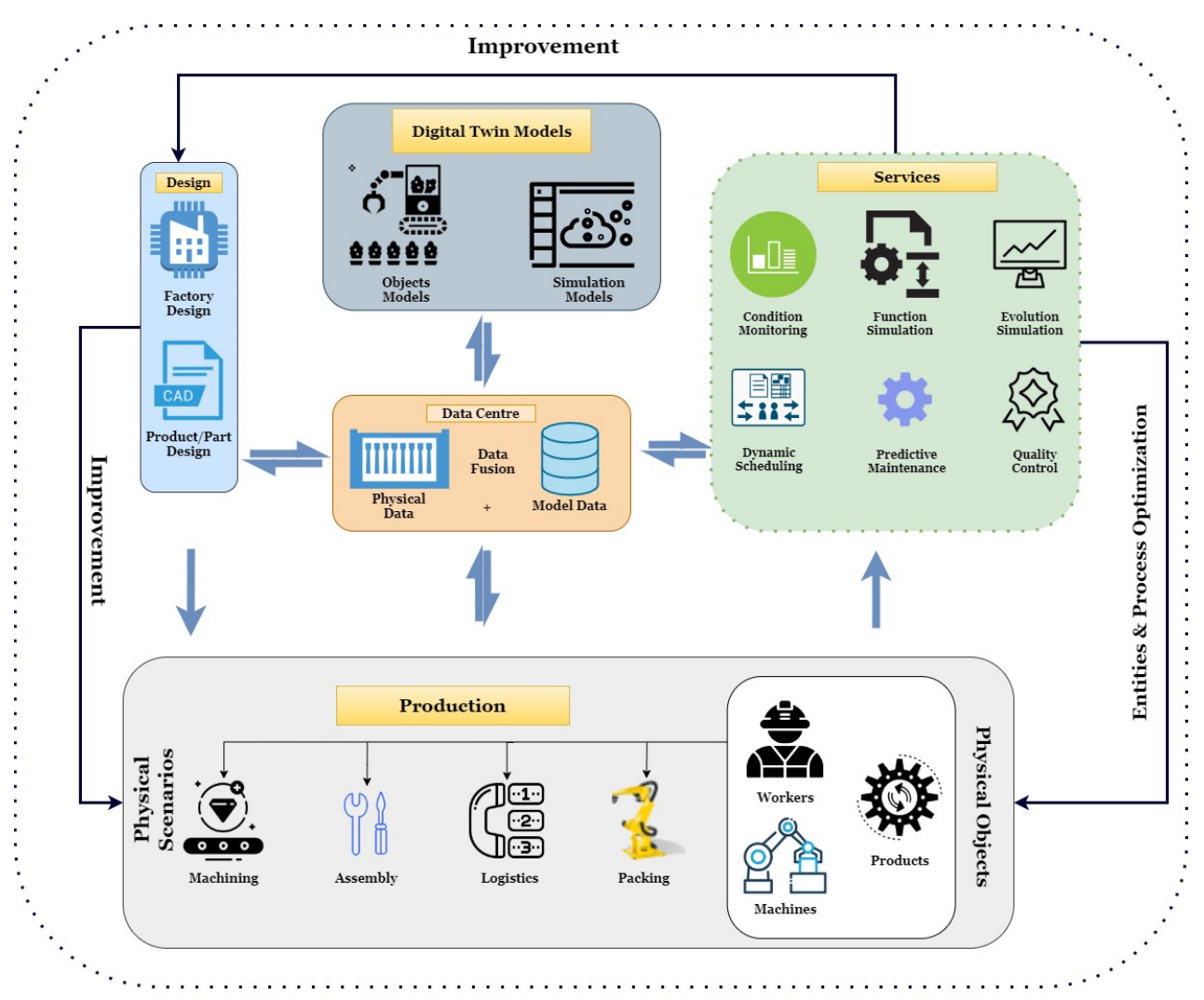

Figure 4. Conceptual framework of digital twin.

All the technologies discussed above aid in the flawless integration of a digital twin and effective data exchange for any application.

\subsection{Application Domains of Digital Twin}

Recently, digital twin technology has attracted extensive interest in various domains. Many IT, manufacturing, and automotive firms have identified DT as the most valuable technology for strategic and systematic development in recent times. The has numerous 
and diverse applications in healthcare, Industry 4.0 and smart manufacturing, aviation, energy, social media, agriculture, and education [55] (shown in Figure 5).

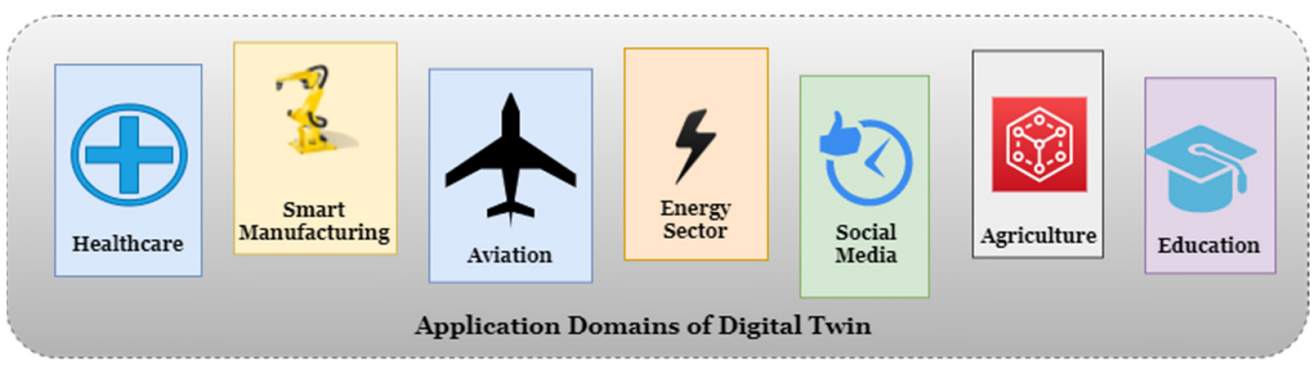

Figure 5. Application areas of digital twin.

In healthcare, DT is used to predict diseases (cancer, cardiovascular and trauma), human well-being, and appropriate treatments. It considers the whole body or a specific human organ for monitoring, diagnosis, and prediction. The DT model is constructed using various parameters and signals from the organ or body, viz., blood pressure, sugar levels, heart rate, metadata and internal chemical secretion, and uses these to predict future risk [56-58].

Smart manufacturing in the framework of Industry 4.0 uses DT technology for machine health monitoring, predictive maintenance, estimation of useful life, process optimization, cost-effective production, and parameter tuning. The DT model is built using multisensor data fusion (vibration, temperature, acoustic, force, speed, position, and camera images) and simulation models. It considers the various working parameters of the process/equipment. Generally, it is used on the shop floor or assembly line, or in machinery operation. Real-time data are also validated through simulation models, which later generate a feedback signal to optimize the process [59-61]. Airplanes, air travel route planners, and space vehicles employ DT to predict fatigue failure and maintenance, and to create flight simulation models and thermal behavior models. It considers various data from the vehicle, its surroundings, and weather, with the aid of intelligent sensors and actuators, to build a real-time virtual replica of a space-going vehicle. Implementing DT in the aviation field reduces planning and optimization costs [62,63].

The virtual replicas of the electricity grid, transportation routes and greenhouse electricity generation facilitate predictive maintenance, fault diagnosis, lifecycle management, cost-effective generation, loss reduction, and usage analysis. The DT model considers various parameters, such as temperature, flow rate, virtual energy flow models and fuel characteristics using different data-capturing techniques [64-66]. Moreover, the DT model can estimate the remaining useful life of equipment, and schedule a maintenance activity (i.e., predictive maintenance) to minimize the downtime and cost of production [67]. Another fundamental application of DT is in social media, which is a vastly growing field. The DT models help to perform sentiment analysis, trend analysis, identification of fraud, and planning of future marketing strategies using data from recent web-surfing and logs from the visited platforms, as well as comments, likes, uploads and sharing to posts, pages, etc. [68]. Due to recent technological advancements, the agriculture sector has also incorporated DT into crop management, disease prediction, the evaluation of fertilizers through data captured from the field (temperature, humidity, soil moisture, light intensity, pressure) and plant image data $[69,70]$.

Additionally, DT helps in effective content delivery, as well as skill and knowledge development, in the education sector via a virtual platform. It stores e-content, recorded or live-streamed videos, and animations on the cloud, and later delivers them through its e-Learning platforms [71,72]. 


\subsection{Benefits of Digital Twin}

The implementation of digital twin enables the user to perform their regular tasks remotely with or without human intervention. It reduces the cost of service and human error, and facilitates the proper allocation of resources [47]. The advantages can be categorized as analytical value, descriptive value, predictive value, and diagnostics value.

i. Analytical value is the ability of the digital twin to capture the data and analyze them. Based on this analysis, decisions are to be made to improve the performance [73,74].

ii. Descriptive value is the benefit to long-distance and remote data transportation and collection, which helps off-site monitoring and the control of the process [73,74].

iii. Predictive value predicts the trends and behaviours of the process by analyzing the data obtained from the sensors and detecting any abnormal activities in the ongoing process. Based on the predictive analysis, an autonomous decision will be generated $[60,73,75]$.

iv. Diagnostics value helps identify the potential causes of failure and departure from trends using advanced analytics and machine learning algorithms, employing data from the process $[60,73]$.

\subsection{Challenges in Implementing a Digital Twin}

The digital twin's application has grown exponentially during the Fourth Industrial Revolution, and it is a newly popular field of study $[30,60]$. The following problems are encountered during its implementation.

i. Education-Recent technological advancements are a barrier to researchers and engineers adopting DTs. With a lack of knowledge about changes and of expertise in technologies, the implementation of the digital twin is cumbersome [76,77].

ii. Accurate representation-Owing to the intricate and complex nature of the process and the lack of availability of technology, the replication of the physical system in virtual space is difficult and time-consuming $[73,77]$.

iii. Data quality-The data are the crucial part of DT. Most of the time, data obtained from the various sensors include some noise due to environmental factors and operational conditions. This necessitates data pre-processing and filtration, thus increasing the computation time [60,78].

iv. Cost - Cost is the primary factor of any new technology. Digital twin implementation requires costly sensors, software modules and data acquisition and storage systems, because of the high volume of data and the complex processes. In the future, this cost will be reduced, but as of now, the cost is a significant concern while implementing a digital twin [73,78].

v. Intellectual property protection-The data are distributed through various departments of an organization; this threatens the confidentiality of the ongoing research activities of the organization [77].

vi. Digital security-Cyber-attacks made by competitive organizations or individuals pose a threat to the security aspects of the digital twin [73,79].

To identify future research trends, tools, and technologies for realizing DTs in the domain of smart manufacturing, the following section elaborates a detailed methodology to perform bibliometric analysis on the selected databases.

\section{Methodology}

The literature review is the best tool for managing the knowledge within the research domain, and evaluating it [80]. To reproduce and evaluate the research area requires extensive analysis and systematic reviews [81,82]. Bibliometric analysis is one such analysis technique that is used in the present study [83]. Bibliometric analysis is a quantitative methodology that allows one to study the scientific literature and its characteristics, evolu- 
tion, methodologies, etc. [34]. It is used in various fields, such as education, management, engineering and agriculture [84].

The present study employs a methodology with five phases, as shown in Figure 6. The phases of the proposed methodology are: (1) search criteria and source identification; (2) software and data extraction; (3) data analysis and interpretation; (4) Proknow-C methodology; (5) case studies. The following subsection deals with the literature review for the bibliometric analysis, the requisite tools for the analysis, and the Proknow-C process.

\section{Methodological Process of Bibliometric Analysis}
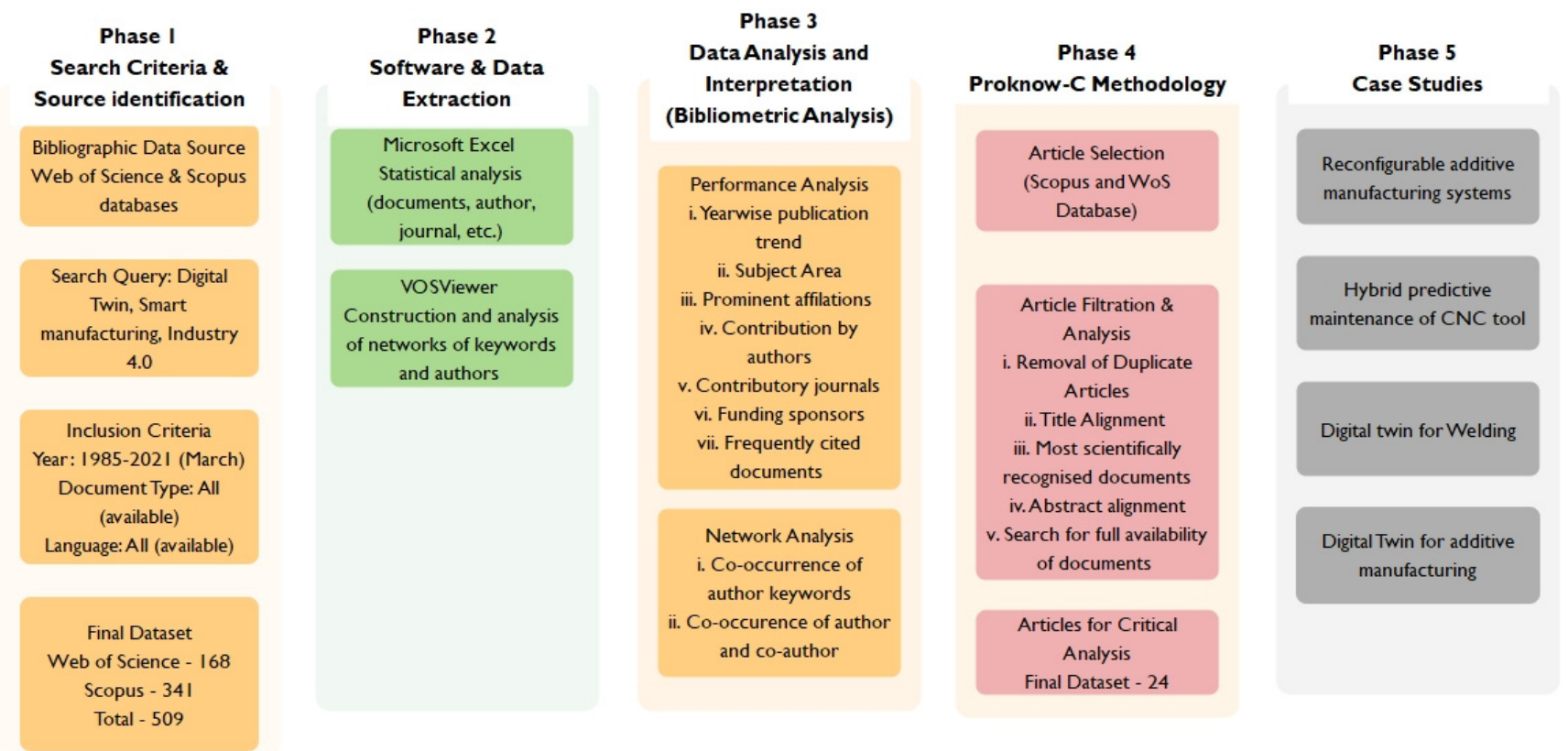

Figure 6. Proposed method diagram showing the methodology carried out in the present study.

\subsection{Literature Review Related to Bibliometric Analysis}

Even though research on digital twins in the context of smart manufacturing is growing exponentially, reviews of the literature are lacking. Table 1 outlines the previous studies that have presented a bibliometric analysis of the application of DT in smart manufacturing and Industry 4.0 .

Table 1. Literature on bibliometric analysis in the context of the digital twin.

\begin{tabular}{|c|c|c|c|c|c|c|c|}
\hline Sr. No & Authors & Scope & Journal & Databases & Method & Sample Size & Years \\
\hline 01 & $\begin{array}{c}\text { Bigliardi et al., } \\
2019 \\
{[85]}\end{array}$ & $\begin{array}{c}\text { Logistics, } \\
\text { Industry } 4.0, \\
\text { Supply chain. }\end{array}$ & $\begin{array}{c}\text { IET collaborative } \\
\text { intelligent } \\
\text { manufacturing }\end{array}$ & Scopus & $\begin{array}{l}\text { Bibliometric } \\
\text { and Statistical }\end{array}$ & 131 & 2013-2020 \\
\hline 02 & $\begin{array}{c}\text { Sayyad et al., } \\
2021 \\
{[86]}\end{array}$ & $\begin{array}{l}\text { Predictive } \\
\text { maintenance, } \\
\text { RUL. }\end{array}$ & $\begin{array}{l}\text { Library Philosophy } \\
\text { and Practice } \\
\text { (e-journal) }\end{array}$ & Scopus & $\begin{array}{c}\text { Bibliometric } \\
\text { and Statistical }\end{array}$ & 1673 & 1985-2020 \\
\hline 03 & $\begin{array}{l}\text { Kumar et al., } \\
2020 \\
{[55]}\end{array}$ & $\begin{array}{c}\text { Digital Twins, } \\
\text { Artificial } \\
\text { intelligence, } \\
\text { manufacturing }\end{array}$ & $\begin{array}{l}\text { Library Philosophy } \\
\text { and Practice } \\
\text { (e-journal) }\end{array}$ & Scopus & $\begin{array}{l}\text { Bibliometric } \\
\text { and Statistical }\end{array}$ & 844 & 2015-2020 \\
\hline 04 & $\begin{array}{l}\text { Fernandes } \\
\text { et al., 2019 } \\
\text { [87] }\end{array}$ & $\begin{array}{c}\text { Smart Factory, } \\
\text { Industry 4.0, } \\
\text { Process } \\
\text { optimization }\end{array}$ & $\begin{array}{c}\text { Procedia } \\
\text { Manufacturing }\end{array}$ & $\begin{array}{l}\text { IEEE, Academic Search } \\
\text { Ultimate, Science } \\
\text { Direct and Engineering } \\
\text { Village (Compendex), } \\
\text { Emerald Insight. }\end{array}$ & $\begin{array}{l}\text { Proknow-C } \\
\text { and } \\
\text { Bibliometric }\end{array}$ & 3562 & 2014-2018 \\
\hline
\end{tabular}


Table 1. Cont.

\begin{tabular}{|c|c|c|c|c|c|c|c|}
\hline Sr. No & Authors & Scope & Journal & Databases & Method & Sample Size & Years \\
\hline 05 & $\begin{array}{c}\text { Jerman et al., } \\
2018 \\
{[88]}\end{array}$ & $\begin{array}{l}\text { Industry } 4.0, \\
\text { Smart factory, } \\
\text { Human } \\
\text { resources. }\end{array}$ & Machines-MDPI & $\begin{array}{c}\text { Thomson Reuters' Web } \\
\text { of Science and } \\
\text { Scopus }\end{array}$ & $\begin{array}{l}\text { Bibliometric } \\
\text { and Statistical } \\
\text { Data Miner }\end{array}$ & 43 & 1985-2018 \\
\hline 06 & $\begin{array}{c}\text { Ante, } 2021 \\
\text { [89] }\end{array}$ & $\begin{array}{c}\text { Digital Twin, } \\
\text { Smart manu- } \\
\text { facturing, } \\
\text { Industry } 4.0\end{array}$ & $\begin{array}{l}\text { Manufacturing } \\
\text { Letters }\end{array}$ & Web of Science & Bibliometric & 23,419 & $\begin{array}{c}1985-2020 \\
\text { (Oct) }\end{array}$ \\
\hline 07 & $\begin{array}{c}\text { De Felice et al., } \\
2018 \\
{[26]}\end{array}$ & $\begin{array}{l}\text { Smart Manu- } \\
\text { facturing, } \\
\text { Artificial } \\
\text { intelligence }\end{array}$ & IFAC Papers Online & Scopus & $\begin{array}{l}\text { Bibliometric } \\
\text { and Analytical }\end{array}$ & 1498 & 2011-2018 \\
\hline
\end{tabular}

In the research work shown in Table 1, most of the studies that have carried out bibliometric analyses have considered the traditional approach for analysis-they used all types of papers, irrespective of their area, language, and document type. Refs. [55,86] used all sorts of documents and analyzed their citations, co-author occurrences, keywords, subject areas, etc. Ref. [87] used the Proknow-C technique for systematic bibliometric analysis in the context of smart factories and Industry 4.0.

No research on bibliometric analysis of digital twins used in smart manufacturing has been identified in the literature. However, a bibliometric analysis of relevant fields, such as fault diagnosis and predictive maintenance [86], RUL [86], and process optimization, has emerged recently, from 2015 onwards. Additionally, research work on digital twins used for smart manufacturing in the Fourth Industrial Revolution attracted significant attention from the group of researchers from the year 2017 onwards [47,55,87,89].

Regarding the method, Table 1 shows that a single article [87] used the Proknow-C method for the bibliometric analysis, which involves executing procedures serially until a final portfolio of articles is obtained, which has a strong correlation with the research theme and contains 3562 articles. As mentioned in Table 1, other studies use the traditional approach to bibliometric analysis, which mainly considers the statistical data.

It can be concluded that there are few studies that provide foundational literature and significant research themes for progressing the research on digital twins in the context of smart manufacturing. Additionally, the present study covers more recent publications, as most of the documents relating to this work have been published in the last three years. Ultimately, a hybrid method for bibliometric analysis using Proknow-C, network analysis, and case studies of the most relevant research articles is proposed. The novel contribution of this work toward identifying the research gaps in, and the future research potential of, this field is also stated.

\subsection{Requisite Tools for Bibliometric Analysis}

A bibliometric analysis is a comprehensive knowledge method that incorporates statistics, mathematics, and linguistics techniques, while paying attention to quantification. The cardinal motives of the bibliometric study are to summarize the current research scenarios and possible research gaps, and to identify the most prominent authors, fields of application, journals, publication titles, funding agencies and affiliations within the defined research theme [90]. The documents used for the analysis were extracted from the Scopus and Web of Science databases. Web of Science is a multidisciplinary database made from an assortment of specific files, gathered by recorded research themes or by topic. The fundamental part of WoS is CC (the Core Collection), which incorporates six primary reference files: SCIE (Science Citation Index Expanded); SSCI (Social Sciences Citation Index); A\&HCI (Arts and Humanities Citation Index); CPCI (Conference Proceedings Citation Index); BKCI (Books Citation Index); and ESCI (Emerging Sources Citation Index) [91]. Scopus is a comparative multidisciplinary and specific database, which Elsevier dispatched in November 2004 [91,92]. 
Network analysis is a group of improved methods and calculations derived from the network hypothesis and involving the improved utilization of the internet and PCs to experimentally analyze the force of informal social impacts on research and its patterns. Different software, such as Microsoft Excel (for statistical analysis), Citespace, VOSviewer, nodeXL, Pajek, Gephi, and many others, have been used in network examination, representation, and the improved comprehension of large quantities of information and data through exploratory approaches. VOSviewer programming was utilized in this investigation $[55,86,88]$. VOSviewer programming has become relevant and undergone improved utilization among scientists in business, particularly for use in graphical and metadata metric studies; for instance, VOSviewer can utilize various data sets in a similar report. Draw.io [86], Wondershare Edrawmax, and Microsoft Visio are utilized. Visio is an imaginative arrangement that assists with picturing information associated with measurements, with a large group of coordinated highlights, that brings the benefits of Microsoft 365 to Visio.

\subsection{Methodology for Systematic/Qualitative Analysis Using Proknow-C}

The Proknow-C (knowledge development process-constructivist) technique was applied to determine the hypothetical reference and development of the vital information, as put forth by [93], and it involves the scrutinizing and determination of articles with relevance to the research theme [94-97].The Proknow-C method is useful for researching within the given research theme and research boundaries. The author's keywords, access to the articles, and scientific recognition all affect the construction of the process $[94,98]$. As such, Proknow-C is the most structured technique for building a research portfolio, based on which the researcher could identify possible research gaps and define the research question.

Proknow-C consists of the following five phases, shown in Figure 7 below.

\begin{tabular}{|c|c|c|c|c|}
\hline Phase I & Phase 2 & Phase 3 & Phase 4 & Phase5 \\
\hline $\begin{array}{c}\text { Article } \\
\text { Selection }\end{array}$ & $\begin{array}{c}\text { Article } \\
\text { Filtration \& } \\
\text { Analysis }\end{array}$ & $\begin{array}{c}\text { Systematic } \\
\text { Analysis }\end{array}$ & $\begin{array}{c}\text { Identification of } \\
\text { research gaps }\end{array}$ & $\begin{array}{l}\text { Research } \\
\text { Objectives }\end{array}$ \\
\hline $\begin{array}{l}\text { Selection of articles } \\
\text { for bibliographic } \\
\text { portfolio which } \\
\text { comprises research } \\
\text { subject }\end{array}$ & $\begin{array}{l}\text { Article filtration } \\
\text { based on the various } \\
\text { criteria and selection } \\
\text { of articles for the } \\
\text { critical analysis }\end{array}$ & $\begin{array}{l}\text { Systematic analysis of } \\
\text { the articles which } \\
\text { comprise bibliographic } \\
\text { portfolio to } \\
\text { understand the } \\
\text { different aspects of } \\
\text { research theme. }\end{array}$ & $\begin{array}{l}\text { Identification of } \\
\text { potential research } \\
\text { gaps and future } \\
\text { research trends from } \\
\text { the systematic analysis } \\
\text { of portfolio }\end{array}$ & $\begin{array}{l}\text { Defining the } \\
\text { research } \\
\text { objectives to } \\
\text { address the } \\
\text { research gaps }\end{array}$ \\
\hline
\end{tabular}

Figure 7. Phases of Proknow-C method.

The five different phases of the Proknow-C method are shown in Figure 7, which elaborates the methodology of the bibliometric analysis in detail. Phase 1 of Proknow-C consists of article selection for a bibliographic portfolio that correlates with the research theme. The articles for the bibliographic portfolio were selected by defining the databases (here Web of Science and Scopus), the search axes, keywords, and their combinations. Figure 8 shows the process flow of article selection in Proknow-C. 


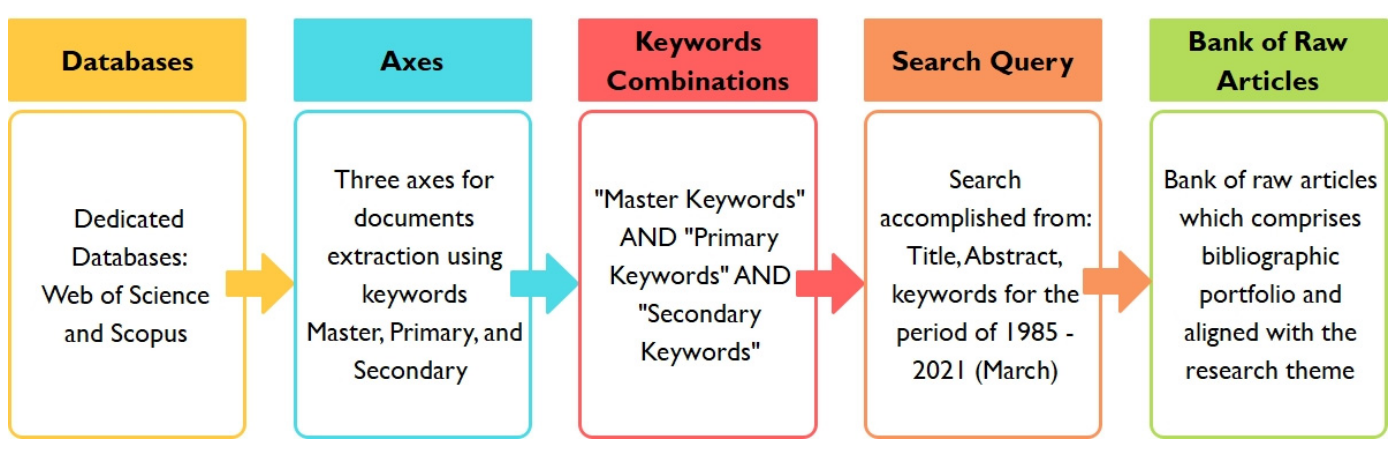

Figure 8. Selection procedure of raw articles for the portfolio.

Three axes were defined for the searching of articles, called Master Keywords, Primary Keywords and Secondary Keywords, and for these three axes, the chosen keywords are listed in Table 2. This selection was made via three research axes: digital twin, smart manufacturing, and enabling tool and technologies. Based on the search string, the keywords were segregated, and (AND) \& (OR) Boolean operators were used in between them. The keyword combinations with Boolean operators were structured as (Master Keyword) AND (Primary Keywords) AND (Secondary Keywords), resulting in a total of 21 combinations. The analysis in this paper is based on the Scopus and Web of Science database for the period of 1985-2021 (March) for all the available languages, document types, and subject areas. The databases were selected based on their availability and agreement with the research theme.

Table 2. List of keywords and their combinations (search string).

\begin{tabular}{cc}
\hline Master Keyword & “Digital Twin" \\
\hline Primary Keywords & "Machinery" OR “Manufacturing" OR "Smart Manufacturing" \\
"Enabling Technologies" OR “Industrial Internet-of-Things" OR \\
"Internet-of-Things" OR “Machine Learning" OR “Artificial \\
Intelligence" OR “Deep Learning" OR "Data-Driven Systems"
\end{tabular}

The portfolio search was accomplished using two databases with blends of keywords, with the help of search queries such as title, abstract, and keywords. The reviews were limited to the last five years (from 2016 to March 2021) and all document types. A compliance test was conducted to ascertain whether there are any requirements for the incorporation of new keywords, with the goal that the portfolio be sufficiently adjusted to finish the choice phase of constructing the crude article bank.

Phase 2 of the Proknow-C considers three different article filtration criteria, described as follows:

i. Filtration of raw articles-Multiple databases result in the repetition of articles. Hence, the first criterion is to remove duplicate articles from the bank of raw articles.

ii. Filtration of articles based on title alignment and scientific recognition-In the second stage of article filtration and selection of Proknow-C, after removing the repeated articles (articles that are common to both the databases), they are filtered based on title alignment. Here, the articles whose titles are not aligned with the research theme are removed from the bibliographic portfolio. Later, the articles are removed based on the citation received (articles that have been cited less than ten times are removed). In addition, articles from the last three years are filtered by reading their abstracts and constructing a summary, since the more recent articles have not received much scientific recognition within the stipulated time.

iii. Filtration of articles based on scientific knowledge-Once the articles are filtered based on the above two criteria, the subsequent filtration process involves reading 
abstracts and checking the availability of entire articles. The articles whose abstracts do not fall within the research theme are removed, and we remove articles whose abstracts are not available.

After this filtration, the remaining articles comprise the final bibliographic portfolio, which contains those with the most significant correlation with the research theme.

Phase 3 concerns the systematic analysis of each article in the bibliographic portfolio, including reading the whole article and studying the techniques applied, the research outcomes, the methodology incorporated, and the significant comments given by the author. The articles that do not fall within the research context are removed from the portfolio. Phase 4 identifies possible research gaps from the systematic analysis and formulates the research question based on the identified research gaps, which helps in defining the research objectives. In phase 5 , based on possible research gaps and research questions, the research objectives are defined, and we suggest a possible methodology for achieving the defined research goals. The following section elaborates the Proknow-C techniques and the results of each phase in the context of the stated research theme, based on the use of data obtained from the specified databases.

\section{Discussion}

4.1. Interpretation from the Statistical Analysis of Publications from Scopus and Web of Science Database (Quantitative Analysis)

We derived 341 documents from the Scopus database and 168 documents from the Web of Science database (WoS). Different languages are used for the publication of the articles related to the research theme. Table 3 summarizes the prominent languages in which research regarding DT is published and considers the articles from both databases that are relevant to the present analysis.

Table 3. No. of documents by languages in Scopus and WoS.

\begin{tabular}{cccc}
\hline Sr. No. & Publication Language & Publications in Scopus & Publications in Web of Science \\
\hline 1 & English & 323 & 196 \\
2 & Russian & 0 & 3 \\
3 & Chinese & 17 & 2 \\
4 & Korean & 1 & 2 \\
5 & German & 1 & 0 \\
\hline
\end{tabular}

\subsubsection{Documents by Type in Scopus and WoS}

Both databases contain different types of publications, as shown in Table 4. It is clear from Table 4 that $37 \%$ and $56 \%$ of the articles are published in the Scopus and WoS databases. In comparison, $45 \%$ of the conference papers are published in the Scopus database, and $31 \%$ of meeting papers are published in the WoS database. Other types of documents, such as book chapters, reviews, and editorials, are also published, but there are fewer of them. This variation shows the ongoing progress of research in the field of digital twins.

Table 4. Types of documents in Scopus and Web of Science.

\begin{tabular}{cccc}
\hline Sr. No. & Document Type & Scopus (\%) & Web of Science (WoS) (\%) \\
\hline 1 & Conference Paper/Meeting & 45 & 31 \\
2 & Article & 37 & 56 \\
3 & Review & 6 & 6 \\
4 & Conference Review /Early Access & 6 & 4 \\
5 & Book Chapter & 5 & 1 \\
6 & Editorial Material & 1 & 2 \\
\hline
\end{tabular}




\subsubsection{Year-Wise Publications in Scopus and WoS Database}

The bibliometric analysis of articles on the use of digital twin in smart manufacturing proceeded from 2016 to 2021. Due to the wide range of digital twin applications, the number of publications and their citation count increased tremendously in the given period. Figure 9 shows a graphical representation of the publications per year in the context of the research theme. From Figure 9, it is concluded that from 2019 to 2020, the research on the use of digital twins in smart manufacturing increased suddenly and is still rising at present. The trend line shows that a more significant number of documents were published in Scopus than in WoS. Additionally, it shows that 2020 was the most influential year, during which 136 and 75 documents were published in Scopus and WoS, respectively.

\section{Yerawise Publication Count in Scopus \& WoS}

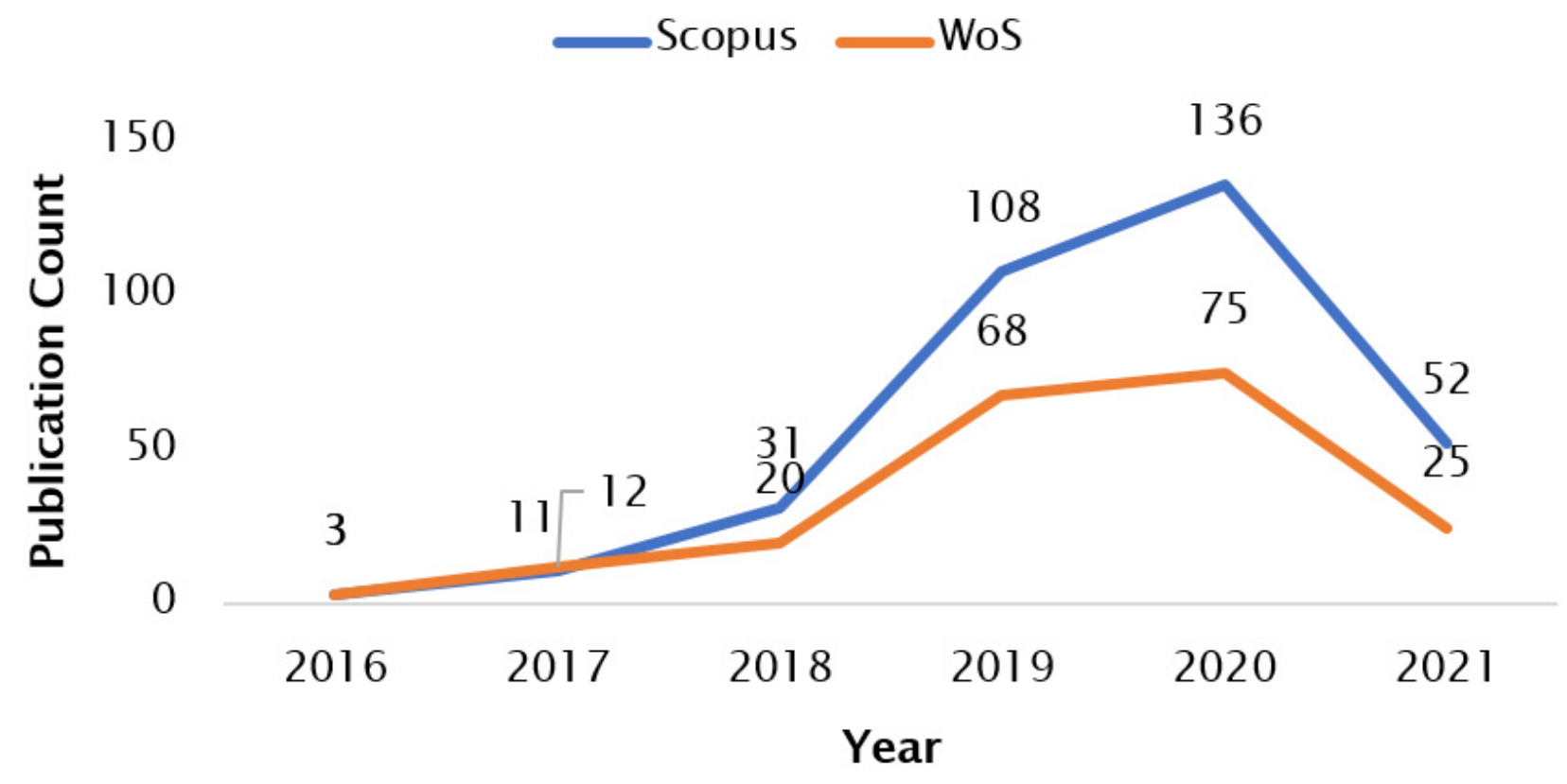

Figure 9. Number of publications per year in Scopus and WoS.

\subsubsection{Documents by Geographic Locations in Scopus and WoS}

The availability of the internet and worldwide access to past research studies has increased the research in this varied application field. According to the Scopus database, most of the research has been done in China (70), followed by the United States (45), Germany (27), Italy (21), and the United Kingdom (20). The least research work has been carried out in countries such as India, France, Brazil, Sweden, and Finland. As per the WoS database, most research works were carried out in the Republic of China (47), followed by the USA (32), China (26), Germany (25) and Italy (17). The countries with the lowest contributions are England, Sweden, France, India, and Singapore. Figure 10 shows the research work carried out across the globe at different locations within the research theme. 


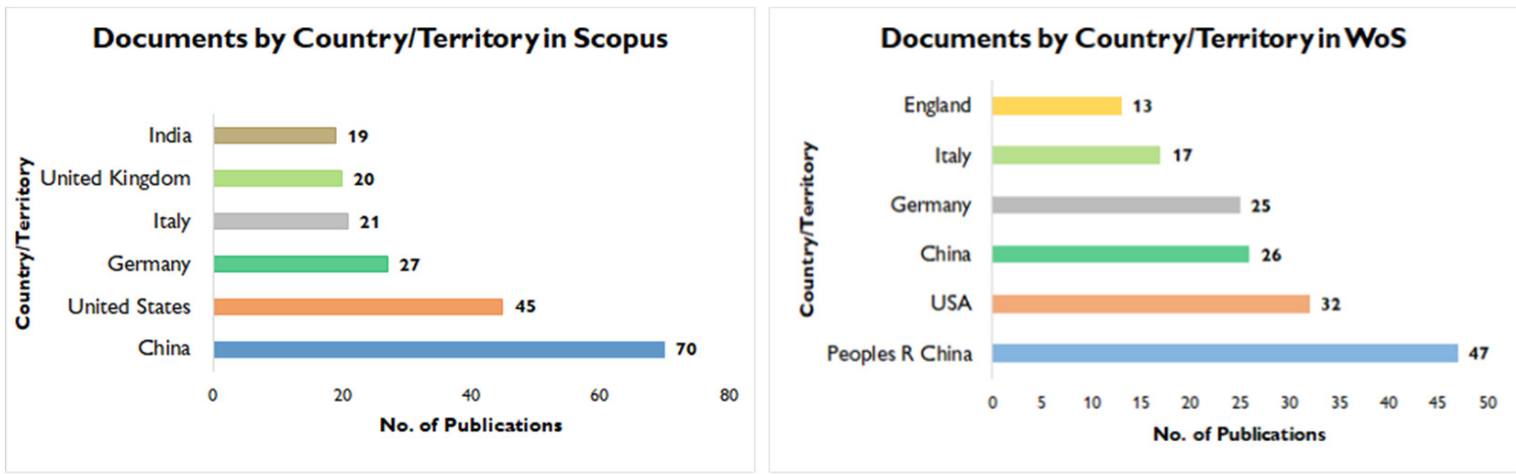

Figure 10. Number of publications by geographic location in Scopus and WoS (Top 6).

\subsubsection{Documents by Subject Area in Scopus and WoS Databases}

The amount of research work carried out in the different subject areas within the boundaries of the research theme is depicted in Figure 11. According to the Scopus and WoS databases, most of the research work was performed in the engineering and computer science domains.

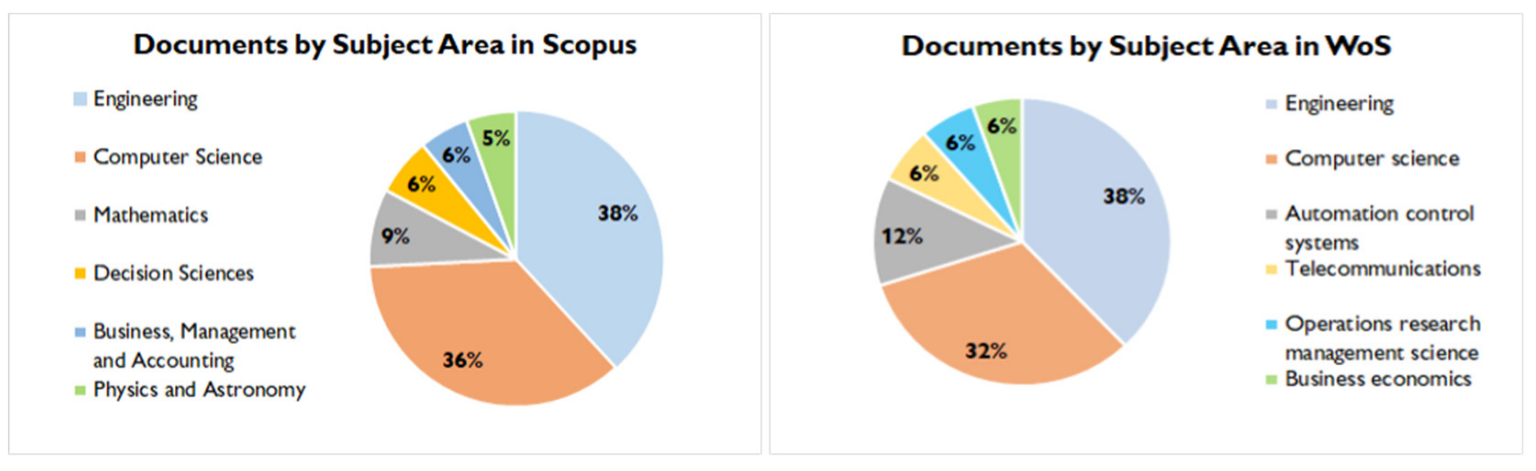

Figure 11. Publications by subject area in Scopus and WoS. (Top 6).

\subsubsection{Documents by Affiliations in Scopus and WoS Databases}

A graphical representation of the top six universities and organizations making significant contributions to the research on digital twins is given in Figure 12. From the Scopus and WoS analyses, it is observed that Beihang University, the Guangdong University of Technology, and the University of Hong Kong made noteworthy contributions to the studies in the research domain.

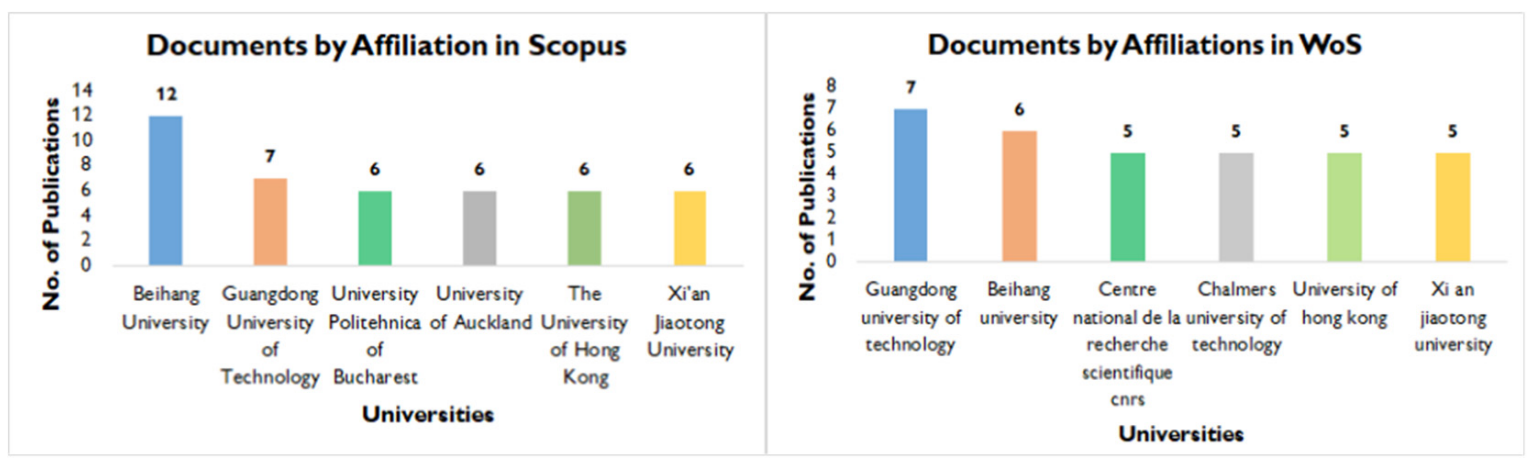

Figure 12. Number of publications by affiliation in Scopus and WoS (Top 6). 


\subsubsection{Documents by Author in Scopus and WoS Databases}

Many people are contributing to research on and development of digital twin technology. Figure 13 shows the prominent authors contributing to the literature related to digital twins, leading to its further development. From the analysis of Figure 13, we see that the authors with the greatest publication counts are Tao F (9), Borangiu, T. (6), Qi, Q (5), Lu Y (5), Zhang M (5), Zhang C (5), etc.

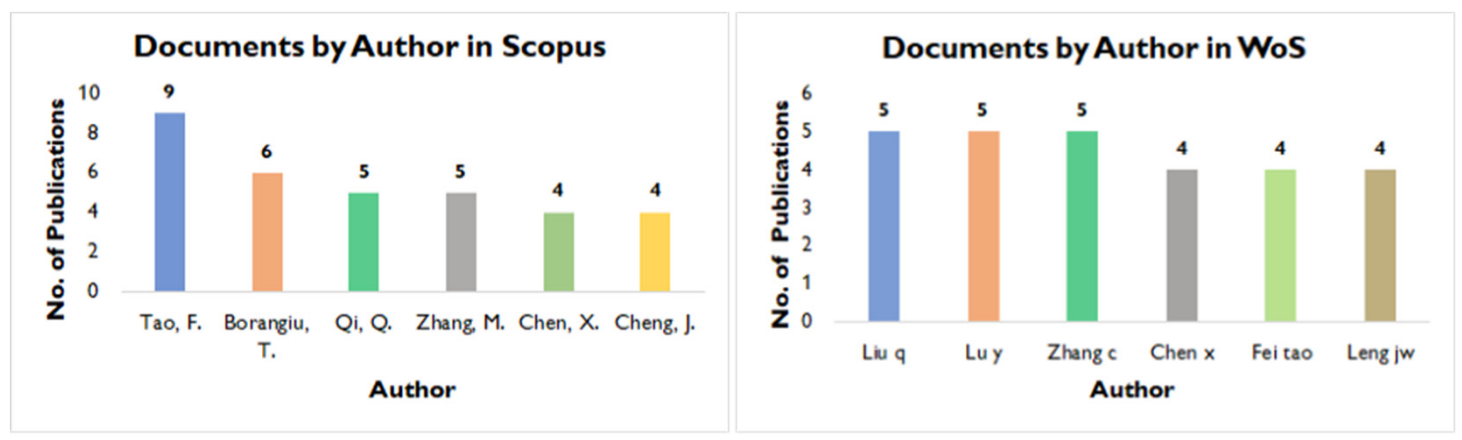

Figure 13. Number of publications by author in Scopus and WoS (Top 6).

\subsubsection{Documents by Source Titles in Scopus and WoS Databases}

A quantitative analysis of the top six articles from the Scopus and WoS databases within the research theme is presented in Figure 14. From the investigation, we see that Procedia CIRP (12) contains the most publications, followed by Studies in Computational Intelligence, International Journal of Computer Integrated Manufacturing, and others in the Scopus database. In contrast, IEEE access (10) has the most publications, followed by the International Journal of Computer Integrated Manufacturing, Procedia CIRP, and others in the WoS database.
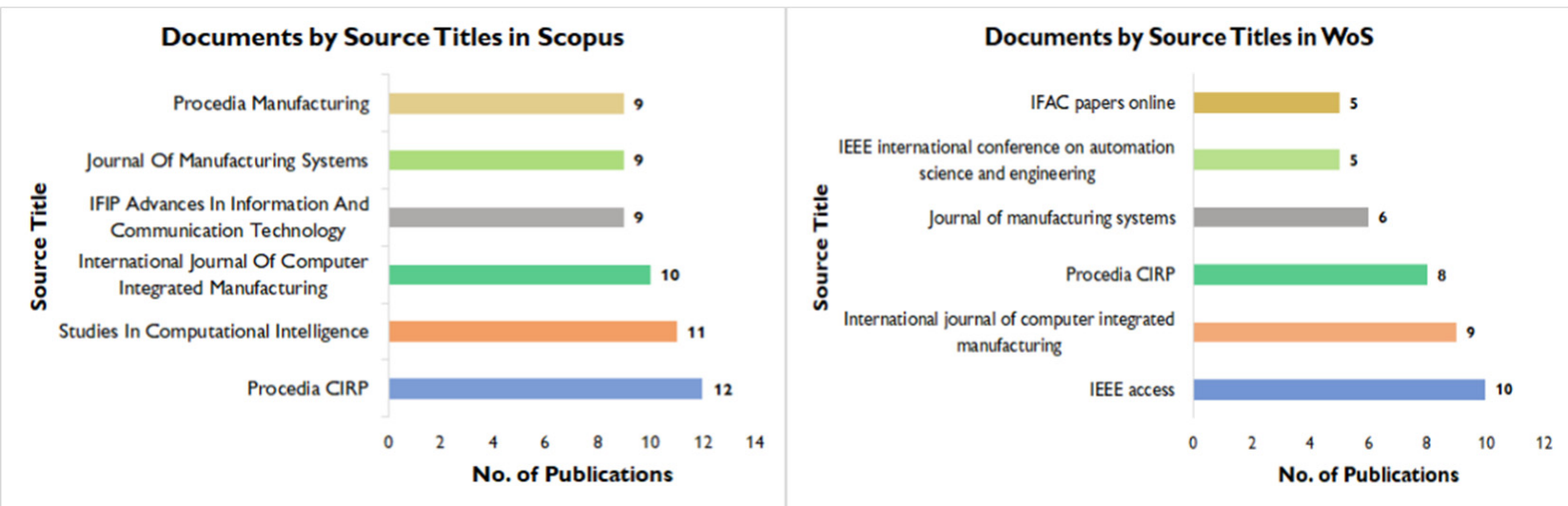

Figure 14. Number of publications by source title in Scopus and WoS (Top 6).

\subsubsection{Documents by Funding Sponsors in Scopus and WoS Databases}

There are many funding agencies, institutions, and organizations worldwide that provide funds for research. Figure 15 shows the statistical analysis of the funding agencies providing funds to study within the research theme. In the Scopus database analysis, the National Natural Science Foundation of China (29) funded most of the research work, followed by the European Commission, Horizon 20202 Framework Programme, etc. In comparison, the National Natural Science Foundation (25) funded most of the research work, followed by research funds from the Central Universities, the National Key Research and Development Program of China, and others, in the WoS database. 


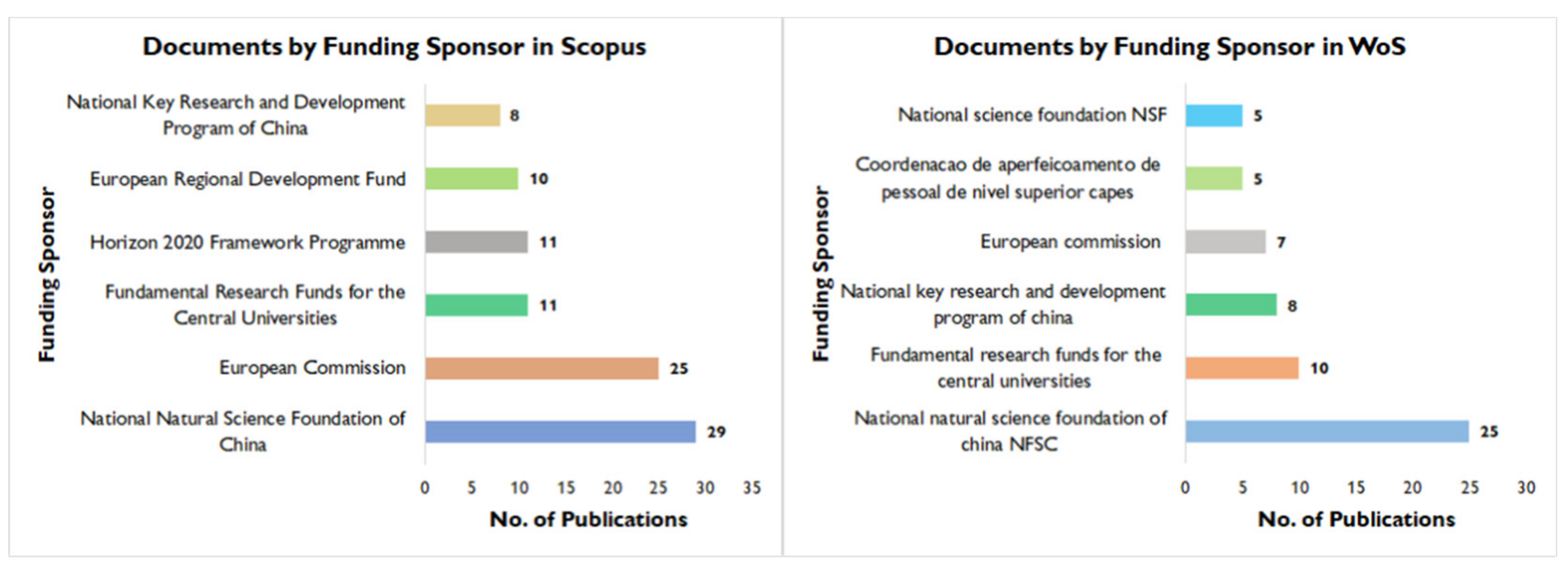

Figure 15. Number of publications by funding sponsor in Scopus and WoS (Top 6).

\subsubsection{Documents by Publication Citations in Scopus and WoS Databases}

The total yearly citations in the publications within the domain of research are shown in Figure 16. The total citation count from the year 2017-2021 is 3237 for Scopus publications and 1628 for WoS publications. The maximum citation counts for both the databases are from 2020-1530 for Scopus, and 815 for WoS publications. Table 5 shows the top ten articles obtained from the Scopus and WoS databases, which have received the maximum number of citations to date. It is observed that the publication entitled "Digital Twin Shop Floor: A New Shop Floor Paradigm Towards Smart Manufacturing" has received the most total citations (298). In contrast, a publication entitled "Digital Twin in Industry: State-of-the-Art" has received the highest number of total citations per year (72.33), as depicted in Table 5.

\section{Trend in Citations/Year in Scopus \& WoS}

\section{Scopus WoS}
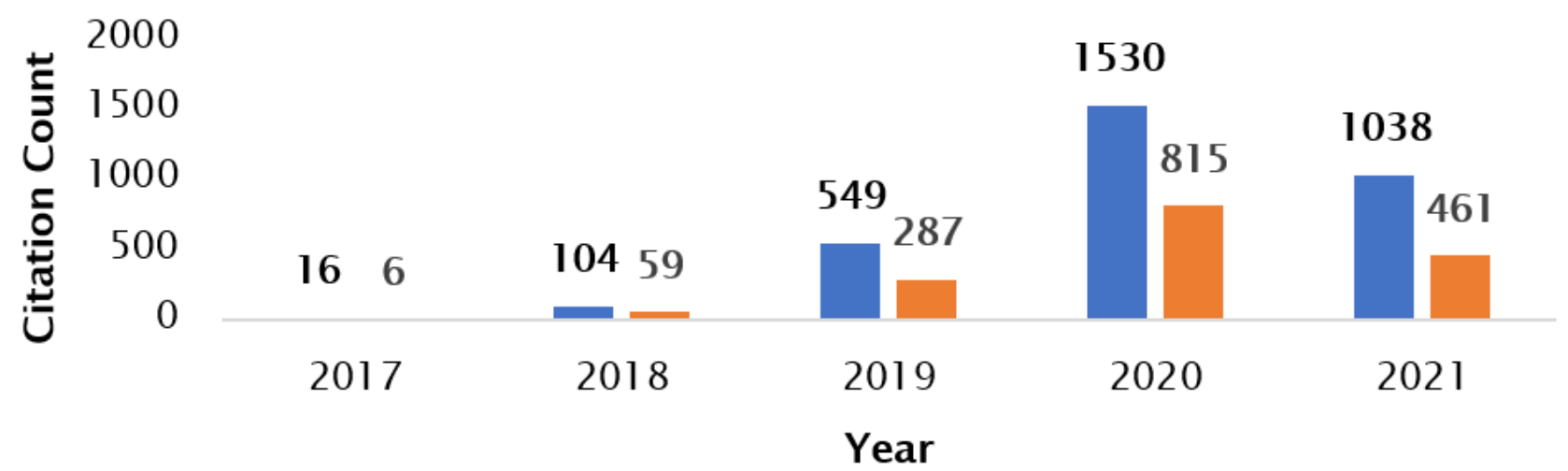

Figure 16. Trend in citations/year in Scopus and WoS databases. 
Table 5. Top ten publications from Scopus and WoS databases with the most citations.

\begin{tabular}{|c|c|c|c|c|c|c|}
\hline Sr. No. & Title & Authors & Journal Title & $\begin{array}{l}\text { Year } \\
\text { (Y) }\end{array}$ & $\begin{array}{l}\text { Total Citation } \\
\text { (TC) }\end{array}$ & $\begin{array}{l}\text { Citation Per } \\
\text { Year (TC/Y) }\end{array}$ \\
\hline 1 & $\begin{array}{c}\text { Digital Twin Shop-Floor: A } \\
\text { New Shop-Floor Paradigm } \\
\text { Towards Smart } \\
\text { Manufacturing }\end{array}$ & $\begin{array}{c}\text { Tao and Zhang, } 2017 . \\
\text { [27] }\end{array}$ & IEEE Access & 2017 & 298 & 59.6 \\
\hline 2 & $\begin{array}{l}\text { Digital Twin in Industry: } \\
\text { State-of-the-Art }\end{array}$ & $\begin{array}{c}\text { Tao et al. } 2019 . \\
{[43]}\end{array}$ & $\begin{array}{l}\text { IEEE Transactions on } \\
\text { Industrial Informatics } \\
\text { Jisuanii Jicheng }\end{array}$ & 2019 & 217 & 72.33 \\
\hline 3 & $\begin{array}{l}\text { Digital twin workshop: a } \\
\text { new paradigm for future } \\
\text { workshop }\end{array}$ & $\begin{array}{c}\text { Tao et al., } 2017 \\
\text { [99] }\end{array}$ & $\begin{array}{c}\text { Zhizao Xitong/ } \\
\text { bComputer Integrated } \\
\text { Manufacturing Systems, } \\
\text { CIMS }\end{array}$ & 2017 & 161 & 32.2 \\
\hline 4 & $\begin{array}{c}\text { Digital Twin Data Modeling } \\
\text { with Automation ML and a } \\
\text { Communication } \\
\text { Methodology for Data } \\
\text { Exchange }\end{array}$ & $\begin{array}{c}\text { Schroeder et al., } 2016 \\
\text { [100] }\end{array}$ & IFAC-Papers Online & 2016 & 154 & 25.66 \\
\hline 5 & $\begin{array}{l}\text { Digital Twins: The } \\
\text { Convergence of Multimedia } \\
\text { Technologies }\end{array}$ & $\begin{array}{l}\text { El Saddik A., } 2018 \\
\text { [68] }\end{array}$ & IEEE Multimedia & 2018 & 139 & 34.75 \\
\hline 6 & $\begin{array}{l}\text { A systematic design } \\
\text { approach for service } \\
\text { innovation of smart } \\
\text { product-service systems }\end{array}$ & $\begin{array}{c}\text { Zheng et al., } 2018 \\
\text { [101] }\end{array}$ & $\begin{array}{l}\text { Journal of Cleaner } \\
\text { Production }\end{array}$ & 2018 & 127 & 31.75 \\
\hline 7 & $\begin{array}{l}\text { Digital twin-driven } \\
\text { manufacturing } \\
\text { cyber-physical system for } \\
\text { parallel controlling of smart } \\
\text { workshop }\end{array}$ & $\begin{array}{c}\text { Leng et al., } 2019 \\
\text { [78] }\end{array}$ & $\begin{array}{l}\text { Journal of Ambient } \\
\text { Intelligence and } \\
\text { Humanized Computing }\end{array}$ & 2019 & 112 & 37.33 \\
\hline 8 & $\begin{array}{c}\text { Scanning the Industry 4.0: A } \\
\text { Literature Review on } \\
\text { Technologies for } \\
\text { Manufacturing Systems } \\
\text { Digital Twins and }\end{array}$ & $\begin{array}{c}\text { Alcacer, } \mathrm{V} \text { and } \\
\text { Cruz-Machado, } 2019 \\
\text { [102] }\end{array}$ & $\begin{array}{l}\text { Engineering science and } \\
\text { technology—an } \\
\text { international } \\
\text { journal-jestech }\end{array}$ & 2019 & 109 & 36.33 \\
\hline 9 & $\begin{array}{c}\text { Cyber-Physical Systems } \\
\text { toward Smart } \\
\text { Manufacturing and Industry } \\
\text { 4.0: Correlation and } \\
\text { Comparison }\end{array}$ & $\begin{array}{c}\text { Tao et al., (2019) } \\
{[20]}\end{array}$ & Engineering & 2019 & 101 & 33.66 \\
\hline 10 & $\begin{array}{l}\text { Review of job shop } \\
\text { scheduling research and its } \\
\text { new perspectives under } \\
\text { Industry } 4.0\end{array}$ & $\begin{array}{c}\text { Zhang et al., (2019) } \\
\text { [28] }\end{array}$ & $\begin{array}{l}\text { Journal of Intelligent } \\
\text { Manufacturing }\end{array}$ & 2019 & 98 & 32.66 \\
\hline
\end{tabular}

\subsection{Network Analysis of the Publications from Scopus and Web of Science Databases}

Network analysis is used to investigate the subjects identified via the relationship among different attributes. This is completed by utilizing graphical configurations. There are several resources available to perform the network analysis, such as VOSviewer, Gephi, Node XL, etc. However, VOSviewer [103] is being used in this analysis to render the network analysis graphs.

\subsubsection{Network of Co-Occurrence of Author Keywords}

Co-occurrence indicates the existence or closeness of comparable keywords, which allows us to examine concepts (keywords) and topics (grouped concepts) [104,105]. Figure 17 shows a network analysis of the co-occurrence of author's keywords in Scopus documents. Each circle denotes a keyword utilized in the articles' source names. As the degree of keyword usage increases, the size of the circle also increases. The links associating the circles show the distance between two keywords. A total of 2300 keywords were extracted from the documents, of which 247 co-occurred in the documents at least three times. In the network analysis shown in Figure 17, cluster 1 emphasizes the importance of the use of digital twin with its enabling technologies. Cluster 2 shows the importance 
of research on smart manufacturing and its enabling technologies. Cluster 3 emphasizes the importance of research in the domain of cyber-physical systems, cyber-physical production systems, Industry 4.0, and Internet-of-Things for the implementation of DT in a real-life scenario. Cluster 4 depicts the importance of progress in the fields of artificial intelligence, augmented reality, digitalization, and data analytics for decision-making in DT. Cluster 5 highlights the technologies enabling the real-time implementation of DT. Table 6 shows the co-occurrence of the keywords, their links, and their link strength within the Scopus databases, which helps in finding the correlation between various concepts.

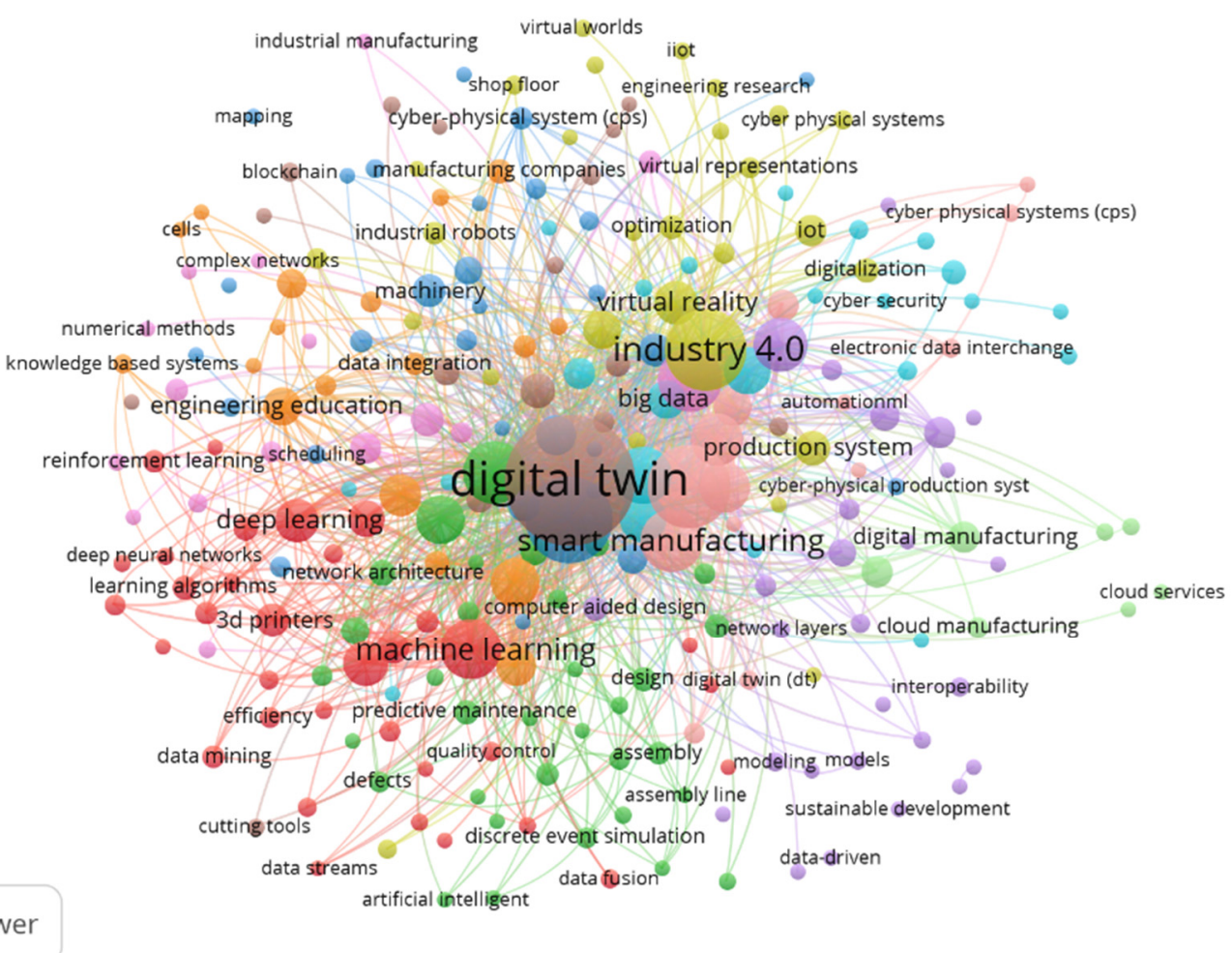

Figure 17. Network analysis of co-occurrence of keywords in Scopus.

Table 6. Results of co-occurrence of author keywords in the Scopus database.

\begin{tabular}{ccccc}
\hline Cluster & Co-Occurrences & Links & Total Link Strength & Author-Keywords \\
\hline & 4 & 9 & 11 & Blockchain \\
\cline { 2 - 5 } & 3 & 6 & 10 & Convolutional Neural Network \\
\cline { 2 - 5 } 1 Red & 13 & 12 & 23 & Deep Learning \\
\cline { 2 - 5 }$(10$ Items $)$ & 21 & 24 & 46 & Digital Twins \\
\cline { 2 - 5 } & 4 & 6 & 8 & Industrial Internet of Things \\
\cline { 2 - 5 } & 13 & 11 & 21 & Intelligent Manufacturing \\
\cline { 2 - 5 } & 4 & 5 & 7 & Internet of Things \\
\cline { 2 - 5 } & 37 & 13 & 22 & Machine Learning \\
\cline { 2 - 5 } & 8 & 26 & 68 & Smart Manufacturing \\
\hline
\end{tabular}


Table 6. Cont.

\begin{tabular}{|c|c|c|c|c|}
\hline Cluster & Co-Occurrences & Links & Total Link Strength & Author-Keywords \\
\hline \multirow{9}{*}{$\begin{array}{l}2 \text { Green } \\
\text { (9 Items) }\end{array}$} & 6 & 14 & 29 & Cloud Manufacturing \\
\hline & 3 & 8 & 16 & Cloud Services \\
\hline & 4 & 10 & 19 & $\begin{array}{c}\text { Cyber Physical Production } \\
\text { Systems }\end{array}$ \\
\hline & 9 & 19 & 35 & Digital Manufacturing \\
\hline & 3 & 3 & 6 & Industrial Internet \\
\hline & 13 & 22 & 46 & Industrial Internet of Things \\
\hline & 3 & 8 & 17 & Multi Agent Systems \\
\hline & 4 & 11 & 22 & Resource Virtualization \\
\hline & 3 & 5 & 6 & Virtual Commissioning \\
\hline \multirow{9}{*}{$\begin{array}{l}3 \text { Blue } \\
\text { (9 Items) }\end{array}$} & 4 & 13 & 17 & Big Data Analytics \\
\hline & 4 & 5 & 15 & Cyber Physical Systems (cps) \\
\hline & 7 & 7 & 16 & Cyber Physical Systems \\
\hline & 3 & 9 & 10 & Industry 4.0 \\
\hline & 63 & 39 & 154 & Industry 4.0 \\
\hline & 31 & 29 & 90 & Internet of Things \\
\hline & 11 & 18 & 36 & Internet of things (iot) \\
\hline & 3 & 5 & 12 & opc \\
\hline & 4 & 6 & 10 & Product Lifecycle management \\
\hline \multirow{7}{*}{$\begin{array}{l}4 \text { Yellow } \\
\text { (7 Items) }\end{array}$} & 18 & 23 & 48 & Artificial Intelligence \\
\hline & 5 & 11 & 17 & Cyber Physical Systems \\
\hline & 5 & 10 & 14 & Data analytics \\
\hline & 8 & 15 & 26 & Digitalization \\
\hline & 4 & 12 & 17 & iiot \\
\hline & 12 & 17 & 32 & iot \\
\hline & 3 & 7 & 8 & Smart Cities \\
\hline \multirow{6}{*}{$\begin{array}{l}5 \text { Purple } \\
\text { (6 Items) }\end{array}$} & 5 & 10 & 17 & Augmented Reality \\
\hline & 4 & 8 & 10 & $\begin{array}{l}\text { Cyber Physical Production } \\
\text { Systems }\end{array}$ \\
\hline & 159 & 53 & 300 & Digital Twin \\
\hline & 3 & 2 & 4 & $\begin{array}{c}\text { Five-Dimensional Digital Twin } \\
\text { Model }\end{array}$ \\
\hline & 5 & 9 & 13 & Life Cycle \\
\hline & 7 & 13 & 19 & Virtual Reality \\
\hline
\end{tabular}

The network analysis of the co-occurrence of keywords in Web of Science documents is depicted in Figure 18. In total, 669 keywords are extracted from the documents, of which 77 co-occurred in the documents at least three times.

Cluster 1 emphasizes the research importance of DT and its enabling tools and technologies, such as cloud computing, machine learning, cyber-physical systems, etc., for the implementation of DT in smart manufacturing. Cluster 2 describes the evolution of research in the domain of digital twins within the industry 4.0 framework, using modeling, simulations, artificial intelligence, etc. Cluster 3 highlights the research on communication technologies and digitalization, carried out to realize DT in smart manufacturing. Cluster 4 shows the research trends in IIoT, IoT, and deep learning for decision-making in DT. Cluster 5 focuses on virtual reality, big data, and life cycles within the Industry 4.0 framework. Table 7 shows the co-occurrence of author keywords, along with the link and 
link strength for the Web of Science database, which helps in identifying the future research trends and topics within the research theme.

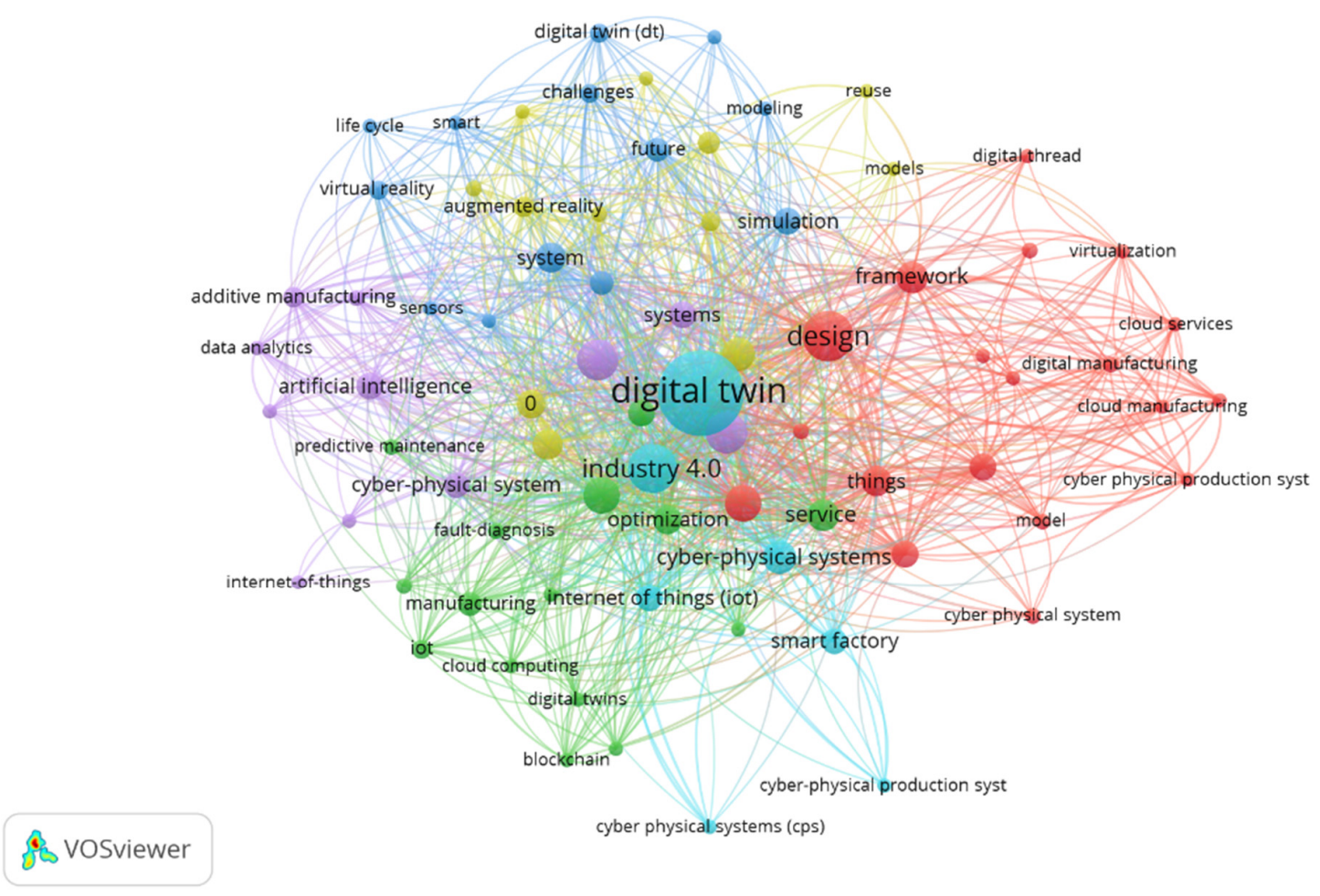

Figure 18. Network analysis of co-occurrence of keywords in Web of Science documents.

Table 7. Results of co-occurrence of author keywords for WoS database.

\begin{tabular}{|c|c|c|c|c|}
\hline Cluster & Co-Occurrences & Links & Total Link Strength & Author-Keywords \\
\hline \multirow{10}{*}{$\begin{array}{c}1 \text { Red } \\
\text { (10 Items) }\end{array}$} & 3 & 7 & 14 & Cloud Manufacturing \\
\hline & 3 & 6 & 12 & Cloud Services \\
\hline & 3 & 7 & 13 & $\begin{array}{l}\text { Cyber Physical Production } \\
\text { systems }\end{array}$ \\
\hline & 4 & 6 & 8 & Cyber Physical Systems \\
\hline & 4 & 11 & 19 & Digital Manufacturing \\
\hline & 84 & 41 & 178 & Digital Twin \\
\hline & 3 & 3 & 5 & Discrete Event Simulation \\
\hline & 10 & 16 & 29 & Industrial Internet of Things \\
\hline & 16 & 28 & 53 & Machine Learning \\
\hline & 6 & 11 & 15 & Simulation \\
\hline \multirow{8}{*}{$\begin{array}{l}2 \text { Green } \\
\text { (8 Items) }\end{array}$} & 3 & 10 & 11 & Artificial Intelligence (ai) \\
\hline & 3 & 5 & 10 & Cyber Physical Systems (cps) \\
\hline & 3 & 4 & 5 & Cyber Physical Systems (cps) \\
\hline & 5 & 8 & 9 & Digital Twin (dt) \\
\hline & 26 & 28 & 64 & Industry 4.0 \\
\hline & 10 & 18 & 34 & Internet of Things (iot) \\
\hline & 3 & 8 & 8 & Modelling \\
\hline & 3 & 13 & 16 & sensors \\
\hline
\end{tabular}


Table 7. Cont.

\begin{tabular}{|c|c|c|c|c|}
\hline Cluster & Co-Occurrences & Links & Total Link Strength & Author-Keywords \\
\hline \multirow{6}{*}{$\begin{array}{l}3 \text { Blue } \\
\text { (6 Items) }\end{array}$} & 3 & 6 & 7 & $\begin{array}{l}\text { Cyber Physical Production } \\
\text { systems }\end{array}$ \\
\hline & 5 & 8 & 12 & Cyber Physical Systems \\
\hline & 4 & 12 & 15 & Digitalization \\
\hline & 18 & 32 & 68 & internet of things \\
\hline & 3 & 8 & 9 & iot \\
\hline & 9 & 14 & 25 & smart factory \\
\hline \multirow{6}{*}{$\begin{array}{l}4 \text { Yellow } \\
\text { (6 Items) }\end{array}$} & 3 & 10 & 13 & Cloud computing \\
\hline & 11 & 12 & 22 & deep learning \\
\hline & 3 & 10 & 12 & Digital Twins \\
\hline & 3 & 8 & 9 & Industrial Internet of Things (iiot) \\
\hline & 3 & 4 & 5 & internet of things \\
\hline & 8 & 14 & 24 & Manufacturing \\
\hline \multirow{5}{*}{$\begin{array}{l}5 \text { Purple } \\
\text { (5 Items) }\end{array}$} & 12 & 19 & 42 & Industry 4.0 \\
\hline & 7 & 17 & 30 & Big data \\
\hline & 13 & 20 & 44 & Industry 4 \\
\hline & 3 & 8 & 10 & Life cycle \\
\hline & 5 & 10 & 13 & Virtual Reality \\
\hline
\end{tabular}

The network graphs of the co-occurrence of keywords for both databases reveal that the correlation of digital twins with other domains is different between the Web of Science and Scopus databases. As such, to gain insights and understand the prominent application domains of digital twins, the authors have considered both the databases.

\subsubsection{Network Analysis of Author and Co-Author}

The author and co-author co-appearances in Scopus and Web of Science are assessed in Figures 19 and 20. This network helps to identify the collaborations among authors using the links, while the total number of co-authorship links shows an author's connection with other authors.

For Scopus, the threshold for the minimum number of documents by an author was set manually to 3, which resulted in 968 authors from Scopus, out of which 38 reached the threshold. The vital link of co-authorship with other authors is evaluated and portrayed in Figure 19. Eight clusters of co-authorship were found and have been represented in the network visualization shown in Figure 19 below, with 38 items derived from the network. The number of links generated among the authors was 29 . The clusters found can be interpreted as active research collaboration among researchers, particularly in the clusters containing such authors as Chen X., Leng J., Liu Q., Zhang D., and Yan D.

For Web of Science, the threshold value for the minimum number of documents by an author was set manually to 3, which resulted in 628 authors from Scopus, out of which 14 reached the threshold. The vital link of co-authorship with other authors is evaluated and portrayed in Figure 20. A single cluster of co-authorship was identified in the network visualization shown in Figure 20 below, with 14 items derived from the network. The number of links generated among the authors was 5 . The clusters found show active research collaboration among researchers, especially in the clusters containing such authors as Chen X., Leng J., Liu Q., Zhang D., and Yan D. 


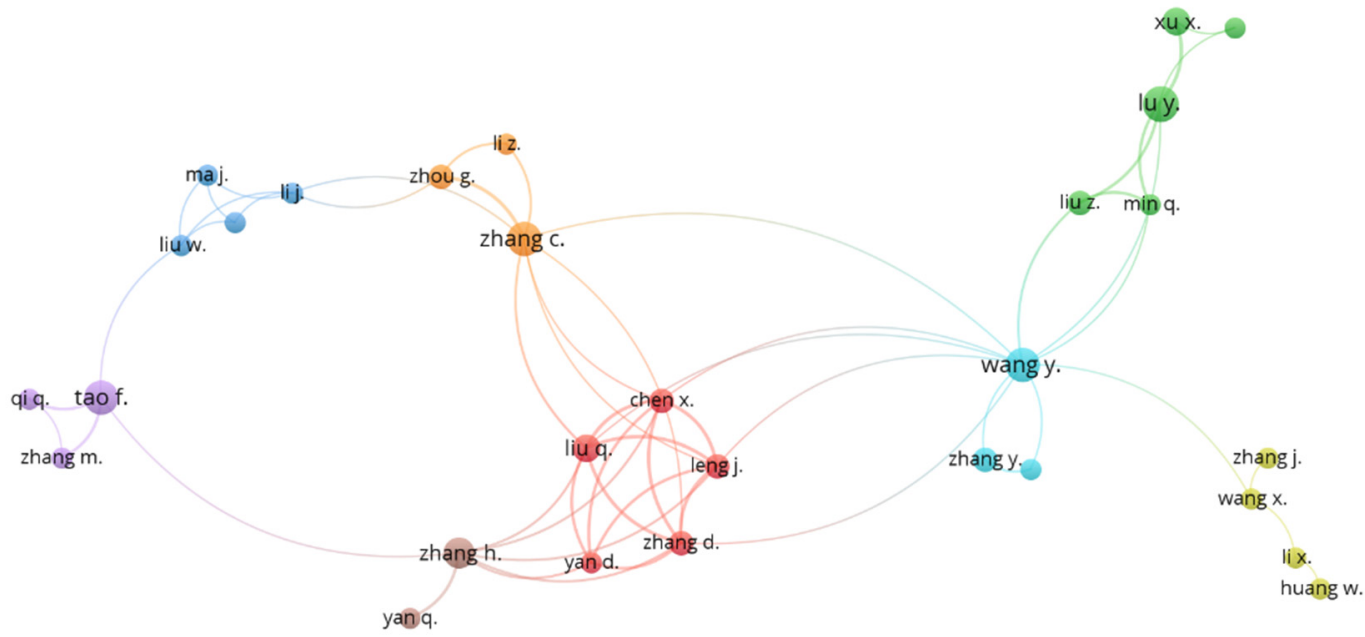

象 VoSviewer

Figure 19. Network visualization of author and co-author for Scopus documents.

VOSviewer

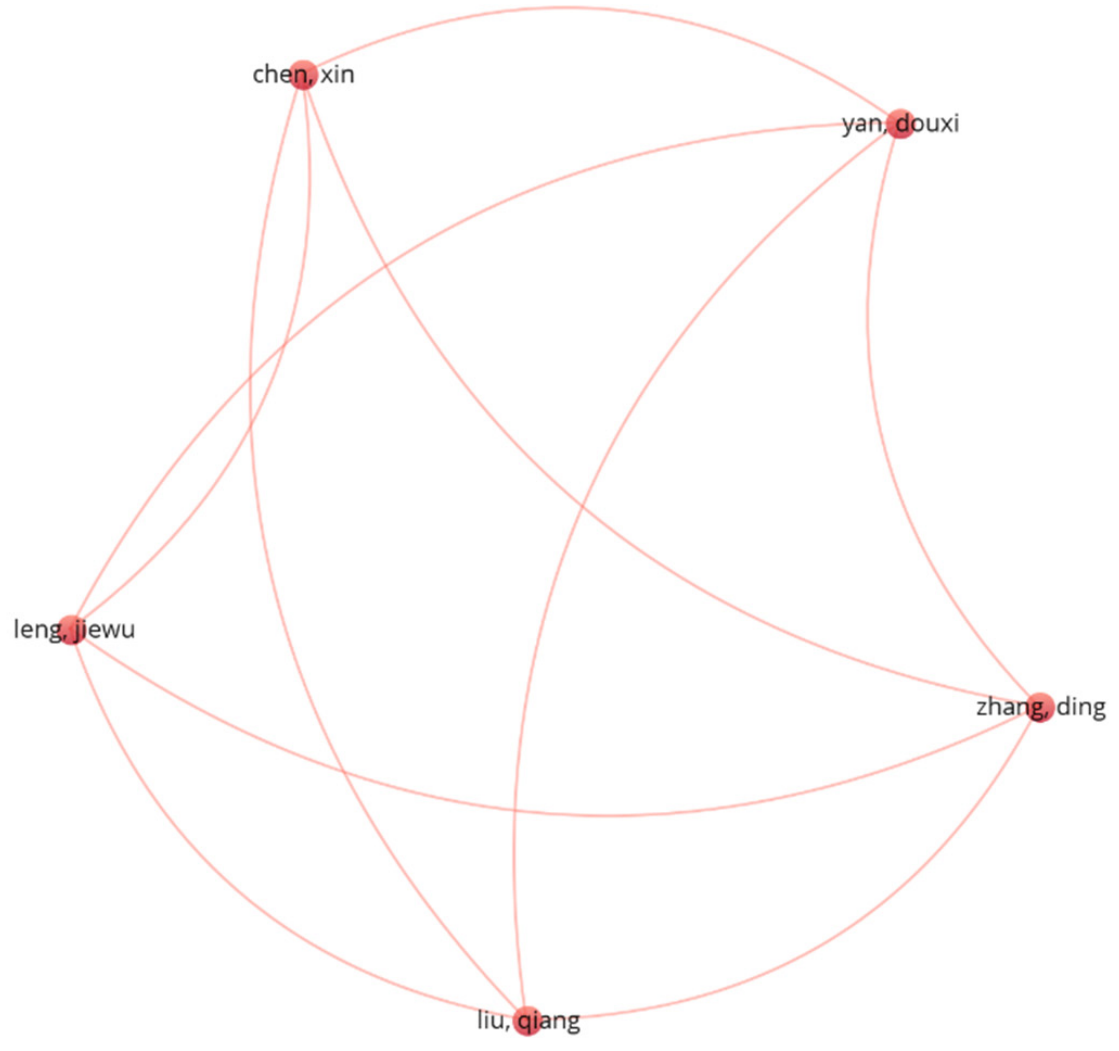

Figure 20. Network visualization of author and co-author for Web of Science documents.

\subsection{Interpretation from Phases 1 and 2 of the Proknow-C Technique}

As explained in Section 2.3, the Proknow-C method is employed for article selection and filtration, and carries out the critical analysis of the obtained bibliographic portfolio. Figure 21 shows an in-detail flowchart for the selection and filtration of articles in the bibliographic portfolio based on the procedure mentioned above. The method initially 
considers the selection of scientific databases. In this work, the author has selected the Web of Science and Scopus databases. Since the prominent application domains of digital twins are varied between the databases, to get a broad view of the digital twin and its application domains, the author has considered both databases. From the selected databases, initially using keyword search queries, a total of 509 articles were obtained, out of which 168 are from Web of Science and 341 are from Scopus. The subsequent stage of the Proknow-C method is to remove duplicate articles (i.e., articles that are common in both the databases). In total, 138 duplicate articles were found and removed from the bibliographic portfolio, and 341 articles remained. In the next stage of article filtration in Proknow-C, the remaining articles were filtered and selected by reading the title of each article and removing the articles whose titles were misaligned with the selected research theme. In this context, 222 articles were found with misaligned titles, and these were removed from the bibliographic portfolio; 128 articles remained. The next step was to consider the scientific recognition of the remaining articles, and based on this, articles were removed from the bibliographic portfolio. Proceeding with this step, all articles with less than ten citations, except those from the last three years, were removed. The articles from the last three years were filtered by reading their abstracts in successive steps. Based on this step, 8 articles were removed that did not meet the scientific recognition criteria, leaving 120 articles in the bibliographic portfolio. Later, the remaining 120 articles were filtered based on abstract adherence to the research theme. After reading the abstracts of 120 articles, only 39 articles were found to be in line with the research theme, and so the remaining were removed from the portfolio. In the second last stage, the articles were scrutinized based on complete accessibility, and nine articles were found to be not completely accessible; these were removed from the portfolio. In the last stage, the 33 articles were read completely, and we found 24 articles in complete agreement with the research theme. These remaining 24 articles were considered for the critical analysis, and comprise the bibliographic portfolio, as shown in Table A1.

\subsection{Statistical Analysis of Bibliographic Portfolio}

The statistical analysis analyzes the application area of the concept and scientifically recognized documents, and the most prominent journals/conferences comprise the bibliometric portfolio. The following paragraphs describe the statistical analysis of the portfolio documents regarding the attributes mentioned above.

The articles that constitute a bibliographic portfolio were classified into five categories based on the application area of digital twins, viz., smart manufacturing, smart components, robotics, specialized machining process, and shop floor and assembly line, as shown in Figure 22. Shop floors and assembly lines use the concept of the digital twin more prominently, followed by smart components, robotics, and specialized machining processes. From this evaluation, it can be observed that the least research work has been carried out in the domain of smart manufacturing in the application of digital twins. 


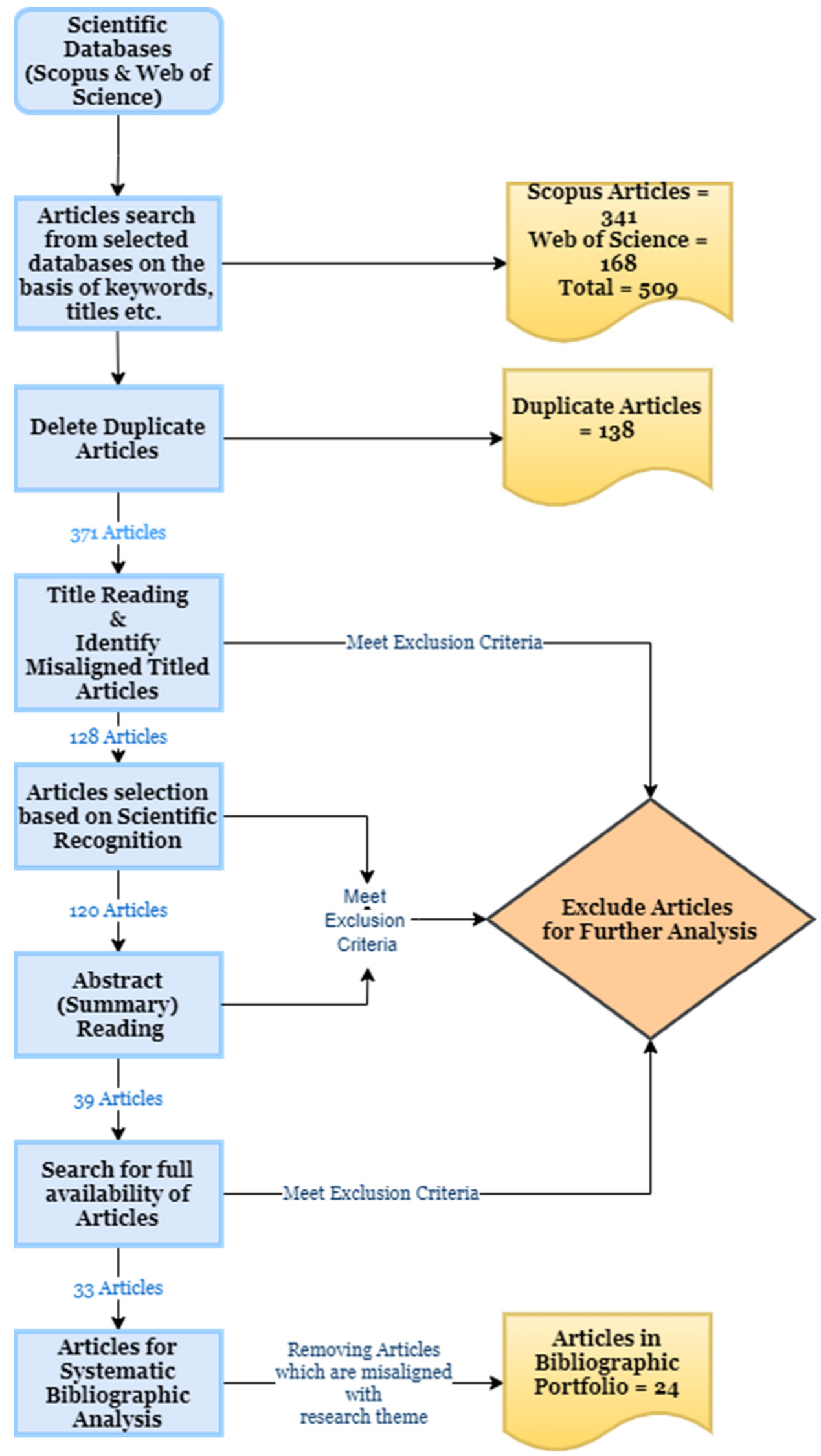

Figure 21. Flowchart of article selection into the bibliographic portfolio. 


\title{
No. of Articles in Bibliographic Portfolio by Application Area
}

\author{
= Shop Floor \& Assembly Line \\ = Smart Component \\ = Robotics \\ Speicalized Machining \\ processes \\ - Smart Manufacturing
}

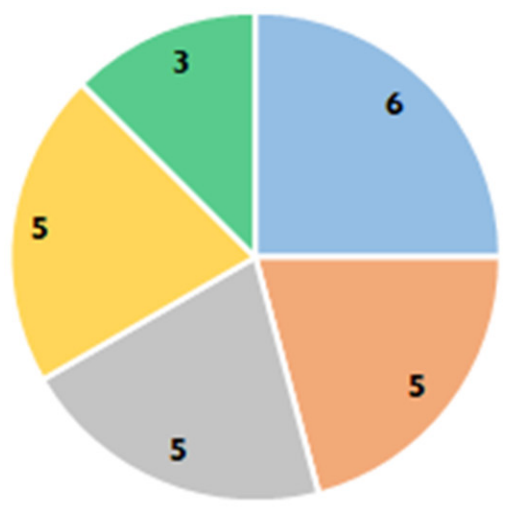

Figure 22. Classification of articles based on application area of digital twin.

Again, from the assessment of the bibliographic portfolio, we see that the International Journal of Computer Integrated Manufacturing and the Journal of Manufacturing Systems have three articles in their portfolios with a significant relationship with the research theme, as shown in Figure 23.

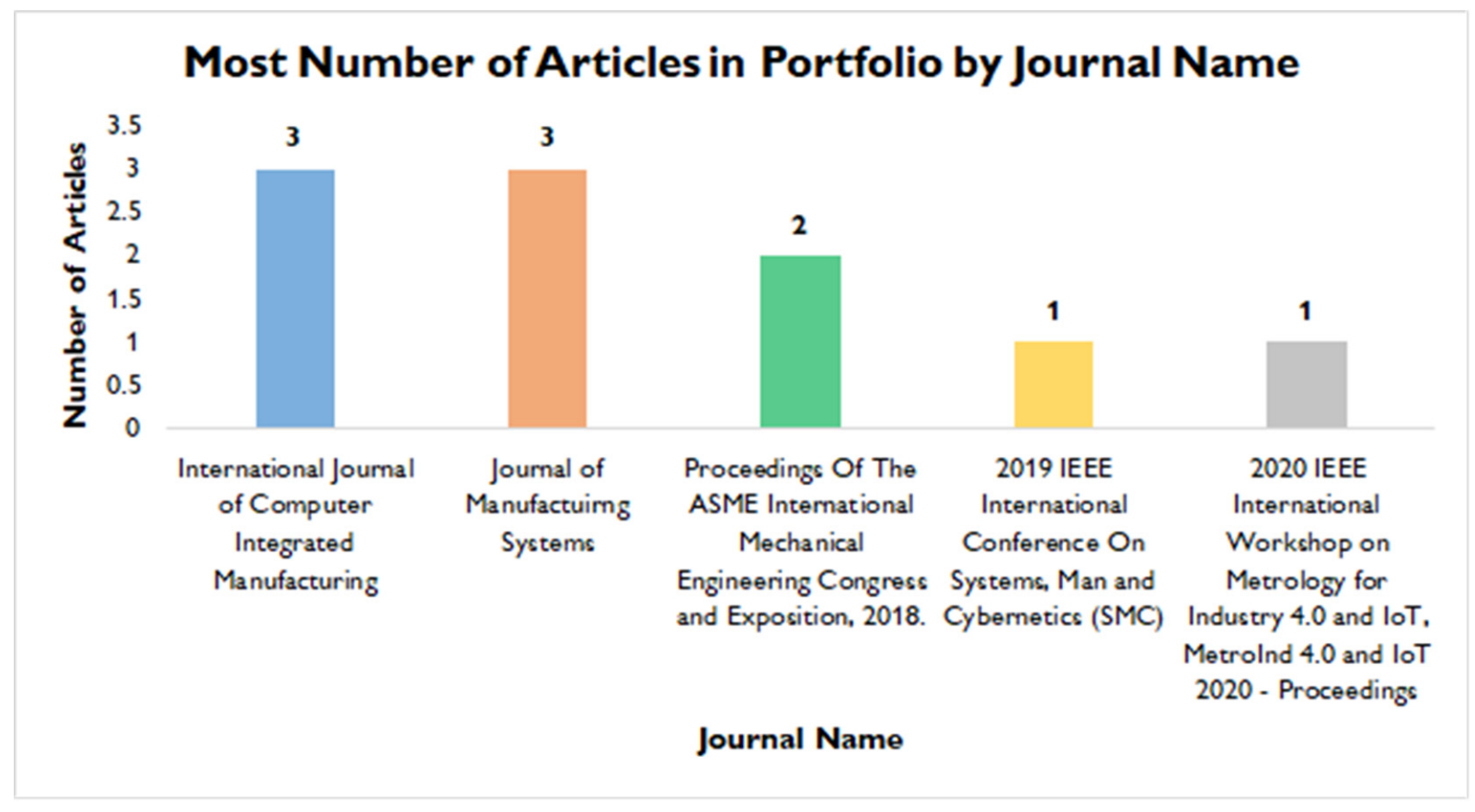

Figure 23. Number of articles in bibliographic portfolio by journal name.

Additionally, the five articles with the highest scientific recognition within the bibliographic portfolio are shown in Figure 24. The article named "Digital Twin of a cutting tool" has acquires the highest scientific acknowledgment (cited 25 times), followed by the other articles depicted in Figure 24. Scientific recognition illustrates the future research potential and the need for digital twins in smart and specialized machining processes. 


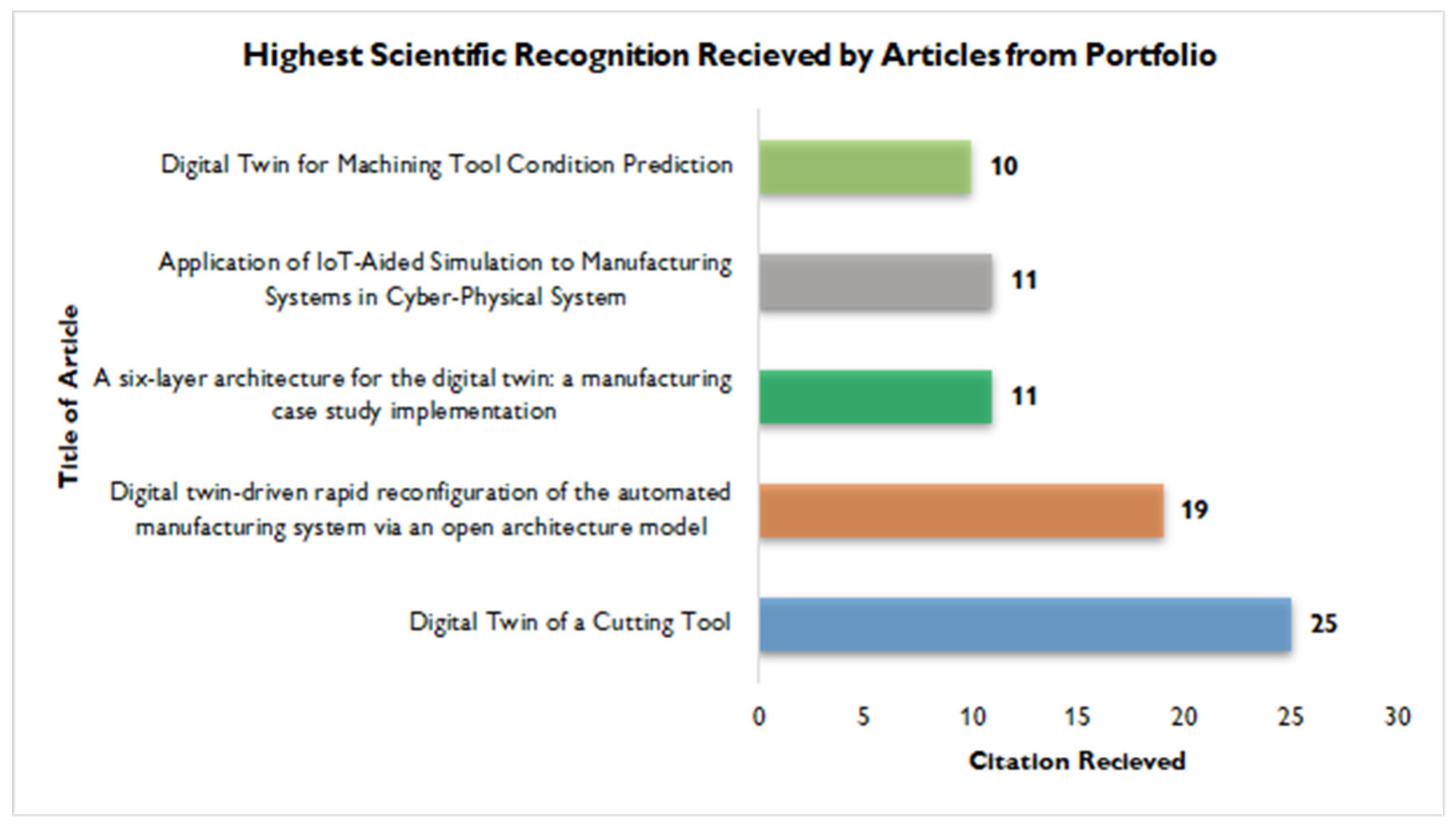

Figure 24. Articles with most scientific recognition within the bibliographic portfolio.

\subsection{Interpretation from the Phase 3 of the Proknow-C Technique}

Phase 3 involves the systematic analysis of the articles in the bibliographic portfolio, which involves studying methodologies, techniques employed, and research outcomes in the articles discussed in 2.3 and emphasized in detail in Table A2. This will also help to identify the recent trends, application areas, methodologies, optimization tools and methods, machine learning algorithms, and communication technologies aligned with the research theme, which then helps identify potential research areas and research gaps in the application areas of digital twins.

From the above systematic analysis of portfolio documents, as depicted in Table A2, it is found that the studies that comprise the bibliographic portfolio use different machine learning algorithms, communication protocols and modules, and sensors for the successful implementation of digital twins. The tables and figures below discuss the various sensors, communication protocols and machine learning algorithms employed in the studies that comprise the portfolio. Table A3 elaborates the different sensors employed and their respective applications in the studies in the bibliographic portfolio.

The data obtained from the various sensors and simulation models, as well as historical and behavioral data, are transferred from one device to another, or to the cloud, for further processing and for taking appropriate and efficient control actions. As such, effective communication between various devices, machines, shop floors, and virtual spaces is vital for achieving efficient control actions and feedback. Thus, different communication protocols and modules have been identified in the studies discussed in Table A2. Figure 25 summarizes the various communication protocols [106] and modules used in articles in the bibliographic portfolio in detail. 


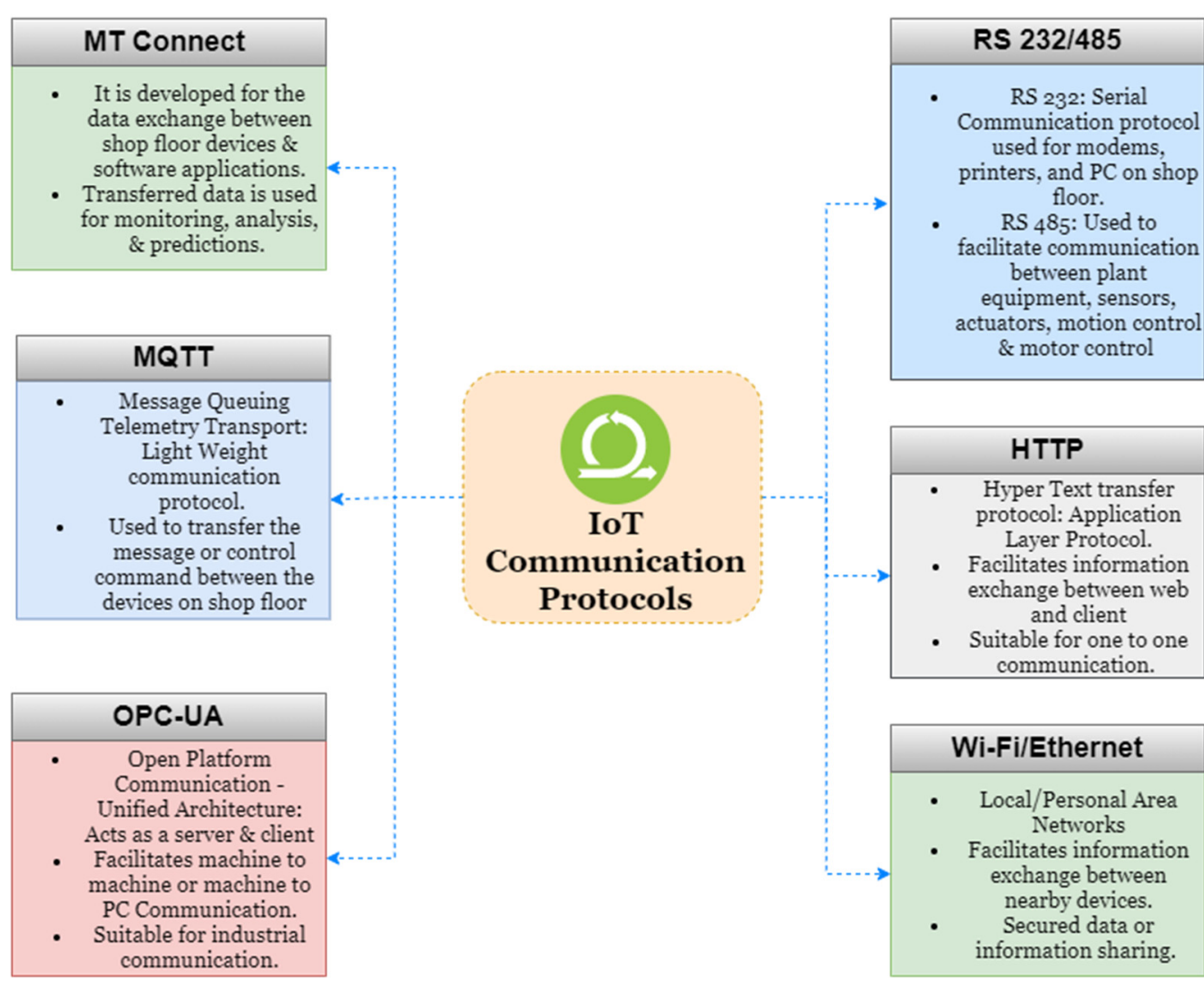

Figure 25. Communication protocols and modules applied in the articles described in the portfolio.

To facilitate effective control action and feedback, efficient and accurate machine learning algorithms possess equal importance to that acquired by communication protocols and modules. The machine learning algorithms take the raw input data from the process, simulation models, mathematical models, and the historical and behavioural data, and process them. Afterwards, the processed data are inserted into the model or algorithm for training purposes. The trained model is then used for prediction or classification purposes in various applications, as discussed by the articles in the bibliographic portfolio. Table A4 depicts the different machine learning algorithms employed in the studies of composing the portfolio.

\subsection{Observations Made Using the Extracted Documents via the Proknow-C}

The following observations are made, and offer information about the recent application areas, sensors, and machine learning algorithms using in the documents extracted by the Proknow-C method. These observations are beneficial to developing the digital twin model, and assist in the formulation of future research objectives, tools and methodologies. The observations made following the above analysis are as follows:

I. Application area-Recent studies show that the shop floor and assembly line implement digital twins in multiple scenarios. Shop floors and assembly lines use DT to optimize the process parameters, improve production, and reduce equipment downtime.

II. Most prominent journal-The journals that comprise the bibliographic portfolio carry relatively more articles aligned with the research theme. Most of the articles are from the Journal of Computer Integrated Manufacturing and the Journal of Manufacturing Systems. This reveals the applications and requirements of a digital twin in the domain of smart manufacturing.

III. Scientifically recognized article-From Figure 24, the article "Digital Twin of a Cutting Tool" from the portfolio is frequently cited. This emphasizes the hidden 
potential of a DT for assessing critical assets of the machine, which favorably affects the outcome of the process.

IV. Sensors-The systematic analysis of documents reveals the wide range of applications of different sensors, such as vibration and acoustics sensors, dynamometers, cameras, and encoders, when building a DT model. It is observed that the multi-sensor fusion was utilized in smart manufacturing applications for real-time process monitoring and building a live DT model. In smart manufacturing, accelerometers and acoustic emission sensors are a highly reliable source for process monitoring and deriving operational data.

V. Communication protocol-The analysis outlines the various communication protocols used for transmitting data between multiple devices and machines. Among all the communication protocols, Open Platform Communication-Unified Architecture (OPC-UA) is the most prominent, and is used by many researchers for building a live DT framework.

VI. Machine learning techniques-The primary application of machine learning algorithms is in predicting system behavior, anomalies, and maintenance. Deep learning algorithms are implemented to detect and classify the data in the various application domains of smart manufacturing.

Phases 4 and 5 of Proknow-C technique are explained in the later sections of this article. A few case studies are discussed in the following section to identify the research gap and questions more precisely, which will also help define accurate research objectives.

\subsection{Case Studies}

To better understand the research theme and its real-world implementation, the following are examples that elaborate on the use of digital twins in smart manufacturing. The case studies below contain details about the implementation of digital twins, as well as the required tools, techniques, and methodology. Due to its diverse applicability in smart manufacturing, it is indispensable to observe, analyze, and establish a holistic understanding of this research theme.

\subsubsection{Reconfigurable Additive Manufacturing Systems Using Robotic Arms}

This study used augmented reality with robotic arms in additive manufacturing for rapidly reconfigurable additive manufacturing systems [107]. The developed methodology helps to apply changes in layout and toolpath quickly. For the successful implementation of the proposed methodology, the researcher built a prototype of additive manufacturing robotic arms. A full HD 1080p camera was used for live video streaming and to give location identification. The prototype was designed using four degrees of freedom Dobot Magician robotic arms. End-effectors of the robotic arm were changed for FDM-style extruders, which feed polylactic acid fiber through singular feeders. Three AR markers were utilized, one of which is used to show the area of the part substrate, while the other two show the positions of both mechanical arms individually. The two markers were incorporated into two positioning cards, which were utilized to find the two arms. The part substrate and the two arms could be moved uninhibitedly for different formats, making the framework reconfigurable. The open-source NyAR Toolkit library was utilized to collect the AR markers, create simulated objects such as format pointers, and to facilitate frameworks.

The spatial interactions between the components, viz., the robotic arms, the part substrate and the camera, are essential to facilitate the association between the physical and cyber domains. This was achieved by computing the coordinate transformations for each combination. The coordinate transformations help derive the relationship between markers and camera, markers and robotic arms, and part substrate and robotic arms, using the four $\times$ four transformation matrices. Later, the proposed methodology was verified by two experimental case studies, viz., layout reading and layout deploying. The former was used to verify the readability of the augmented reality for the reconfiguration of the 
digital twin, while the latter verified the potential of augmented reality for implementing the layout using the simulated results and a digital twin.

These two case studies show that the developed technique enables the quick recovery of position data from the actual framework format into the digital twin and facilitates successful deployment and optimization. However, it was observed that there is innate incorrectness in the marker following augmented reality, because of different reasons, such as camera picture contortion, marker misdetection, horrible lighting conditions, and so forth. Accordingly, the AR strategy may not be suitable for use as a technique for associating the digital and the actual spaces, yet it will be suitable for quickly organizing an unpleasant format from the advanced twin, and for reproducing the design.

\subsubsection{Hybrid Predictive Maintenance of CNC Tool Using Digital Twin}

As the CNC machine is the mother of all computerized machines, the machine tool is its most vital component, impacting the product quality, machining quality, time, and cost. Hence, performing timely maintenance is the most crucial task. The traditional maintenance method permits some human error, leading to significant equipment downtime, and increasing the cost. Therefore, the researcher here proposed a hybrid predictive maintenance method for the CNC machine tool using digital twin, and verified the proposed methodology for use in estimating the remaining life of the cutting tool [108]. In the hybrid approach, the model-based and data-driven methods are combined to derive more precise projections/forecasts.

To create the digital twin, a multi-space model of the CNC machine tool is constructed considering the degradation mechanism, which acts according to operating conditions and the material attributes. Through multi-physical simulation with the limit condition derived from the actual CNC machine tool, the condition inside can be configured, which resembles virtual detecting. The framework state space model is an adaptation of the DT actual degradation model, and is used to calculate framework states through hypothetical examination of the framework inside via re-enactment. Different sorts of sensors are introduced into the physical CNC machine tool, and give information supporting the data-driven technique to estimate the RUL of the parts. In the data-driven strategy, precise data must go through a few stages, such as feature extraction, noise filtration, data preprocessing, and state acknowledgment; lastly, the become useful for forecasting. The RUL anticipated by the data-driven technique is utilized as the framework perception of the CNC machine tool. Hybrid algorithms combine the state space value, simulated value, and observational value, which are used to predict the reaming useful life and verify it, as depicted in Figure 26 below.

The proposed methodology was implemented for the prediction of the RUL of the $\mathrm{CNC}$ milling machine tool. The data-driven models were built using the run-time values derived from accelerometer, dynamometer, and acoustic emission sensors. Simultaneously, the simulation model was developed using the data from the tool wear equation, and mathematical models for drive and working conditions gave data such as feed, spindle speed, depth of cut, and surrounding temperature. In the hybrid approach, data from both the models are fused to train the particle filtering algorithm, which overcomes the limitations of each model in predicting the remaining useful life of the tool. Additionally, using the data from both the models, a digital twin for a tool is developed, and using communication protocols, the developed DT is updated continuously in the run-time environment.

Thus, the proposed hybrid predictive maintenance algorithm enables the better integration of system data and the precise prediction of the RUL of a milling tool through its digital twin. 


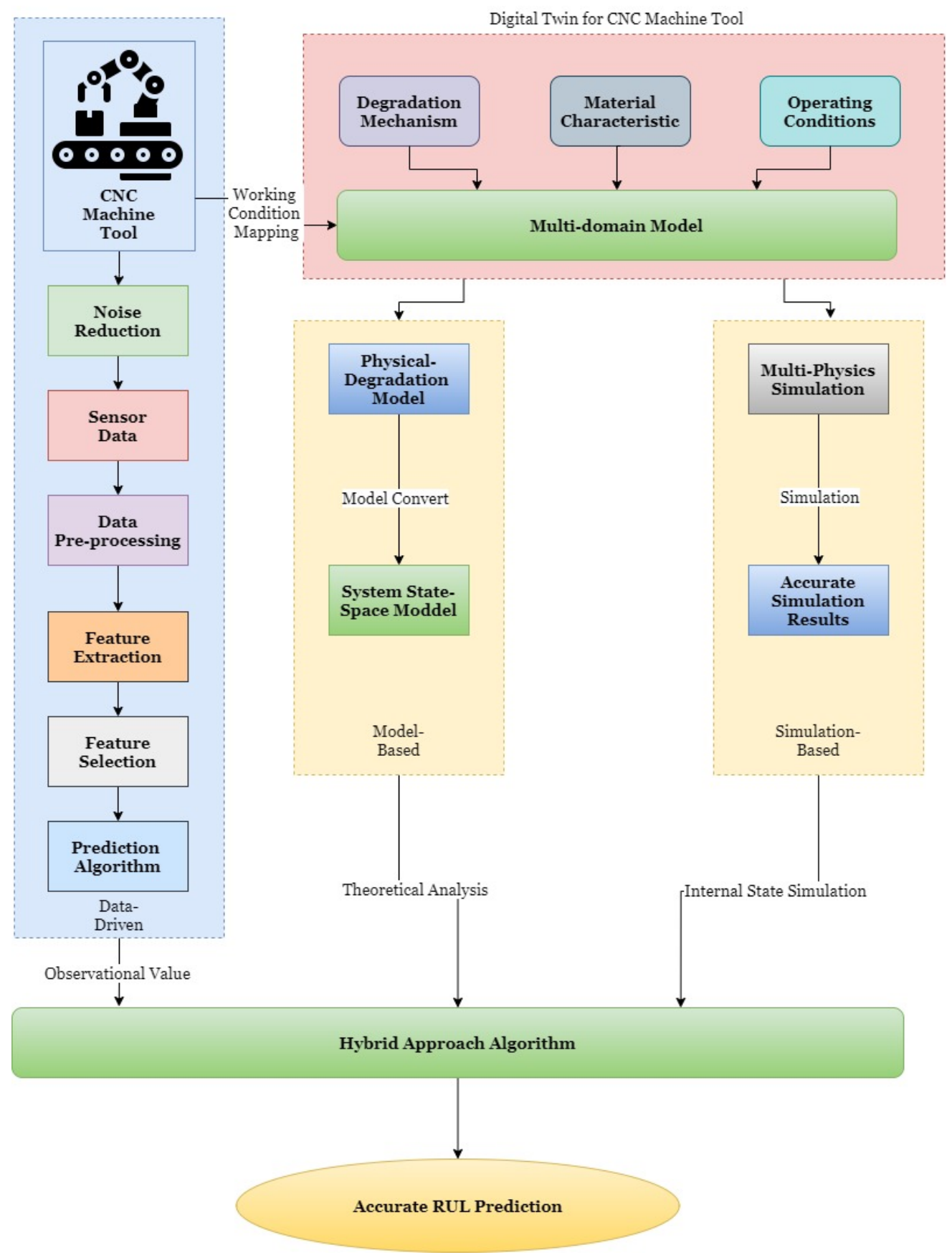

Figure 26. Framework for hybrid predictive maintenance approach for RUL estimation.

\subsubsection{Digital Twin for Weld Joint Growth and Penetration Control}

The study focused on the latent calibre of deep learning algorithms in the context of smart manufacturing. The author developed a digital twin-based graphical user interface for the purpose of monitoring, controlling, and visualizing a gas tungsten arc welding process [109]. In the welding process, the quality of the joint goes through three states, viz., incomplete fusion, reasonable fusion, and burn through, depending on the size of the weld pool. Additionally, the joining material, heat input, and surface tension affect the quality of the joint. Therefore, it becomes necessary to monitor the process consistently. The required backside bead width ensures that the weld joint quality is less than the backside bead width (BSBW). To monitor this comparison in the traditional way is laborious; hence, the digital twin is implemented to ease the process. 
The system consisted of a computer-controlled automatic welding machine with a motor-driven conveyor for workpiece movement. The arc sensors are used to monitor arc voltage and arc current, while the industrial camera is used to capture weld images. A GUIbased digital twin model was developed in subsequent stages, which first pre-processes the raw data obtained from the sensors. A DT module was built in the Open CV environment, with the $\mathrm{C}++, \mathrm{C} \#$ Unity engine platforms. Figure 27 demonstrates the proposed framework for the welding process. The top side bead width (TSBW) and backside bead width (BSBW) are the two indirect information parameters obtained from the sensors.

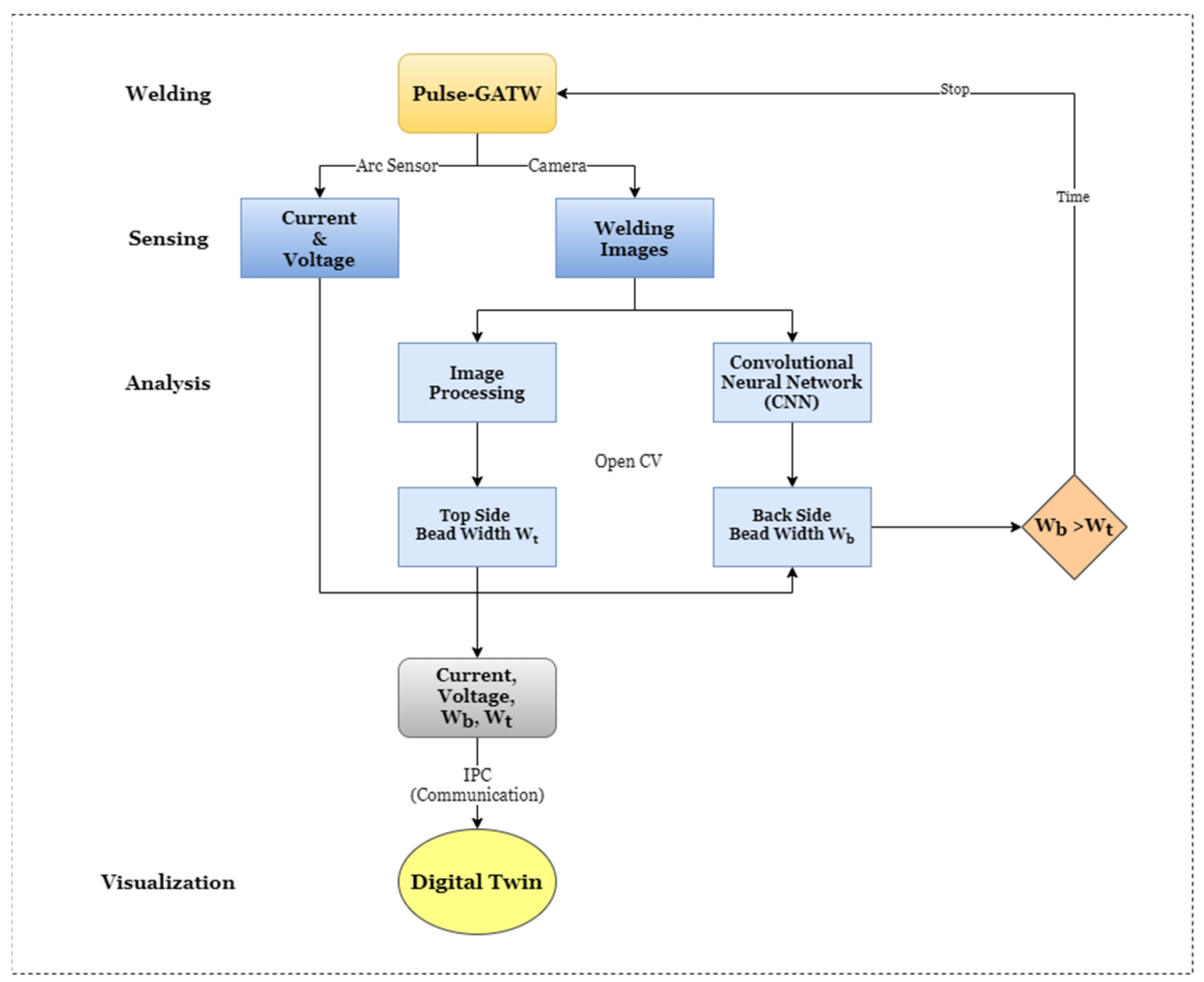

Figure 27. Proposed process flow for weld joint inspection and penetration control.

The raw data obtained from the sensors are processed to acquire the exact feature, which strongly correlates with process output. In the welding process, the two weld quality parameters TSBW and BSBW are computed indirectly from the machine learning algorithm, which is a mathematical computation. From this, the TSBW width of the weld pool is calculated from the image obtained from an industrial camera, using a watershed segmentation-based algorithm to identify the weld pool boundary. The identified boundary and algorithm help detect the peak of the weld pool, which later computes the weld pool width. The BSBW is calculated from the deep learning-based convolutional neural networks, since BSBW is not seen directly, but can be evaluated from the obtained data. The data obtained from the camera are pre-processed for the removal of noise and to find the region of interest; later, the filtered image data are used to train the $\mathrm{CNN}$ algorithm to find the BSBW. In the last phase, a GUI-based digital twin model is built through the unity engine, which shows the welding process information in four aspects, viz., weld joint geometry, weld images, weld joint growth dynamics, and arc information. The weld images and arc information are obtained from the sensors used for data capturing. In contrast, welding joint geometry data and growth dynamics data are obtained from the TSBW and BSBW computations.

Thus, a developed digital twin model facilitates the monitoring, control, and visualization of the gas tungsten arc welding process, and helps monitor and control the quality of the weld joint and the depth of penetration. 
4.7.4. Monitoring Part Geometry for Fused Filament Fabrication: Sing Computer Vision and Digital Twin

The study demonstrated part geometry monitoring and process quality control through the optical imaging and digital twin for FFF (fused filament fabrication) technique [30]. The traditional approaches to part geometry monitoring involve some difficulties and human errors. As such, the present study used the hidden potential of optical imaging and digital twin technology. The digital twin in a fused filament fabrication process monitors the product quality, and identifies edges, contours, stacked counters, etc. In this process, the digital twin models are developed through images obtained from real-time data from the deployed sensors and machine parameters, which help predict the part geometry and process parameters, and in the identification of anomalies between the measured and expected contours, edges, and other parts' features.

The data required to estimate part features and the development of digital twin models are obtained from the camera mounted on the FFF machine, the inbuilt sensors, and the G-Code of the machines. The data capture and communication through different modules and feedback systems are achieved through an NI data acquisition system, an Ethernet cable, and an interfacing computer.

The real-time monitoring of the process facilitates path planning, contour edge detection, contour quality inspection and contour stacking through the digital twin. To achieve this, the MATLAB and mathematical computation models are used to generate accurate results. The digital twin-enabled microscope automatically plans an inspection process for each contour and edge for each layer. As discussed above, fusing the simulated data and the process data in the DT helps identify the anomalies in part geometry in the last stage. Thus, the DT helps to modify the part program through the feedback generated from the inspection of part geometry. Figure 28 shows the proposed framework of the DT-enabled examination.

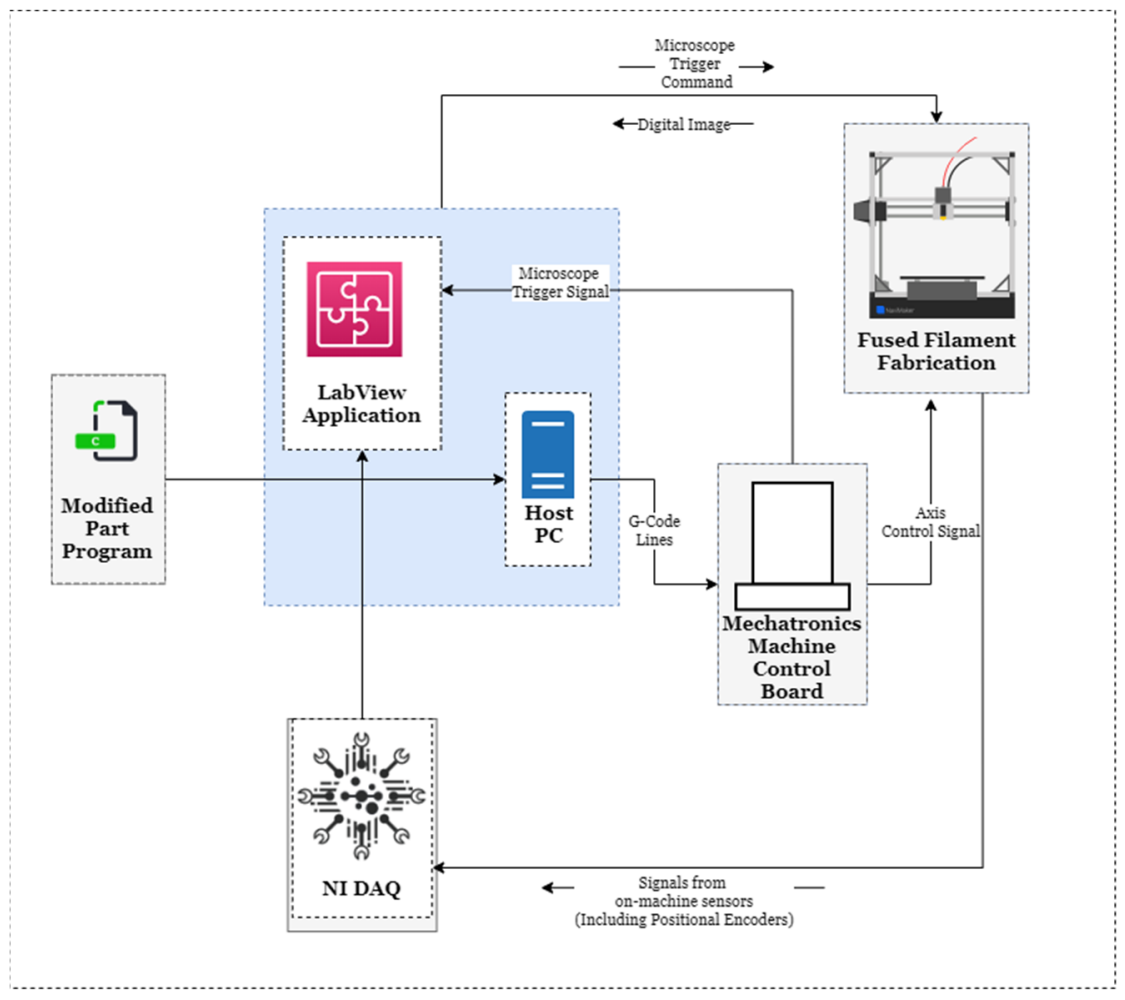

Figure 28. Digital twin for part geometry monitoring during fused filament fabrication.

\subsection{Future Directions of Digital Twin}

Based on the above discussion, DTs involve the blending of various technologies, such as IoT, IIoT, artificial intelligence, machine learning, deep learning, Big Data, cloud 
computing, simulations, and many others. These technologies have been on a path of constant evolution; hence it is assumed that DT will evolve continuously in parallel with these technologies. This is verified from the estimation of the DT market globally. The global market for DTs is expected to grow up to $58 \%$ by 2026; this means that it will reach USD 48.2 billion [110]. The COVID-19 pandemic has proven one of the key factors driving the growth of the DT market, since industries are pushing themselves to be more digitalized. As humans are a vital part of any industry, and one cannot simply avoid them during the development of DT, the Institute of Electrical and Electronics Engineers (IEEE) believes that via the development of machines and human-machine relationship, DT will become a crucial part of future industries [111]. Many of the researchers see "digital triplet" as the next phase of DT [112-114]. A digital triplet addresses the "intelligent activity world" along with the physical world and cyber-physical world. In the "intelligent activity world", humans solve problems with the help of DT. The digital triplet considers human interaction with the process and systems, thus creating value from data using human intelligence and knowledge. The goal of the digital triplet is to assist in engineering activities throughout the product's lifecycle, involving design, manufacturing, application, maintenance, and resource circulations, by integrating the physical world, the cyber-physical world, and the intelligent activity world $[112,113]$. In the future, DT can be combined with various other technologies, such as augmented reality, virtual reality, etc., and can be implemented in various fields, such as aerospace, agriculture, automobiles, biomedicine, education, manufacturing, and healthcare.

The scope of this bibliometric analysis is limited to very few research journals and keywords. The study was limited to scientific documents for assessing the application of the digital twin in smart manufacturing from Scopus and Web of Science databases. From the systematic bibliometric analysis, some research gaps have been identified (phase 4 of Proknow-C), which are discussed below:

- The existing literature illustrates the use of digital twins for the whole process or plant. Additionally, there is little trace of its application in miniature components. Hence, digital twin development for the micro-milling process for aerospace or biomedical applications will give a zero-defect output with optimized cost.

- The developed digital models only use sensor fusion technology and predict system behavior. However, there is no significant literature available on the fusion of multidomain models that considers numerical simulation, mathematical modeling and data-driven models for system monitoring and optimization.

- Hence, a multi-domain model can be developed for the stated micro-milling process, which will combine data from all the models and replicate real-time behavior in the virtual domain, enabling better process understanding and defect identification.

- The existing literature utilizes machine learning algorithms for decision-making, assisted by multi-sensor fusion data, but most of the studies do not validate them through simulation models and mathematical models. This practice reduces the efficiency of the developed digital twin model. Therefore, a hybrid approach must be developed using multiple machine learning algorithms, and the results will be validated through developed simulation and mathematical models.

From this analysis, it is identified that there is little research on building a cost-effective digital model for a micro-milling machine, for monitoring, simulating, controlling, and optimizing the machining process using multi-domain modeling, which will address the challenges and issues involved in implementing the digital twin. Since micro-milling develops, the attention of the world is now moving towards miniaturization and manufacturing parts in micrometre sizes, with high material removal rates, higher cutting forces, and time-effective production. This has vast application in aerospace, biomedicine, health, automobile manufacturing, etc. 


\section{Conclusions}

Implementing the Proknow-C strategy, it was feasible to choose a bibliographic portfolio that addressed the needs of the research theme, identifying 24 articles strongly correlated to the research theme. By way of the bibliometric investigation and organized examination, it was feasible to derive vital data. The analysis deductively recognized more relevant articles via journals in which the articles were distributed, and focusing on writers with more prominent acknowledgments. It permitted the design of a rich portfolio for the research domain. There are very limited studies on employing digital twins to address numerous issues in smart manufacturing, especially in micro-milling. There is additionally a requirement for speculation of the $\mathrm{AI}$ model for flaw-finding and process anomaly identification. Similar issues should be addressed in the industrial environment to confirm the innovation. Additionally, a newly arising field that must be addressed is the use of digital twins for in-process monitoring, simulation, control, and optimization. This finding can be considered as a hole in the logical exploration, representing an area of interest for enterprises. By this approach, it is feasible to affirm that the exploration point is progressing, which offers new strategies and methods to conduct determinations utilizing multi-domain information combinations during the Fourth Industrial Revolution.

Author Contributions: Conceptualization, V.W., S.K. and K.K.; methodology, V.W., S.K. and A.B.; validations, S.K. and K.K.; data curation, V.W. and S.K.; writing original draft preparation, V.W., S.K. and K.K.; writing review and editing, S.K., A.B. and K.K.; supervision, S.K., A.B. and K.K. All authors have read and agreed to the published version of the manuscript.

Funding: This work was supported by the Research Support Fund (RSF) of Symbiosis International (Deemed University), Pune, India.

Institutional Review Board Statement: Not applicable.

Informed Consent Statement: Not applicable.

Data Availability Statement: Data supporting the findings in this study can be accessed through https:/ / www.scopus.com/ and http:/ / apps.webofscience.com (accessed on 1 March 2021).

Conflicts of Interest: The authors declare no conflict of interest.

Appendix A

Table A1. Consolidated bibliographic portfolio.

\begin{tabular}{|c|c|c|c|c|c|}
\hline Sr. No & Research Theme & Source Title & Year & $\begin{array}{c}\text { Scientific } \\
\text { Recognition }\end{array}$ & Database \\
\hline 01 & $\begin{array}{c}\text { DT-enabled cutting tool modeling, } \\
\text { simulation, and analysis. } \\
\text { [115] }\end{array}$ & $\begin{array}{l}\text { 51st CIRP conference on } \\
\text { manufacturing systems }\end{array}$ & 2018 & 25 & Web of Science \\
\hline 02 & $\begin{array}{c}\text { DT-driven reconfigurable automated } \\
\text { industrial systems. } \\
{[3]}\end{array}$ & $\begin{array}{c}\text { Robotics \& } \\
\text { computer-integrated } \\
\text { manufacturing }\end{array}$ & 2020 & 19 & Web of Science \\
\hline 03 & $\begin{array}{c}\text { A six-layer DT architecture for } \\
\text { effective data and information } \\
\text { exchange. }\end{array}$ & $\begin{array}{l}\text { Journal of intelligent } \\
\text { manufacturing }\end{array}$ & 2020 & 11 & Web of Science \\
\hline 04 & $\begin{array}{c}\text { Application of an IoT-enabled } \\
\text { manufacturing systems in } \\
\text { cyber-physical domains. } \\
\text { [116] }\end{array}$ & Machines & 2019 & 11 & Web of Science \\
\hline 05 & $\begin{array}{c}\text { Prediction of tool condition through } \\
\text { DT model. } \\
\text { [35] }\end{array}$ & $\begin{array}{l}\text { 52nd CIRP conference on } \\
\text { manufacturing systems } \\
\text { (CMS) }\end{array}$ & 2019 & 10 & Web of Science \\
\hline
\end{tabular}


Table A1. Cont.

\begin{tabular}{|c|c|c|c|c|c|}
\hline Sr. No & Research Theme & Source Title & Year & $\begin{array}{l}\text { Scientific } \\
\text { Recognition }\end{array}$ & Database \\
\hline 06 & $\begin{array}{l}\text { Data management of metal additive } \\
\text { manufacturing system with the aid of DT } \\
\text { framework. } \\
\text { [117] }\end{array}$ & $\begin{array}{l}\text { Journal of Manufacturing } \\
\text { Systems }\end{array}$ & 2020 & 10 & Scopus \\
\hline 07 & $\begin{array}{c}\text { DT-enabled smart manufacturing } \\
\text { assembly systems. } \\
{[31]}\end{array}$ & Sustainability & 2020 & 9 & Web of Science \\
\hline 08 & $\begin{array}{l}\text { Application of machine vision in } \\
\text { industrial robots. } \\
{[118]}\end{array}$ & $\begin{array}{l}\text { Proceedings of the ASME } \\
\text { international mechanical } \\
\text { engineering congress and } \\
\text { exposition, 2018, vol } 2\end{array}$ & 2019 & 4 & Web of Science \\
\hline 09 & $\begin{array}{c}\text { Applications of artificial intelligence and } \\
\text { machine learning in DT-based } \\
\text { manufacturing. [119] }\end{array}$ & $\begin{array}{l}\text { International journal of } \\
\text { computer integrated } \\
\text { manufacturing }\end{array}$ & 2020 & 4 & Web of Science \\
\hline 10 & $\begin{array}{l}\text { DT architectures and machine vision in } \\
\text { manufacturing systems. } \\
\text { [120] }\end{array}$ & $\begin{array}{l}\text { Annals of DAAAM and } \\
\text { Proceedings of the } \\
\text { International DAAAM } \\
\text { Symposium }\end{array}$ & 2017 & 4 & Scopus \\
\hline 11 & $\begin{array}{c}\text { DT framework for smart product } \\
\text { manufacturing. } \\
{[121]}\end{array}$ & $\begin{array}{l}\text { International journal of } \\
\text { advanced robotic systems }\end{array}$ & 2019 & 2 & Web of Science \\
\hline 12 & $\begin{array}{c}\text { Simulation and machine learning } \\
\text { fusion-based DT for the manufacturing of } \\
\text { composites. } \\
\text { [122] }\end{array}$ & $\begin{array}{l}\text { Journal of manufacturing and } \\
\text { materials processing }\end{array}$ & 2020 & 2 & Web of Science \\
\hline 13 & $\begin{array}{l}\text { DT approach for reducing the energy } \\
\text { consumption in smart manufacturing. } \\
\text { [123] }\end{array}$ & $\begin{array}{l}\text { International journal of } \\
\text { computer integrated } \\
\text { manufacturing }\end{array}$ & 2020 & 1 & Web of Science \\
\hline 14 & $\begin{array}{l}\text { DT for the material removal process. } \\
\text { [106] }\end{array}$ & $\begin{array}{l}\text { International journal of } \\
\text { advanced manufacturing } \\
\text { technology }\end{array}$ & 2020 & 1 & Web of Science \\
\hline 15 & $\begin{array}{c}\text { Design and development of DT } \\
\text { framework for die cutting machine. } \\
\text { [124] }\end{array}$ & $\begin{array}{l}\text { International Journal of } \\
\text { Production Research }\end{array}$ & 2020 & 1 & Scopus \\
\hline 16 & $\begin{array}{l}\text { DT-driven predictive maintenance } \\
\text { approach for an automotive brake. } \\
\text { [125] }\end{array}$ & $\begin{array}{c}\text { 2nd international conference } \\
\text { on recent trends in advanced } \\
\text { computing icrtac-disruptive } \\
\text { innovation, } 2019\end{array}$ & 2019 & 1 & Web of Science \\
\hline 17 & $\begin{array}{l}\text { Cloud-based DT framework for smart } \\
\text { manufacturing. } \\
{[126]}\end{array}$ & $\begin{array}{c}\text { International journal of } \\
\text { computer integrated } \\
\text { manufacturing }\end{array}$ & 2020 & 0 & Web of Science \\
\hline 18 & $\begin{array}{c}\text { DT-competent deep reinforcement } \\
\text { learning framework for smart } \\
\text { manufacturing plants. } \\
\text { [127] }\end{array}$ & $\begin{array}{l}\text { Journal of manufacturing } \\
\text { systems }\end{array}$ & 2021 & 0 & Web of Science \\
\hline 19 & $\begin{array}{c}\text { DT enabled cutting tool modeling, } \\
\text { application, and service framework. } \\
\text { [128] }\end{array}$ & $\begin{array}{l}\text { Journal of manufacturing } \\
\text { systems }\end{array}$ & 2021 & 0 & Web of Science \\
\hline 20 & $\begin{array}{l}\text { DT concept for systems in manufacturing. } \\
\text { [129] }\end{array}$ & $\begin{array}{l}\text { Proceedings of the ASME } \\
\text { international mechanical } \\
\text { engineering congress and } \\
\text { exposition, 2018, vol } 2\end{array}$ & 2019 & 0 & Web of Science \\
\hline 21 & $\begin{array}{l}\text { DT for serial and parallel manipulators. } \\
\qquad[130]\end{array}$ & $\begin{array}{l}2019 \text { IEEE international } \\
\text { conference on systems, man, } \\
\text { and cybernetics (SMC) }\end{array}$ & 2019 & 0 & Web of Science \\
\hline 22 & $\begin{array}{l}\text { Smart spindle concept for Industry } 4.0 \\
\text { machine tools. } \\
{[131]}\end{array}$ & $\begin{array}{l}2020 \text { IEEE International } \\
\text { Workshop on Metrology for } \\
\text { Industry } 4.0 \text { and iot, Metroid } \\
4.0 \text { and iot } 2020 \text {-Proceedings }\end{array}$ & 2020 & 0 & Scopus \\
\hline 23 & $\begin{array}{c}\text { Real-time evaluation of additive } \\
\text { manufacturing through MiCLAD } \\
\text { platform. } \\
\text { [132] }\end{array}$ & Procedia CIRP & 2020 & 0 & Scopus \\
\hline 24 & $\begin{array}{l}\text { The cognitive DT framework for } \\
\text { manufacturing systems. } \\
\text { [133] }\end{array}$ & CEUR workshop proceedings & 2020 & 0 & Scopus \\
\hline
\end{tabular}


Table A2. Systematic analysis of bibliographic portfolio.

\begin{tabular}{|c|c|c|c|c|c|}
\hline Sr. No & Research Theme & Research Objective & $\begin{array}{c}\text { Sensors/Data } \\
\text { Acquisition/ } \\
\text { Communication } \\
\text { Protocols }\end{array}$ & $\begin{array}{l}\text { Decision Making } \\
\text { Algorithms }\end{array}$ & Research Outcome \\
\hline 01 & $\begin{array}{l}\text { DT-enabled cutting } \\
\text { tool modeling, } \\
\text { simulation, and } \\
\text { analysis. } \\
\text { [115] }\end{array}$ & $\begin{array}{l}\text { To examine the } \\
\text { concept of digital } \\
\text { twin for cutting tool } \\
\text { and production } \\
\text { systems }\end{array}$ & $\begin{array}{l}\text { NC Controller Data, } \\
\text { Force Sensor. }\end{array}$ & $\mathrm{O}$ & $\begin{array}{l}\text { The proposed model enables } \\
\text { the replication of the cutting } \\
\text { tool and aids in process control, } \\
\text { simulation, and analysis }\end{array}$ \\
\hline 02 & $\begin{array}{c}\text { DT-driven } \\
\text { reconfigurable } \\
\text { automated industrial } \\
\text { systems. } \\
{[3]}\end{array}$ & $\begin{array}{l}\text { Development of } \\
\text { digital twin-driven } \\
\text { framework for } \\
\text { rapidly reconfigure } \\
\text { the manufacturing } \\
\text { system }\end{array}$ & $\begin{array}{c}\text { Physical Simulation } \\
\text { Model, } \\
\text { Acoustic, } \\
\text { Temperature, NC } \\
\text { Code, IIoT }\end{array}$ & $\begin{array}{c}\text { Complex } \\
\text { Manufacturing } \\
\text { Network (CMN) }\end{array}$ & $\begin{array}{l}\text { The proposed approach realizes } \\
\text { the rapid reconfiguration of } \\
\text { manufacturing systems and } \\
\text { retrofitting the multiple } \\
\text { processes into them. Enables } \\
\text { the immediate launch of a new } \\
\text { product and reduces the cost. }\end{array}$ \\
\hline 03 & $\begin{array}{l}\text { A six-layer DT } \\
\text { architecture for } \\
\text { effective data and } \\
\text { information } \\
\text { exchange. } \\
\text { [44] }\end{array}$ & $\begin{array}{c}\text { To incorporate the } \\
\text { six-layer architecture } \\
\text { in a cyber-physical } \\
\text { system. }\end{array}$ & $\begin{array}{c}\text { Pressure Sensor, } \\
\text { Airflow Sensor, } \\
\text { Tecnomatix Process } \\
\text { Simulator, OPC-UA }\end{array}$ & $\mathrm{O}$ & $\begin{array}{l}\text { It draws attention to the } \\
\text { capabilities of digital twin in } \\
\text { information exchange. It also } \\
\text { reduces the expert requirement. }\end{array}$ \\
\hline 04 & $\begin{array}{l}\text { An IoT-enabled } \\
\text { manufacturing } \\
\text { system in } \\
\text { cyber-physical } \\
\text { domains. } \\
\text { [116] }\end{array}$ & $\begin{array}{l}\text { Study the concept of } \\
\text { DT and essential } \\
\text { issues during the } \\
\text { development of DT. }\end{array}$ & $\begin{array}{l}\text { Light Sensor, Color } \\
\text { Sensor, Arduino }\end{array}$ & $\begin{array}{l}\text { Probability } \\
\text { Distributions }\end{array}$ & $\begin{array}{l}\text { The proposed framework is } \\
\text { used for diagnosis, failure } \\
\text { prediction and remote process } \\
\text { monitoring, verified with } \\
\text { factory prototype. }\end{array}$ \\
\hline 05 & $\begin{array}{c}\text { Prediction of tool } \\
\text { condition through } \\
\text { DT model. } \\
\text { [35] }\end{array}$ & $\begin{array}{l}\text { To address the } \\
\text { challenges in DT } \\
\text { implementation } \\
\text { through systematic } \\
\text { development of } \\
\text { cyber-physical tool } \\
\text { system }\end{array}$ & $\begin{array}{l}\text { Dynamometer, } \\
\text { Accelerometer, } \\
\text { Acoustic Emission } \\
\text { Sensor, NI DAQ }\end{array}$ & $\begin{array}{l}\text { Deep Stacked Gated } \\
\text { Recurrent Unit (Deep } \\
\text { Stacked GRU) }\end{array}$ & $\begin{array}{l}\text { DT integrates the physical data } \\
\text { and data-driven computation } \\
\text { for the fault diagnosis and } \\
\text { performance evaluation. }\end{array}$ \\
\hline 06 & $\begin{array}{l}\text { Data management of } \\
\text { Metal Additive } \\
\text { Manufacturing } \\
\text { system with the aid } \\
\text { of DT framework. } \\
\text { [117] }\end{array}$ & $\begin{array}{l}\text { To employ a DT } \\
\text { framework for } \\
\text { bridging the research } \\
\text { gaps in data } \\
\text { management in AM. }\end{array}$ & $\begin{array}{c}\text { Temperature Sensor } \\
\text { and Pressure Sensor, } \\
\text { Cloud. }\end{array}$ & $\begin{array}{l}\text { Deep Learning and } \\
\text { Data Analytics }\end{array}$ & $\begin{array}{l}\text { The proposed framework } \\
\text { shows the future potential of } \\
\text { DT for additive manufacturing } \\
\text { to control, simulate, and } \\
\text { predict. }\end{array}$ \\
\hline 07 & $\begin{array}{c}\text { DT-enabled smart } \\
\text { manufacturing } \\
\text { assembly systems. } \\
{[31]}\end{array}$ & $\begin{array}{l}\text { Complete } \\
\text { digitalization of fault } \\
\text { detection and } \\
\text { inspection in an } \\
\text { experimental smart } \\
\text { manufacturing } \\
\text { assembly system }\end{array}$ & $\begin{array}{l}\text { Optical, Laser, } \\
\text { Proximity. Camera, } \\
\text { OPC-UA, Mind } \\
\text { Connect }\end{array}$ & $\begin{array}{c}\text { Convolutional } \\
\text { Neural Networks } \\
\text { (CNN) }\end{array}$ & $\begin{array}{l}\text { Study and experimental } \\
\text { verification for contactless data } \\
\text { capturing, processing, and } \\
\text { analysis for the realization of } \\
\text { complete digitalization of } \\
\text { assembly system }\end{array}$ \\
\hline 08 & $\begin{array}{c}\text { Application of } \\
\text { machine vision in } \\
\text { industrial robots. } \\
{[118]}\end{array}$ & $\begin{array}{l}\text { To reduce the human } \\
\text { effort of } \\
\text { reprogramming and } \\
\text { self-learning in } \\
\text { industrial robots. }\end{array}$ & $\begin{array}{l}\text { LIDAR Sensor, } \\
\text { Camera }\end{array}$ & $\begin{array}{l}\text { Markov Decision } \\
\text { Process (MDP) }\end{array}$ & $\begin{array}{l}\text { The approach reduces the } \\
\text { human efforts in roots } \\
\text { decision-making and makes } \\
\text { robots intelligent through the } \\
\text { perception from the machine } \\
\text { learning algorithm }\end{array}$ \\
\hline 09 & $\begin{array}{l}\text { Applications of } \\
\text { artificial intelligence } \\
\text { and machine learning } \\
\text { in DT-based } \\
\text { manufacturing. [119] }\end{array}$ & $\begin{array}{l}\text { Developed a DT } \\
\text { based framework for } \\
\text { building a machine } \\
\text { learning-based } \\
\text { application in smart } \\
\text { manufacturing }\end{array}$ & $\begin{array}{l}\text { Optical Camera } \\
\text { Sensor }\end{array}$ & $\begin{array}{c}\text { Convolutional } \\
\text { Neural Network } \\
\text { (CNN) } \\
\text { Artificial Neural } \\
\text { Network (ANN), }\end{array}$ & $\begin{array}{l}\text { The developed framework } \\
\text { reduces the human effort for } \\
\text { handling the parts which } \\
\text { require specialized treatment } \\
\text { and realizes the potential of the } \\
\text { proposed framework }\end{array}$ \\
\hline 10 & $\begin{array}{l}\text { DT architectures and } \\
\text { machine vision in } \\
\text { manufacturing } \\
\text { systems. } \\
\text { [120] }\end{array}$ & $\begin{array}{l}\text { Application of vision } \\
\text { system for the } \\
\text { production line to } \\
\text { identify objects and } \\
\text { real-time inspection }\end{array}$ & LIDAR Sensor & $\begin{array}{l}\text { You Look Only Once } \\
\text { (YOLO), Word Tree }\end{array}$ & $\begin{array}{l}\text { Allows the use of a single } \\
\text { computer to monitor, control, } \\
\text { inspect, and count objects on a } \\
\text { distributed production line. }\end{array}$ \\
\hline
\end{tabular}


Table A2. Cont.

\begin{tabular}{|c|c|c|c|c|c|}
\hline Sr. No & Research Theme & Research Objective & $\begin{array}{c}\text { Sensors/Data } \\
\text { Acquisition/ } \\
\text { Communication } \\
\text { Protocols }\end{array}$ & $\begin{array}{l}\text { Decision Making } \\
\text { Algorithms }\end{array}$ & Research Outcome \\
\hline 11 & $\begin{array}{l}\text { DT framework for } \\
\text { smart product } \\
\text { manufacturing. } \\
\text { [121] }\end{array}$ & $\begin{array}{l}\text { Discussion on DT } \\
\text { drove application } \\
\text { framework and } \\
\text { implement in the } \\
\text { blade manufacturing } \\
\text { industry to reduce } \\
\text { the machine } \\
\text { deformation and } \\
\text { machining time }\end{array}$ & $\begin{array}{l}\text { Force, Acoustic and } \\
\text { Accelerometer. } \\
\text { OPC-UA }\end{array}$ & $\begin{array}{l}\text { Machine learning } \\
\text { algorithms }\end{array}$ & $\begin{array}{l}\text { Framework improved the } \\
\text { production efficiency and } \\
\text { successful interconnection and } \\
\text { communication between } \\
\text { physical and cyberspace. }\end{array}$ \\
\hline 12 & $\begin{array}{c}\text { Simulation and } \\
\text { machine learning } \\
\text { fusion-based DT for } \\
\text { the manufacturing of } \\
\text { composites. } \\
\text { [122] }\end{array}$ & $\begin{array}{l}\text { Development of DT } \\
\text { model using the } \\
\text { fusion of FEM } \\
\text { simulations and } \\
\text { machine learning to } \\
\text { support the quality } \\
\text { control in composites } \\
\text { manufacturing }\end{array}$ & $\begin{array}{l}\text { FEM Simulation } \\
\text { Data, Geometrical } \\
\text { Modeling and } \\
\text { Simulation Data }\end{array}$ & $\begin{array}{l}\text { XG Boost, Random } \\
\text { Forest, Decision Tree, } \\
\text { ADA Boost }\end{array}$ & $\begin{array}{c}\text { The developed surrogate model } \\
\text { predicts the structural } \\
\text { properties, physical } \\
\text { distribution, and local } \\
\text { properties of composites. }\end{array}$ \\
\hline 13 & $\begin{array}{l}\text { DT approach for } \\
\text { reducing the energy } \\
\text { consumption in } \\
\text { smart manufacturing. } \\
\text { [123] }\end{array}$ & $\begin{array}{c}\text { Design and } \\
\text { development of an } \\
\text { operational } \\
\text { framework of DT in } \\
\text { smart manufacturing }\end{array}$ & $\begin{array}{l}\text { DH Parameters, CAD } \\
\text { Design Data }\end{array}$ & $\mathrm{O}$ & $\begin{array}{l}\text { The model enables } \\
\text { communication between a } \\
\text { physical and virtual model, } \\
\text { which aids in systematic } \\
\text { integration, analysis, and } \\
\text { optimization of the system and } \\
\text { improves the energy } \\
\text { consumption in manufacturing. }\end{array}$ \\
\hline 14 & $\begin{array}{c}\text { DT for the material } \\
\text { removal process. } \\
\text { [106] }\end{array}$ & $\begin{array}{l}\text { Investigation of laser } \\
\text { material removal } \\
\text { process through } \\
\text { molecular dynamics } \\
\text { simulation and DT } \\
\text { for decision-making }\end{array}$ & $\begin{array}{l}\text { Hyper Spectral } \\
\text { Camera }\end{array}$ & $\begin{array}{l}\text { Hidden Markov } \\
\text { Model (HMM) }\end{array}$ & $\begin{array}{l}\text { The proposed framework is } \\
\text { verified by two case studies viz. } \\
\text { calibration by detecting } \\
\text { variation in boundary } \\
\text { conditions and quality } \\
\text { assessment for defect detection } \\
\text { in laser material removal } \\
\text { process, which minimizes } \\
\text { evaluation time and reduces the } \\
\text { error rate. }\end{array}$ \\
\hline 15 & $\begin{array}{l}\text { Design and } \\
\text { development of DT } \\
\text { framework for die } \\
\text { cutting machine. } \\
\text { [124] }\end{array}$ & $\begin{array}{l}\text { Building a DT } \\
\text { framework for the } \\
\text { die cutting machine } \\
\text { for the real-time } \\
\text { monitoring and to } \\
\text { function the } \\
\text { predictive } \\
\text { maintenance }\end{array}$ & $\begin{array}{l}\text { Speed, position, } \\
\text { accelerometer and } \\
\text { acoustic. } \\
\text { OPC-UA }\end{array}$ & $\begin{array}{l}\text { Reliability and } \\
\text { Failure Rate } \\
\text { Estimation } \\
\text { Algorithm }\end{array}$ & $\begin{array}{l}\text { The GUI-based DT approach is } \\
\text { used for real-time monitoring of } \\
\text { the die-cutting machine (case } \\
\text { study) and predicting machine } \\
\text { health. }\end{array}$ \\
\hline 16 & $\begin{array}{l}\text { DT-driven predictive } \\
\text { maintenance } \\
\text { approach for an } \\
\text { automotive brake. } \\
\text { [125] }\end{array}$ & $\begin{array}{l}\text { Study the role of DT } \\
\text { in the automotive } \\
\text { industry. }\end{array}$ & $\begin{array}{l}\text { Pressure Sensor, } \\
\text { ThingWorx Cloud }\end{array}$ & $\begin{array}{c}\text { Filter and Wrapped } \\
\text { Based Algorithms }\end{array}$ & $\begin{array}{c}\text { The predictive maintenance and } \\
\text { wear rate computation of } \\
\text { vehicle brake through a DT } \\
\text { framework }\end{array}$ \\
\hline 17 & $\begin{array}{c}\text { Cloud-based DT } \\
\text { framework for smart } \\
\text { manufacturing. } \\
{[126]}\end{array}$ & $\begin{array}{c}\text { Design and } \\
\text { development of } \\
\text { interoperable data } \\
\text { scheme for smart } \\
\text { manufacturing }\end{array}$ & - & $\begin{array}{l}\text { Factory design and } \\
\text { improvement } \\
\text { extensible markup } \\
\text { language (FDIXML) }\end{array}$ & $\begin{array}{l}\text { The developed system assists in } \\
\text { space optimization, real-time } \\
\text { monitoring and performance } \\
\text { optimization and removes the } \\
\text { barrier of lack of experience, } \\
\text { improves user accessibility for } \\
\text { the flexible manufacturing } \\
\text { systems }\end{array}$ \\
\hline 18 & $\begin{array}{l}\text { DT-competent deep } \\
\text { reinforcement } \\
\text { learning framework } \\
\text { for smart } \\
\text { manufacturing plants. } \\
\text { [127] }\end{array}$ & $\begin{array}{c}\text { Application of } \\
\text { data-driven digital } \\
\text { transformation for } \\
\text { smart manufacturing } \\
\text { to automate the } \\
\text { systems }\end{array}$ & $\begin{array}{l}\text { Proximity, Camera, } \\
\text { Encoders. } \\
\text { OPC-UA }\end{array}$ & Deep Q Learning & $\begin{array}{c}\text { Developed Deep Reinforcement } \\
\text { Learning (DRL)-based artificial } \\
\text { intelligence industrial control } \\
\text { process called digital engine to } \\
\text { gain process knowledge, } \\
\text { scheduling manufacturing } \\
\text { tasks, and performing optimal } \\
\text { actions }\end{array}$ \\
\hline
\end{tabular}


Table A2. Cont.

\begin{tabular}{|c|c|c|c|c|c|}
\hline Sr. No & Research Theme & Research Objective & $\begin{array}{c}\text { Sensors/Data } \\
\text { Acquisition/ } \\
\text { Communication } \\
\text { Protocols }\end{array}$ & $\begin{array}{l}\text { Decision Making } \\
\text { Algorithms }\end{array}$ & Research Outcome \\
\hline 19 & $\begin{array}{l}\text { DT-enabled cutting } \\
\text { tool modeling, } \\
\text { application, and } \\
\text { service framework. } \\
\text { [128] }\end{array}$ & $\begin{array}{c}\text { Construction of a DT } \\
\text { model for the cutting } \\
\text { tool to simulate, } \\
\text { monitor, and } \\
\text { evaluate a tool's } \\
\text { performance. }\end{array}$ & $\begin{array}{c}\text { Current, force, } \\
\text { acoustic, and } \\
\text { Accelerometer, CNC } \\
\text { Controller. }\end{array}$ & $\begin{array}{l}\text { ANN, SVM, HMM, } \\
\text { CNN }\end{array}$ & $\begin{array}{l}\text { Develop a DT model to realize } \\
\text { the real-time monitoring, } \\
\text { simulation, optimization, } \\
\text { failure analysis, forecasting, } \\
\text { implementation of maintenance } \\
\text { approach and } \\
\text { computer-generated } \\
\text { maintenance of the cutting tool. }\end{array}$ \\
\hline 20 & $\begin{array}{l}\text { DT concept for } \\
\text { systems in } \\
\text { manufacturing. } \\
\text { [129] }\end{array}$ & $\begin{array}{l}\text { Development of DT } \\
\text { based framework for } \\
\text { manufacturing using } \\
\text { virtual reality for } \\
\text { physical processes }\end{array}$ & Proximity Sensor & $\mathrm{O}$ & $\begin{array}{l}\text { The digital twin model gives } \\
\text { real-time insights into the } \\
\text { ongoing processes and stages, } \\
\text { which is further used for } \\
\text { decision-making and } \\
\text { performance optimization }\end{array}$ \\
\hline 21 & $\begin{array}{c}\text { DT for serial and } \\
\text { parallel manipulators. } \\
\text { [130] }\end{array}$ & $\begin{array}{c}\text { Design and } \\
\text { development of DT } \\
\text { for serial and parallel } \\
\text { manipulators of } \\
\text { robot }\end{array}$ & $\begin{array}{c}\text { Encoders. } \\
\text { OPC-UA, MQTT }\end{array}$ & $\mathrm{O}$ & $\begin{array}{l}\text { DT model helps to monitor the } \\
\text { joint movement of a robot, } \\
\text { which is helpful in maintenance } \\
\text { operations due to its capacity } \\
\text { for faster problem identification }\end{array}$ \\
\hline 22 & $\begin{array}{c}\text { Smart spindle } \\
\text { concept for Industry } \\
4.0 \text { machine tools. } \\
\text { [131] }\end{array}$ & $\begin{array}{l}\text { Study and analysis of } \\
\text { critical enablers for } \\
\text { an intelligent } \\
\text { component and } \\
\text { experiment } \\
\text { validation through } \\
\text { smart spindle }\end{array}$ & $\begin{array}{c}\text { Accelerometers, } \\
\text { Gyroscopes, } \\
\text { temperature, acoustic } \\
\text { emissions, and } \\
\text { current sensors } \\
\text { OPC-UA, MQTT, MT } \\
\text { Connect }\end{array}$ & $\mathrm{O}$ & $\begin{array}{l}\text { Proposed DT is used to predict } \\
\text { the performance, real-time } \\
\text { control, and health estimation } \\
\text { of the spindle. }\end{array}$ \\
\hline 23 & $\begin{array}{l}\text { Real-time evaluation } \\
\text { of additive } \\
\text { manufacturing } \\
\text { through MiCLAD } \\
\text { platform. } \\
\text { [132] }\end{array}$ & $\begin{array}{l}\text { Development of a } \\
\text { framework for } \\
\text { real-time monitoring } \\
\text { of additive } \\
\text { manufacturing } \\
\text { systems. }\end{array}$ & $\begin{array}{l}\text { Camera } \\
\text { Ethernet }\end{array}$ & $\begin{array}{c}\text { ANN, } \\
\text { Self-Organizing } \\
\text { Pareto based } \\
\text { Evolutionary } \\
\text { Algorithm (SOPEA) }\end{array}$ & $\begin{array}{l}\text { The proposed framework } \\
\text { accurately maps the process in } \\
\text { virtual space and facilitates } \\
\text { real-time monitoring and } \\
\text { control of it. }\end{array}$ \\
\hline 24 & $\begin{array}{l}\text { The cognitive DT } \\
\text { framework for } \\
\text { manufacturing } \\
\text { systems. } \\
\text { [133] }\end{array}$ & $\begin{array}{c}\text { Study and } \\
\text { implementation of } \\
\text { cognitive twin for } \\
\text { decision making in } \\
\text { Industry } 4.0\end{array}$ & - & Knowledge Graphs & $\begin{array}{l}\text { The proposed cognitive } \\
\text { framework was implemented } \\
\text { for the shop floor to facilitate } \\
\text { intelligent decision-making } \\
\text { with the help of machine } \\
\text { learning algorithms, which } \\
\text { consist of four components, viz., } \\
\text { ontology, knowledge graphs, } \\
\text { data (current and historical), } \\
\text { machine learning algorithms } \\
\text { and decisions }\end{array}$ \\
\hline
\end{tabular}


Table A3. Sensors and their applications in portfolio documents.

\begin{tabular}{|c|c|c|c|c|}
\hline Sr. No & Sensor & Used to Measure & Benefits & Limitations \\
\hline 1 & Proximity Sensor & $\begin{array}{c}\text { Presence of nearby objects } \\
\text { without any physical } \\
\text { contact } \\
{[29,106]}\end{array}$ & $\begin{array}{l}\text { Detects the presence of metallic and } \\
\text { non-metallic objects without any } \\
\text { physical contact } \\
\text { Low cost, good resolution, high speed, } \\
\text { low power usage. }\end{array}$ & $\begin{array}{l}\text { Limited detection range. } \\
\text { Not able to detect objects with } \\
\text { textures. }\end{array}$ \\
\hline 2 & Pressure Sensor & $\begin{array}{l}\text { Pressure measurement for } \\
\text { the gripper, cutting tool. } \\
\qquad[30,77,117]\end{array}$ & $\begin{array}{l}\text { High flexibility, high sensitivity, light } \\
\text { weight, and linear output } \\
\text { resistance to shock, vibration, and } \\
\text { dynamic pressure change. }\end{array}$ & $\begin{array}{l}\text { Needs external power supply, } \\
\text { temperature-dependent output. }\end{array}$ \\
\hline 3 & Airflow Sensor & $\begin{array}{l}\text { Mass flow rate of air. } \\
\text { [30] }\end{array}$ & $\begin{array}{l}\text { Fast response time, less airflow } \\
\text { restrictions, absence of moving parts, } \\
\text { and high durability. }\end{array}$ & $\begin{array}{c}\text { Foreign particle contamination } \\
\text { affects the accuracy. } \\
\text { Requires frequent calibrations. } \\
\text { High velocity limits the accuracy. }\end{array}$ \\
\hline 4 & Encoder & $\begin{array}{l}\text { Motion or position. } \\
\text { [118] }\end{array}$ & $\begin{array}{c}\text { Fuses with modern control systems due } \\
\text { to integrated electronics. } \\
\text { Reliable and accurate. } \\
\text { High resolutions } \\
\text { High-temperature stability, simple }\end{array}$ & $\begin{array}{l}\text { The presence of Magnetic or } \\
\text { radio interference affects the } \\
\text { accuracy. } \\
\text { Problem with dirt, oil, and dust. }\end{array}$ \\
\hline 5 & Accelerometer & $\begin{array}{l}\text { Vibration. } \\
\text { [117] }\end{array}$ & $\begin{array}{l}\text { interfacing, less noise, and robustness. } \\
\text { Integrated electronics. } \\
\text { More significant response to sudden } \\
\text { changes in vibrations due to the } \\
\text { variation in machining parameters. } \\
\text { Wide range of temperature }\end{array}$ & $\begin{array}{l}\text { Fixed range of measurement. } \\
\text { Error in measurement due to } \\
\text { hysteresis and permeant } \\
\text { deformation in sensing elements. }\end{array}$ \\
\hline 6 & Temperature Sensor & Temperature [117] & $\begin{array}{l}\text { measurements, durable, fast response } \\
\text { time for temperature measurement } \\
\text { during the ongoing process. } \\
\text { Small and integrated electronics. }\end{array}$ & $\begin{array}{c}\text { Difficult calibrations. } \\
\text { Environmental factors affect the } \\
\text { measurement. }\end{array}$ \\
\hline 7 & Dynamometer & $\begin{array}{l}\text { Cutting force or simple } \\
\text { force } \\
{[128]}\end{array}$ & $\begin{array}{l}\text { Excellent response to cutting force. } \\
\text { Free from hysteresis and eddy current } \\
\text { losses. }\end{array}$ & $\begin{array}{l}\text { The low sensitivity and size of } \\
\text { the workpiece limits the usage of } \\
\text { it. } \\
\text { Installation is a challenging task. }\end{array}$ \\
\hline 8 & Acoustic Sensor & $\begin{array}{l}\text { Sound, Noise } \\
{[124,128,131]}\end{array}$ & $\begin{array}{c}\text { The capability of defect identification is } \\
\text { based on the frequency or intensity of the } \\
\text { sound wave. } \\
\text { High processing speed. }\end{array}$ & $\begin{array}{l}\text { Measurement is affected by } \\
\text { improper sensor calibration, lack } \\
\text { of hardware amd software, } \\
\text { nature of the signal, and } \\
\text { operating conditions. }\end{array}$ \\
\hline 9 & Gyroscope & $\begin{array}{c}\text { Angular rotational } \\
\text { velocity } \\
\text { [131] }\end{array}$ & $\begin{array}{l}\text { It provides a faster response to the } \\
\text { change in the angular position of the } \\
\text { robotic arm or the end effector. } \\
\text { Excellent tool for measurement of the } \\
\text { orientation of an object in a coordinated } \\
\text { system }\end{array}$ & $\begin{array}{l}\text { Higher cost. } \\
\text { The effect of earth's gravitational } \\
\text { force may hamper the accuracy } \\
\text { of the gyroscope. }\end{array}$ \\
\hline 10 & Current Sensor & $\begin{array}{c}\text { Current draws by the } \\
\text { equipment or device } \\
{[128,131]}\end{array}$ & $\begin{array}{l}\text { Better accuracy in prediction and health } \\
\text { monitoring of equipment or device. }\end{array}$ & $\begin{array}{l}\text { Sensor may not withstand high } \\
\text { current ranges. } \\
\text { Temperature and other } \\
\text { environmental factors affect the } \\
\text { accuracy. }\end{array}$ \\
\hline 11 & $\begin{array}{l}\text { LIDAR } \\
\text { (Light detection and } \\
\text { ranging) }\end{array}$ & $\begin{array}{c}\text { Variable distances } \\
{[118,120]}\end{array}$ & $\begin{array}{l}\text { It offers simultaneous location and } \\
\text { mapping of the robots' path. } \\
\text { It offers rapid response to the obstacle in } \\
\text { the path of robot. }\end{array}$ & $\begin{array}{l}\text { Reflectivity of the objects may } \\
\text { affect the object detection. } \\
\text { Limited range. }\end{array}$ \\
\hline
\end{tabular}


Table A4. Decision-making algorithms and their application in studies.

\begin{tabular}{|c|c|c|c|c|c|c|c|c|c|c|c|}
\hline \multirow[b]{2}{*}{ Use Case } & \multirow[b]{2}{*}{$\begin{array}{l}\text { Decision-Making } \\
\text { Algorithms }\end{array}$} & \multirow[b]{2}{*}{ Accelerometer } & \multirow[b]{2}{*}{$\begin{array}{l}\text { Acoustic } \\
\text { Emission }\end{array}$} & \multirow[b]{2}{*}{ Dynamometer } & \multicolumn{2}{|c|}{ Sensors Used } & \multirow[b]{2}{*}{ LIDAR } & \multirow[b]{2}{*}{ Camera } & \multirow[b]{2}{*}{$\begin{array}{l}\text { Proximity } \\
\text { Sensor }\end{array}$} & \multirow[b]{2}{*}{ Encoder } & \multirow{2}{*}{$\begin{array}{l}\text { Simulation/ } \\
\text { Mathematical } \\
\text { Model }\end{array}$} \\
\hline & & & & & $\begin{array}{l}\text { Current } \\
\text { Sensor }\end{array}$ & Temperature & & & & & \\
\hline $\begin{array}{l}\text { Cutting tool } \\
{[128]}\end{array}$ & $\begin{array}{l}\text { Convolutional Neural } \\
\text { Network (CNN) }\end{array}$ & $\checkmark$ & $\checkmark$ & $\checkmark$ & $\checkmark$ & & & & & & \\
\hline $\begin{array}{c}\text { Thermoplastics composites } \\
\text { [122] }\end{array}$ & Random Forests & & & & & & & & & & $\checkmark$ \\
\hline $\begin{array}{c}\text { Thermoplastics composites } \\
\text { [122] }\end{array}$ & Decision Trees & & & & & & & & & & $\checkmark$ \\
\hline $\begin{array}{c}\text { Cutting Tool [128], Robot } \\
\text { [118] } \\
\text { Material Removal [106] }\end{array}$ & Hidden Markov Models & $\checkmark$ & $\checkmark$ & $\checkmark$ & $\checkmark$ & & & $\checkmark$ & & & \\
\hline $\begin{array}{c}\text { Thermoplastic Composites } \\
\text { [122] }\end{array}$ & XG Boost & & & & & & & & & & $\checkmark$ \\
\hline $\begin{array}{c}\text { Cutting Tool } \\
{[128]}\end{array}$ & $\begin{array}{l}\text { Support Vector Machines } \\
\text { (SVM) }\end{array}$ & $\checkmark$ & $\checkmark$ & $\checkmark$ & $\checkmark$ & & & & & & \\
\hline $\begin{array}{l}\text { Smart Manufacturing Plants } \\
\text { Control Process [128] }\end{array}$ & Deep Q-Learning & & & & & & & $\checkmark$ & $\checkmark$ & $\checkmark$ & \\
\hline $\begin{array}{l}\text { Object Detection (Robotic } \\
\text { Vision) [120] }\end{array}$ & $\begin{array}{l}\text { YOLO (You Look Only } \\
\text { Once) }\end{array}$ & & & & & & $\checkmark$ & $\checkmark$ & & & \\
\hline $\begin{array}{l}\text { Automatic Manufacturing } \\
\text { Reconfiguration [3] }\end{array}$ & $\begin{array}{l}\text { Complex Manufacturing } \\
\text { Network }(\mathrm{CMN})\end{array}$ & & $\checkmark$ & & & $\checkmark$ & & & & & $\checkmark$ \\
\hline $\begin{array}{c}\text { Cutting tool [128] } \\
\text { Laser Material Deposition } \\
\text { [132] }\end{array}$ & $\begin{array}{l}\text { Artificial Neural } \\
\text { Network }\end{array}$ & $\checkmark$ & $\checkmark$ & $\checkmark$ & $\checkmark$ & & & & $\checkmark$ & & \\
\hline
\end{tabular}




\section{References}

1. Paritala, P.; Manchikatla, S.; Yarlagadda, P. Digital Manufacturing- Applications Past, Current, and Future Trends. Procedia Eng. 2017, 174, 982-991. [CrossRef]

2. Benotsmane, R.; Kovács, G.; Dudás, L. Economic, social impacts and operation of smart factories in Industry 4.0 focusing on simulation and artificial intelligence of collaborating robots. Soc. Sci. 2019, 8, 143. [CrossRef]

3. Leng, J.; Liu, Q.; Ye, S.; Jing, J.; Wang, Y.; Zhang, C.; Zhang, D.; Chen, X. Digital twin-driven rapid reconfiguration of the automated manufacturing system via an open architecture model. Robot. Comput. Integr. Manuf. 2020, 63, 101895. [CrossRef]

4. Markets and Markets. Smart Manufacturing Market by Enabling Technology, Information Technology, Industry, and Region I COVID-19 Impact Analysis I MarketsandMarkets TM. 2020. Available online: https:/ / www.marketsandmarkets.com/MarketReports/smart-manufacturing-market-105448439.html?gclid=Cj0KCQjwzZj2BRDVARIsABs319LqNjw2gircZUP8sh_4EJw0 WOKqqOQHpDNwK2ZOw8r_xCaLk2Jr2CQaAtXtEALw_wcB (accessed on 6 July 2021).

5. Aimienrovbiye, G. Maintenance impact on Production Profitability: A Case Study. 2010, p. 69. Available online: https: / / www.diva-portal.org/smash/get/diva2:327878/FULLTEXT01.pdf (accessed on 6 July 2021).

6. Tucci, M.; Rapaccini, M.; De Carlo, F.; Borgia, O. New Maintenance Opportunities in Legacy Plants; IFAC: Szczecin, Poland, 2008; Volume 41, ISBN 9783902661401.

7. Krar, S. The Importance of Maintenance. 2014. Available online: https://www.automationmag.com/images/stories/LWTechfiles/94\%20Intelligent\%20Systems.pdf (accessed on 8 June 2020).

8. Manufacturing Machinery Maintenance _ NIST. National Institute of Standards and Technology U.S. Department of Commerce. 2020. Available online: https://www.nist.gov/el/applied-economics-office/manufacturing/topics-manufacturing/ manufacturing-machinery-maintenance\#: $\sim\{$ :text=Oneoftheapplicationsof, andApplicationforManufacturingOperations (accessed on 6 July 2021).

9. Smith, A.; Hinchcliffe, G. Preventive Maintenance-Definition and Structure. In RCM Gateway to World Class Maintenance; Elsevier: Amsterdam, The Netherlands, 2004; pp. 19-37, ISBN 9780750674614. [CrossRef]

10. Vilarinho, S.; Lopes, I.; Oliveira, J.A. Preventive Maintenance Decisions through Maintenance Optimization Models: A Case Study. Procedia Manuf. 2017, 11, 1170-1177. [CrossRef]

11. Swanson, L. Linking maintenance strategies to performance. Int. J. Prod. Econ. 2001, 70, 237-244. [CrossRef]

12. Nita Ali, K.; Sun, M.; Petley, G.; Barrett, P. Improving the business process of reactive maintenance projects. Facilities 2002, 20, 251-261. [CrossRef]

13. Kahraman, C.; Onar, S.Ç. Intelligent Techniques in Engineering Management Theory and Applications; Springer International Publishing: Basel, Switzerland, 2015; Volume 87, ISBN 978-3-319-17905-6.

14. Amihai, I.; Gitzel, R.; Kotriwala, A.M.; Pareschi, D.; Subbiah, S.; Sosale, G. An industrial case study using vibration data and machine learning to predict asset health. In Proceedings of the 2018 IEEE 20th Conference on Business Informatics (CBI), Vienna, Austria, 11-14 July 2018; Volume 1, pp. 178-185.

15. Man, J.; Zhou, Q. Prediction of hard failures with stochastic degradation signals using Wiener process and proportional hazards model. Comput. Ind. Eng. 2018, 125, 480-489. [CrossRef]

16. Schroeder, T. Benefits of Predictive Maintenance in Manufacturing. Excellence Blog. 2017. Available online: https://blog. softexpert.com/en/the-benefits-of-predictive-maintenance/ (accessed on 7 July 2021).

17. Upkeep Maintenance Management. Maintenance Statistics: Predictive \& Preventive, Labor \& Costs. 2021. Available online: https://www.onupkeep.com/learning/maintenance-metrics/maintenance-statistics (accessed on 7 July 2021).

18. Vavra, B. Plant Engineering _ 2018 Maintenance Survey_Playing Offense and Defense. 2018. Available online: https://www. plantengineering.com/articles/2018-maintenance-survey-playing-offense-and-defense/ (accessed on 7 July 2021).

19. Errandonea, I.; Beltrán, S.; Arrizabalaga, S. Digital Twin for maintenance: A literature review. Comput. Ind. 2020, 123, 103316. [CrossRef]

20. Tao, F.; Qi, Q.; Wang, L.; Nee, A.Y.C. Digital Twins and Cyber-Physical Systems toward Smart Manufacturing and Industry 4.0: Correlation and Comparison. Engineering 2019, 5, 653-661. [CrossRef]

21. Tao, F.; Liu, W.; Zhang, M.; Hu, T.; Qi, Q.; Zhang, H.; Sui, F.; Wang, T.; Xu, H.; Huang, Z.; et al. Five-dimension digital twin model and its ten applications. Jisuanji Jicheng Zhizao Xitong/Comput. Integr. Manuf. Syst. CIMS 2019, 25, 1-18.

22. Fuller, A.; Fan, Z.; Day, C.; Barlow, C. Digital Twin: Enabling Technologies, Challenges and Open Research. IEEE Access 2020, 8 , 108952-108971. [CrossRef]

23. Ashtari Talkhestani, B.; Weyrich, M. Digital Twin of manufacturing systems: A case study on increasing the efficiency of reconfiguration. At-Automatisierungstechnik 2020, 68, 435-444. [CrossRef]

24. Qi, Q.; Tao, F. Digital Twin and Big Data Towards Smart Manufacturing and Industry 4.0: 360 Degree Comparison. IEEE Access 2018, 6, 3585-3593. [CrossRef]

25. Markets and Markets. Digital Twin Market by Technology, Type, Application, Industry ICOVID-19 Impact Analysis I MarketsandMarkets ${ }^{\text {TM }}$. 2020. Available online: https://www.marketsandmarkets.com/Market-Reports/digital-twin-market225269522.html?gclid=EAIaIQobChMIl8GUtO3c7wIVEuh3Ch2zWgfrEAAYAiAAEgIUTfD_BwE (accessed on 7 July 2021). 
26. De Felice, F.; Petrillo, A.; Zomparelli, F. A Bibliometric Multicriteria Model on Smart Manufacturing from 2011 to 2018. IFACPapersOnLine 2018, 51, 1643-1648. [CrossRef]

27. Tao, F.; Zhang, M. Digital Twin Shop-Floor: A New Shop-Floor Paradigm Towards Smart Manufacturing. IEEE Access 2017, 5, 20418-20427. [CrossRef]

28. Zhang, J.; Ding, G.; Zou, Y.; Qin, S.; Fu, J. Review of job shop scheduling research and its new perspectives under Industry 4.0. J. Intell. Manuf. 2019, 30, 1809-1830. [CrossRef]

29. Tao, F.; Zhang, M.; Liu, Y.; Nee, A.Y.C. Digital twin driven prognostics and health management for complex equipment. CIRP Ann. 2018, 67, 169-172. [CrossRef]

30. Moretti, M.; Rossi, A.; Senin, N. In-process monitoring of part geometry in fused filament fabrication using computer vision and digital twins. Addit. Manuf. 2021, 37, 101609.

31. Židek, K.; Pitel', J.; Adámek, M.; Lazorík, P.; Hošovskỳ, A. Digital twin of experimental smart manufacturing assembly system for industry 4.0 concept. Sustainability 2020, 12, 3658. [CrossRef]

32. Hänel, A.; Seidel, A.; Frieß, U.; Teicher, U.; Wiemer, H.; Wang, D.; Wenkler, E.; Penter, L.; Hellmich, A.; Ihlenfeldt, S. Digital Twins for High-Tech Machining Applications-A Model-Based Analytics-Ready Approach. J. Manuf. Mater. Process. $2021,5,80$.

33. Jones, D.; Snider, C.; Nassehi, A.; Yon, J.; Hicks, B. Characterising the Digital Twin: A systematic literature review. CIRP J. Manuf. Sci. Technol. 2020, 29, 36-52. [CrossRef]

34. Herrera-Franco, G.; Montalván-Burbano, N.; Carrión-Mero, P.; Jaya-Montalvo, M.; Gurumendi-Noriega, M. Worldwide research on geoparks through bibliometric analysis. Sustainability 2021, 13, 1175. [CrossRef]

35. Qiao, Q.; Wang, J.; Ye, L.; Gao, R.X. Digital twin for machining tool condition prediction. Procedia CIRP 2019, 81, 1388-1393. [CrossRef]

36. Rosen, R.; Von Wichert, G.; Lo, G.; Bettenhausen, K.D. About the importance of autonomy and digital twins for the future of manufacturing. IFAC-PapersOnLine 2015, 28, 567-572. [CrossRef]

37. Grieves, M. Digital Twin: Manufacturing Excellence through Virtual Factory Replication This paper introduces the concept of a A Whitepaper by Dr. Michael Grieves. White Pap. 2015. Available online: https://www.researchgate.net/publication/275211047_ Digital_Twin_Manufacturing_Excellence_through_Virtual_Factory_Replication (accessed on 8 July 2021).

38. Tuegel, E.J.; Ingraffea, A.R.; Eason, T.G.; Spottswood, S.M. Reengineering aircraft structural life prediction using a digital twin. Int. J. Aerosp. Eng. 2011, 2011. [CrossRef]

39. Glaessgen, E.H.; Stargel, D.S. The digital twin paradigm for future NASA and U.S. Air force vehicles. In Proceedings of the 53rd AIAA/ASME/ASCE/AHS/ASC Structures, Structural Dynamics and Materials Conference 20th AIAA/ASME/AHS Adaptive Structures Conference 14th AIAA, Honolulu, HI, USA, 23-26 April 2012; pp. 1-14.

40. Söderberg, R.; Wärmefjord, K.; Carlson, J.S.; Lindkvist, L. Toward a Digital Twin for real-time geometry assurance in individualized production. CIRP Ann.-Manuf. Technol. 2017, 66, 137-140. [CrossRef]

41. Shafto, M.; Conroy, M.; Doyle, R.; Glaessgen, E.; Kemp, C.; LeMoigne, J.; Wang, L. Modeling, Simulation, information Technology \& Processing Roadmap. Technol. Area 11 2012, 32, 1-38.

42. Negri, E.; Fumagalli, L.; Macchi, M. A Review of the Roles of Digital Twin in CPS-based Production Systems. Procedia Manuf. 2017, 11, 939-948. [CrossRef]

43. Tao, F.; Zhang, H.; Liu, A.; Nee, A.Y.C. Digital Twin in Industry: State-of-the-Art. IEEE Trans. Ind. Inform. 2019, 15, $2405-2415$. [CrossRef]

44. Redelinghuys, A.J.H.; Basson, A.H.; Kruger, K. A six-layer architecture for the digital twin: A manufacturing case study implementation. J. Intell. Manuf. 2020, 31, 1383-1402. [CrossRef]

45. Lee, J.; Bagheri, B.; Kao, H.A. A Cyber-Physical Systems architecture for Industry 4.0-based manufacturing systems. Manuf. Lett. 2015, 3, 18-23. [CrossRef]

46. Qi, Q.; Tao, F.; Hu, T.; Anwer, N.; Liu, A.; Wei, Y.; Wang, L.; Nee, A.Y.C. Enabling technologies and tools for digital twin. J. Manuf. Syst. 2021, 58, 3-21. [CrossRef]

47. Moshood, T.D.; Nawanir, G.; Sorooshian, S.; Okfalisa, O. Digital Twins Driven Supply Chain Visibility within Logistics: A New Paradigm for Future Logistics. Appl. Syst. Innov. 2021, 4, 29. [CrossRef]

48. Jordan, M.I.; Mitchell, T.M. Machine learning: Trends, perspectives, and prospects. Science 2015, 349, 255-260. [CrossRef] [PubMed]

49. Ben-Daya, M.; Hassini, E.; Bahroun, Z. Internet of things and supply chain management: A literature review. Int. J. Prod. Res. 2019, 57, 4719-4742. [CrossRef]

50. Haße, H. Digital Twin for Real-Time Data Processing in Logistics. Artificial Intelligence and Digital Transformation in Supply Chain Management: Innovative Approaches for Supply Chains. In Proceedings of the Hamburg International Conference of Logistics (HICL), Berlin, Germany, 11 June 2019; Volume 27, p. 1. [CrossRef]

51. Arora, R.; Parashar, A. Secure User Data in Cloud Computing Using Encryption Algorithms. Int. J. Eng. Res. Appl. 2013, 3, 1922-1926.

52. Olshannikova, E.; Ometov, A.; Koucheryavy, Y.; Olsson, T. Visualizing Big Data with augmented and virtual reality: Challenges and research agenda. J. Big Data 2015, 2, 1-27. [CrossRef]

53. Ge, X.; Pan, L.; Li, Q.; Mao, G.; Tu, S. Multipath Cooperative Communications Networks for Augmented and Virtual Reality Transmission. IEEE Trans. Multimed. 2017, 19, 2345-2358. [CrossRef] 
54. Ofoeda, J.; Boateng, R.; Effah, J. Application Programming Interface (API) Research: A Review of the Past to Inform the Future. Int. J. Enterp. Inform. Syst. 2019, 15, 76-95. [CrossRef]

55. Kumar, S.; Bongale, A.; Patil, S.; Bongale, A.M.; Kamat, P.; Kotecha, K. Demystifying Artificial Intelligence based Digital Twins in Manufacturing- A Bibliometric Analysis of Trends and Techniques. Libr. Philos. Pract. 2020, 2020, 1-21.

56. Bruynseels, K.; de Sio, F.S.; van den Hoven, J. Digital Twins in health care: Ethical implications of an emerging engineering paradigm. Front. Genet. 2018, 9, 1-11. [CrossRef] [PubMed]

57. Farsi, M.; Daneshkhah, A.; Hosseinian-Far, A.; Jahankhani, H. Internet of Things Digital Twin Technologies and Smart Cities; Springer International Publishing: Cham, Switzerland, 2020; ISBN 9783030187316.

58. Liu, Y.; Zhang, L.; Yang, Y.; Zhou, L.; Ren, L.; Wang, F.; Liu, R.; Pang, Z.; Deen, M.J. A Novel Cloud-Based Framework for the Elderly Healthcare Services Using Digital Twin. IEEE Access 2019, 7, 49088-49101. [CrossRef]

59. Fei, T.; Jiangfeng, C.; Qinglin, Q.; Zhang, M.; Zhang, H.; Fangyuan, S. Digital twin-driven product design, manufacturing and service with big data. Int. J. Adv. Manuf. Technol. 2018, 94, 3563-3576. [CrossRef]

60. Uhlemann, T.H.J.; Lehmann, C.; Steinhilper, R. The Digital Twin: Realizing the Cyber-Physical Production System for Industry 4.0. Procedia CIRP 2017, 61, 335-340. [CrossRef]

61. Vachálek, J.; Bartalský, L.; Rovný, O.; Morháč, M.; Lokšík, M. In Proceedings of the IEEE 2017 21st International Conference on Process Control (PC), Strbske Pleso, Slovakia, 6 June 2017; pp. 258-262. [CrossRef]

62. Aydemir, H.; Zengin, U.; Durak, U.; Hartmann, S. The digital twin paradigm for aircraft-Review and outlook. AIAA Scitech 2020 Forum 2020, 1 PartF, 1-12.

63. Bachelor, G.; Brusa, E.; Ferretto, D.; Mitschke, A. Model-Based Design of Complex Aeronautical Systems through Digital Twin and Thread Concepts. IEEE Syst. J. 2020, 14, 1568-1579. [CrossRef]

64. Francisco, A.; Mohammadi, N.; Taylor, J.E. Smart City Digital Twin-Enabled Energy Management: Toward Real-Time Urban Building Energy Benchmarking. J. Manag. Eng. 2020, 36, 04019045. [CrossRef]

65. Min, Q.; Lu, Y.; Liu, Z.; Su, C.; Wang, B. Machine Learning based Digital Twin Framework for Production Optimization in Petrochemical Industry. Int. J. Inf. Manag. 2019, 49, 502-519. [CrossRef]

66. O'Dwyer, E.; Pan, I.; Charlesworth, R.; Butler, S.; Shah, N. Integration of an energy management tool and digital twin for coordination and control of multi-vector smart energy systems. Sustain. Cities Soc. 2020, 62, 102412. [CrossRef]

67. Aivaliotis, P.; Georgoulias, K.; Arkouli, Z.; Makris, S. Methodology for enabling digital twin using advanced physics-based modelling in predictive maintenance. Procedia CIRP 2019, 81, 417-422. [CrossRef]

68. El Saddik, A. Digital Twins: The Convergence of Multimedia Technologies. IEEE Multimed. 2018, 25, 87-92. [CrossRef]

69. Alves, R.G.; Souza, G.; Maia, R.F.; Tran, A.L.H.; Kamienski, C.; Soininen, J.P.; Aquino, P.T.; Lima, F. A digital twin for smart farming. In Proceedings of the 2019 IEEE Global Humanitarian Technology Conference (GHTC), Seattle, WA, USA, 17-20 October 2019; pp. 19-22.

70. Verdouw, C.; Kruize, J.W.; Wolfert, S.; Chatzikostas, G. Digital Twins in Farm Management Illustrated by cases from FIWARE Accelerators SmartAgriFood and Fractals. In Proceedings of the 11th International European Forum (Igls-Forum) (161st EAAE Seminar) on System Dynamics and Innovation in Food Networks, Innsbruck-Igls, Austria, 13-19 February 2017; Volume 31, p. 84752.

71. Nikolaev, S.; Gusev, M.; Padalitsa, D.; Mozhenkov, E.; Mishin, S.; Uzhinsky, I. Implementation of "Digital Twin" Concept for Modern Project-Based Engineering Education; Springer International Publishing: Berlin/Heidelberg, Germany, 2018; Volume 540, ISBN 9783030016135.

72. Sepasgozar, S.M.E. Digital twin and web-based virtual gaming technologies for online education: A case of construction management and engineering. Appl. Sci. 2020, 10, 4678. [CrossRef]

73. Blomkvist, Y.; Ullemar Loenbom, L.E.O. Improving Supply Chain Visibility within Logistics by Implementing a Digital Twin: A Case Study at Scania Logistics; KTH Institute of Technology: Stockholm, Sweden, 2020.

74. Elgarah, W.; Falaleeva, N.; Saunders, C.S.; Ilie, V.; Shim, J.T.; Courtney, J.F. Data Exchange in Interorganizational Relationships: Review Through Multiple Conceptual Lenses. Data Base Adv. Inf. Syst. 2005, 36, 8-29. [CrossRef]

75. Yang, C.S. Maritime shipping digitalization: Blockchain-based technology applications, future improvements, and intention to use. Transp. Res. Part E Logist. Transp. Rev. 2019, 131, 108-117. [CrossRef]

76. Loup, R.; Koller, R. The Road to Commitment: Capturing the head, hearts and hands of people to effect change. Organ. Dev. J. 2005, 23, 73-81.

77. Modoni, G.E.; Caldarola, E.G.; Sacco, M.; Terkaj, W. Synchronizing physical and digital factory: Benefits and technical challenges. Procedia CIRP 2019, 79, 472-477. [CrossRef]

78. Leng, J.; Zhang, H.; Yan, D.; Liu, Q.; Chen, X.; Zhang, D. Digital twin-driven manufacturing cyber-physical system for parallel controlling of smart workshop. J. Ambient Intell. Humaniz. Comput. 2019, 10, 1155-1166. [CrossRef]

79. Birkel, H.; Müller, J.M. Potentials of industry 4.0 for supply chain management within the triple bottom line of sustainability-A systematic literature review. J. Clean. Prod. 2021, 289, 125612. [CrossRef]

80. Murata, K.; Wakabayashi, K.; Watanabe, A. Study on and instrument to assess knowledge supply chain systems using advanced kaizen activity in SMEs. Supply Chain Forum 2014, 15, 20-32. [CrossRef]

81. Gomezelj, D.G. A systematic review of research on innovation in hospitality and tourism. Int. J. Contemp. Hosp. Manag. 2016, 28, 516-558. [CrossRef] 
82. Feng, Y.; Zhu, Q.; Lai, K.H. Corporate social responsibility for supply chain management: A literature review and bibliometric analysis. J. Clean. Prod. 2017, 158, 296-307. [CrossRef]

83. Casprini, E.; Dabic, M.; Kotlar, J.; Pucci, T. A bibliometric analysis of family firm internationalization research: Current themes, theoretical roots, and ways forward. Int. Bus. Rev. 2020, 29, 101715. [CrossRef]

84. Giraldo, P.; Benavente, E.; Manzano-Agugliaro, F.; Gimenez, E. Worldwide research trends on wheat and barley: A bibliometric comparative analysis. Agronomy 2019, 9, 352. [CrossRef]

85. Bigliardi, B.; Casella, G.; Bottani, E. Industry 4.0 in the logistics field: A bibliometric analysis. IET Collab. Intell. Manuf. 2021, 3, 4-12. [CrossRef]

86. Sayyad, S.; Kumar, S.; Bongale, A.; Bongale, A.M.; Patil, S. Estimating Remaining Useful Life in Machines Using Artificial Intelligence: A Scoping Review. Libr. Philos. Pract. 2021, 2021, 1-26.

87. Fernandes, E.C.; Fitzgerald, B.; Brown, L.; Borsato, M. Machine learning and process mining applied to process optimization: Bibliometric and systemic analysis. Procedia Manuf. 2019, 38, 84-91. [CrossRef]

88. Jerman, A.; Bach, M.P.; Bertoncelj, A. A bibliometric and topic analysis on future competences at smart factories. Machines 2018, 6, 41. [CrossRef]

89. Ante, L. Digital twin technology for smart manufacturing and industry 4.0: A bibliometric analysis of the intellectual structure of the research discourse. Manuf. Lett. 2021, 27, 96-102. [CrossRef]

90. Xue, X.; Wang, L.; Yang, R.J. Exploring the science of resilience: Critical review and bibliometric analysis. Nat. Hazards 2018, 90, 477-510. [CrossRef]

91. Wang, B.; Pan, S.Y.; Ke, R.Y.; Wang, K.; Wei, Y.M. An overview of climate change vulnerability: A bibliometric analysis based on Web of Science database. Nat. Hazards 2014, 74, 1649-1666. [CrossRef]

92. Gorraiz, J.; Schloegl, C. A bibliometric analysis of pharmacology and pharmacy journals: Scopus versus Web of Science. J. Inf. Sci. 2008, 34, 715-725. [CrossRef]

93. Linhares, J.E.; Pessa, S.L.R.; Bortoluzzi, S.C.; da Luz, R.P. Work ability and functional aging: A systemic analysis of the literature using proknow-c (knowledge development process-Constructivist). Cienc. Saude Coletiva 2019, 24, 53-66. [CrossRef] [PubMed]

94. Afonso, M.; Souza, J.; Ensslin, S.; Ensslin, L. Como construir conhecimento sobre o tema de pesquisa? aplicação do processo proknow-c na busca de literatura sobre avaliação do desenvolvimento sustentável. Rev. Gestão Soc. Ambient. 2012, 5, 47-62. [CrossRef]

95. De Carvalho, G.D.G.; Sokulski, C.C.; Da Silva, W.V.; De Carvalho, H.G.; De Moura, R.V.; De Francisco, A.C.; Da Veiga, C.P. Bibliometrics and systematic reviews: A comparison between the Proknow-C and the Methodi Ordinatio. J. Informetr. 2020, 14, 101043. [CrossRef]

96. Ensslin, L.; Dutra, A.; Ensslin, S.R.; Chaves, L.C.; Dezem, V. Research Process for Selecting a Theoretical Framework and Bibliometric Analysis of a Theme: Illustration for the Management of Customer Service in a Bank. Modern Econ. 2015, 6, 782-796. [CrossRef]

97. Salles, P.V.; Batista, R.P.; Viana, T.M.; Azevedo, R.C.; Poggiali, F.S.J.; Rodrigues, C.S. Carbonation of Recycled Aggregates Concrete-Application of the ProKnow-C Methodology in the Selection of Bibliographic Portfolio, Systematic and Bibliometric Analysis. Int. J. Multidiscip. Sci. Eng. 2017, 8, 1-5.

98. de Lacerda, R.T.O.; Ensslin, L.; Ensslin, S.R. Uma análise bibliométrica da literatura sobre estratégia e avaliação de desempenho. Gestão Produção 2012, 19, 59-78. [CrossRef]

99. Tao, F.; Zhang, M.; Cheng, J.; Qi, Q. Digital twin workshop: A new paradigm for future workshop. Comput. Integr. Manuf. Syst. 2017, 23, 1-9. [CrossRef]

100. Schroeder, G.N.; Steinmetz, C.; Pereira, C.E.; Espindola, D.B. Digital Twin Data Modeling with AutomationML and a Communication Methodology for Data Exchange. IFAC-PapersOnLine 2016, 49, 12-17. [CrossRef]

101. Zheng, P.; Lin, T.J.; Chen, C.H.; Xu, X. A systematic design approach for service innovation of smart product-service systems. J. Clean. Prod. 2018, 201, 657-667. [CrossRef]

102. Alcácer, V.; Cruz-Machado, V. Scanning the Industry 4.0: A Literature Review on Technologies for Manufacturing Systems. Eng. Sci. Technol. Int. J. 2019, 22, 899-919. [CrossRef]

103. Hallinger, P.; Nguyen, V.T. Mapping the landscape and structure of research on education for sustainable development: A bibliometric review. Sustaintability 2020, 12, 1947. [CrossRef]

104. Waltman, L.; van Eck, N.J.; Noyons, E.C.M. A unified approach to mapping and clustering of bibliometric networks. J. Informetr. 2010, 4, 629-635. [CrossRef]

105. Cancino, C.; Merigó, J.M.; Coronado, F.; Dessouky, Y.; Dessouky, M. Forty years of Computers \& Industrial Engineering: A bibliometric analysis. Comput. Ind. Eng. 2017, 113, 614-629.

106. Stavropoulos, P.; Papacharalampopoulos, A.; Athanasopoulou, L. A molecular dynamics based digital twin for ultrafast laser material removal processes. Int. J. Adv. Manuf. Technol. 2020, 108, 413-426. [CrossRef]

107. Cai, Y.; Wang, Y.; Burnett, M. Using augmented reality to build digital twin for reconfigurable additive manufacturing system. J. Manuf. Syst. 2020, 56, 598-604. [CrossRef]

108. Luo, W.; Hu, T.; Ye, Y.; Zhang, C.; Wei, Y. A hybrid predictive maintenance approach for CNC machine tool driven by Digital Twin. Robot. Comput. Integr. Manuf. 2020, 65, 101974. [CrossRef] 
109. Wang, Q.; Jiao, W.; Zhang, Y.M. Deep learning-empowered digital twin for visualized weld joint growth monitoring and penetration control. J. Manuf. Syst. 2020, 57, 429-439. [CrossRef]

110. Singh, M.; Fuenmayor, E.; Hinchy, E.P.; Qiao, Y.; Murray, N.; Devine, D. Digital twin: Origin to future. Appl. Syst. Innov. 2021, 4, $1-19$.

111. Saracco, R. Digital Twins: Advantages \& Issues of a Powerful Emerging Technology; IEEE Future Directions, 2018; Available online: https:/ / cmte.ieee.org/futuredirections / 2018/06/14/digital-twins-advantages-issues-of-a-powerful-emerging-technology/ (accessed on 8 July 2021).

112. Umeda, Y.; Ota, J.; Shirafuji, S.; Kojima, F.; Saito, M.; Matsuzawa, H.; Sukekawa, T. Exercise of digital kaizen activities based on "digital triplet" concept. Procedia Manuf. 2020, 45, 325-330. [CrossRef]

113. Umeda, Y.; Ota, J.; Kojima, F.; Saito, M.; Matsuzawa, H.; Sukekawa, T.; Takeuchi, A.; Makida, K.; Shirafuji, S. Development of an education program for digital manufacturing system engineers based on "Digital Triplet" concept. Procedia Manuf. 2019, 31, 363-369. [CrossRef]

114. Gichane, M.M.; Byiringiro, J.B.; Chesang, A.K.; Nyaga, P.M.; Langat, R.K.; Smajic, H.; Kiiru, C.W. Digital triplet approach for real-time monitoring and control of an elevator security system. Designs 2020, 4, 9. [CrossRef]

115. Botkina, D.; Hedlind, M.; Olsson, B.; Henser, J.; Lundholm, T. Digital Twin of a Cutting Tool. Procedia CIRP 2018, 72, 215-218. [CrossRef]

116. Tan, Y.; Yang, W.; Yoshida, K.; Takakuwa, S. Application of IoT-aided simulation to manufacturing systems in cyber-physical system. Machines 2019, 7, 2. [CrossRef]

117. Liu, C.; Le Roux, L.; Körner, C.; Tabaste, O.; Lacan, F.; Bigot, S. Digital Twin-enabled Collaborative Data Management for Metal Additive Manufacturing Systems. J. Manuf. Syst. 2020. [CrossRef]

118. Kuts, V.; Otto, T.; Tähemaa, T.; Bondarenko, Y. Digital twin based synchronised control and simulation of the industrial robotic cell using virtual reality. J. Mach. Eng. 2019, 19, 128-144. [CrossRef]

119. Alexopoulos, K.; Nikolakis, N.; Chryssolouris, G. Digital twin-driven supervised machine learning for the development of artificial intelligence applications in manufacturing. Int. J. Comput. Integr. Manuf. 2020, 33, 429-439. [CrossRef]

120. Deac, G.C.; Deac, C.N.; Popa, C.L.; Ghinea, M.; Cotet, C.E. Machine vision inmanufacturing processes and the digital twin ofmanufacturing architectures. Ann. DAAAM Proc. 2017, 28, 733-736.

121. Zhang, X.; Zhu, W. Application framework of digital twin-driven product smart manufacturing system: A case study of aeroengine blade manufacturing. Int. J. Adv. Robot. Syst. 2019, 16, 1-16. [CrossRef]

122. Hürkamp, A.; Gellrich, S.; Ossowski, T.; Beuscher, J.; Thiede, S.; Herrmann, C.; Dröder, K. Combining simulation and machine learning as digital twin for the manufacturing of overmolded thermoplastic composites. J. Manuf. Mater. Process. $2020,4,92$. [CrossRef]

123. Vatankhah Barenji, A.; Liu, X.; Guo, H.; Li, Z. A digital twin-driven approach towards smart manufacturing: Reduced energy consumption for a robotic cellular. Int. J. Comput. Integr. Manuf. 2020, 1-16. [CrossRef]

124. Wang, K.J.; Lee, Y.H.; Angelica, S. Digital twin design for real-time monitoring-A case study of die cutting machine. Int. J. Prod. Res. 2020, 1-15. [CrossRef]

125. Rajesh, P.K.; Manikandan, N.; Ramshankar, C.S.; Vishwanathan, T.; Sathishkumar, C. Digital Twin of an Automotive Brake Pad for Predictive Maintenance. Procedia Comput. Sci. 2019, 165, 18-24. [CrossRef]

126. Park, Y.; Woo, J.; Choi, S.S. A Cloud-based Digital Twin Manufacturing System based on an Interoperable Data Schema for Smart Manufacturing. Int. J. Comput. Integr. Manuf. 2020, 33, 1259-1276. [CrossRef]

127. Xia, K.; Sacco, C.; Kirkpatrick, M.; Saidy, C.; Nguyen, L.; Kircaliali, A.; Harik, R. A digital twin to train deep reinforcement learning agent for smart manufacturing plants: Environment, interfaces and intelligence. J. Manuf. Syst. 2021, 58, 210-230. [CrossRef]

128. Xie, Y.; Lian, K.; Liu, Q.; Zhang, C.; Liu, H. Digital twin for cutting tool: Modeling, application and service strategy. J. Manuf. Syst. 2021, 58, 305-312. [CrossRef]

129. Ellgass, W.; Richmond, J.; Holt, N.; Barenji, A.V.; Saldana-Lemus, H.; Gonzalez-Badillo, G. A digital twin concept for manufacturing systems. In Proceedings of the ASME International Mechanical Engineering Congress and Exposition, American Society of Mechanical Engineers, Advanced Manufacturing, V002T02A073, ASME, Pittsburgh, PA, USA, 9-15 November 2018 ; Volume 2. [CrossRef]

130. Huynh, B.H.; Akhtar, H.; Sett, M.K. A universal methodology to create digital twins for serial and parallel manipulators. In Proceedings of the 2019 IEEE International Conference on Systems, Man and Cybernetics (SMC), Bari, Italy, 6-9 October 2019; pp. 3104-3109.

131. Wojcicki, J.; Bianchi, G. A Smart Spindle Component concept as a standalone measurement system for Industry 4.0 Machine Tools. In Proceedings of the 2020 IEEE International Workshop on Metrology for Industry 4.0 \& IoT, Roma, Italy, 7-9 June 2020; pp. 278-282.

132. Ertveldt, J.; Guillaume, P.; Helsen, J. MiCLAD as a platform for real-time monitoring and machine learning in laser metal deposition. Procedia CIRP 2020, 94, 456-461. [CrossRef]

133. Rožanec, J.M.; Jinzhi, L.; Košmerlj, A.; Kenda, K.; Dimitris, K.; Jovanoski, V.; Rupnik, J.; Karlovčec, M.; Fortuna, B. Towards actionable cognitive digital twins for manufacturing. In Proceedings of the CEUR Workshop Proceedings, Crete, Greece, 31 May-4 June 2020; Volume 2615. 